$$
\begin{gathered}
\text { UNIVERSIDADE DE SÃo PAULO - USP } \\
\text { Instituto de Ciências Matemáticas de são Carlos } \\
\text { Departamento de Ciências da Computação e Estatística }
\end{gathered}
$$

\title{
Um Sistema de Compressão de Imagens Digitais
}

Carlos Fernando Assis Paniago

Orientadora: Prof. Dra. Agma Juci Machado Traina

Dissertação apresentada ao ICMSC-USP como parte dos requisitos para a obtenção do Titulo de Mestre em "Ciências da Computação e Matemática Computacional". 


\section{RESUMO}

Este trabalho apresenta técnicas de compressão de dados com ênfase para aplicações em sensoreamento remoto e medicina. Baseados em tais técnicas desenvolveu-se um sistema modular de compressão de imagens com a preocupação de que pudesse ser executado em múltiplas plataformas computacionais. 


\section{ABSTRACT}

This work presents data compression techniques for remote sensing and medical applications. Using these techniques a modular compression system was developed for these kinds of images. This system was conceived to run in several different machines. 
À memória de Terry Welch.

\section{Dedicatória:}

À Vera Lucia Ferracini, minha esposa, Felipe e Carla, meus filhos. 


\section{Agradecimentos}

A professora Dra. Agma Juci Machado Traina pela excelente orientação, apoio e paciência no desenvolver desse trabalho.

Aos professores e funcionários do ICMSC, pelo apoio e amizade.

A EMBRAPA pelo apoio total concedido.

Ao Pessoal da. EMBRAPA, pela amizade, e apoio em todos os momentos.

Aos colegas do ICMSC, pela paciência e apoio.

A minha familia (Vera, Felipe e Carla) pelo apoio e compreensão. 


\section{Índice}

Indice $\ldots \ldots \ldots \ldots \ldots \ldots \ldots \ldots \ldots \ldots \ldots \ldots \ldots \ldots \ldots \ldots \ldots \ldots \ldots$

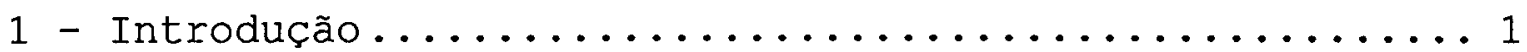

1.1 - Considerações Iniciais.................

1.2 - Motivação..................... 3

1.2 - Apresentação do Trabalho ................ 7

2 - Métodos de Compressão de Dados................... 9

2.1 - Codificação de Shannon-Fano............... 12

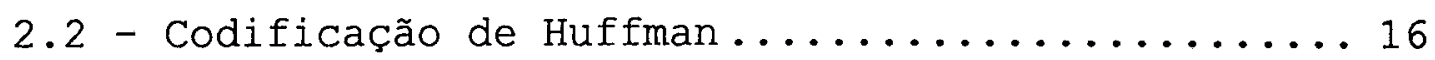

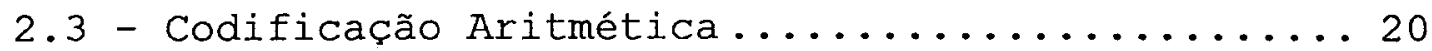

2.4 - Codificação Usando Dicionários............. 23

2.5 - Codificação Lz77 .................... 24

2.6 - Codificação Lz78 .................... 27

2.7 - Joint Photographic Experts Group - JPEG....... 30

2.8 - QuadTrees......................... 33

2.9 - Outros Métodos..................... 35

2.10 - Comparação Entre Sistemas de Compressão de

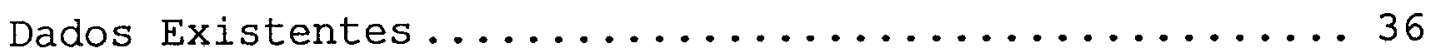

2.11 - Conclusões ....................... 39

3 - o Sistema Desenvolvido...................... 40

A) 3.1 - o problema do Formato de Imagem........... 40

3.2 - O Sistema de Compressão de Imagens.......... 44

3.3 - Compressão de Huffman ................. 45 
3.4 - Compressão de Truncagem de Bloco - BTC.......446

3.5 - Compressão Usando DCT .................. 49

3.6 - Conclusão....................... 56

4 - Conclusões e Linhas de Futuras Pesquisas........... 57

4.1 - Conclusões Gerais.................... 57

4.2 - Linhas de Futuras Pesquisas..............63

5 - Bibliografia........................... 65

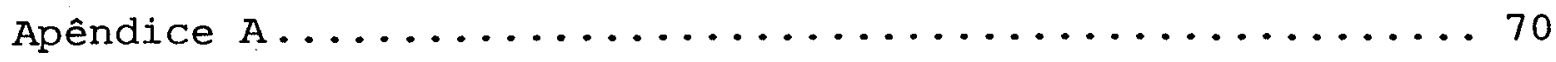

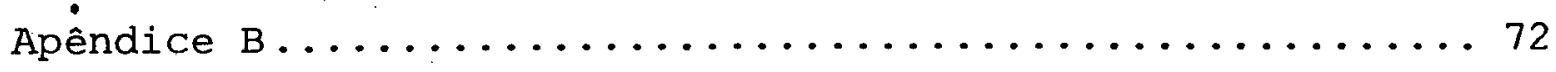

Apêndice $C \ldots \ldots \ldots \ldots \ldots \ldots \ldots \ldots \ldots \ldots \ldots \ldots \ldots \ldots \ldots$

Apêndice $D \ldots \ldots \ldots \ldots \ldots \ldots \ldots \ldots \ldots \ldots \ldots \ldots \ldots \ldots \ldots$

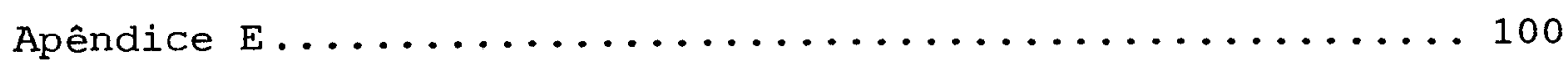

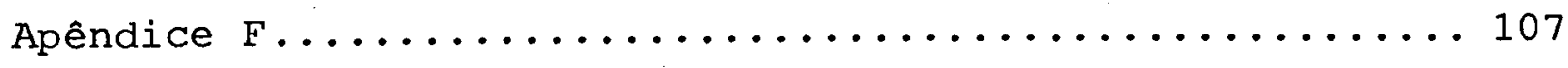

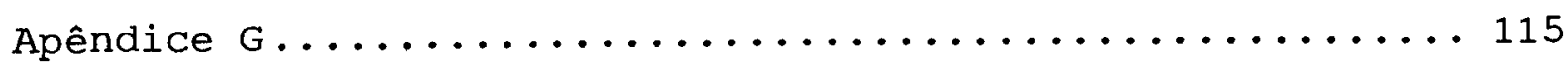




\section{Capítulo 1}

\section{1 - Introdução}

\section{1 - Considerações Iniciais}

Este trabalho apresenta as técnicas de compactação de dados, principalmente as voltadas à compressão de imagens de satélites (sensoreamento remoto), com aplicações para a agricultura; e também para imagens médicas, com ênfase em imagens tomográficas obtidas a partir do tomógrafo que utiliza a técnica de Ressonância Magnética (RM) desenvolvido no Instituto de Física e Química de São Carlos - IFQSC [PAN_85]. A partir de tais técnicas define-se um sistema de compactação de dados, direcionando-o a imagens de sensoreamento remoto e imagens médicas.

o sistema desenvolvido leva em conta o tipo dos dados a serem comprimidos (imagens digitais), bem como considerações de portabilidade, dada a característica de que um sistema de compactação aplicado tanto a dados de sensoreamento remoto quanto imagens médicas, deve adequar-se a várias plataformas computacionais. Originalmente o sistema foi desenvolvido num computador IBM PC - clone 486DX usando o Sistema Operacional FreeBSD 0.1 (um sistema compatível com Unix BSD 4.3 da universidade de Berkeley), e foi portado para equipamentos 
SUN, com sistema SUNOS 4.1.1, sendo totalmente implementado na linguagem de programação 'C'.

Matematicamente uma imagem digital pode ser definida como uma função bidimensional $\mathrm{A}(\mathrm{x}, \mathrm{y})$ definida em uma certa região do plano:

$$
A:[0, r] \times[0, s] \rightarrow[0, t]
$$

Assim a imagem é definida num retângulo $[0, r] \times[0, s]$, e os valores tomados estão contidos no intervalo $[0, t]$. Ao valor $A(x, y)$ no ponto $(x, y)$ dá-se o nome de Nível de cinza [TRA_92] .

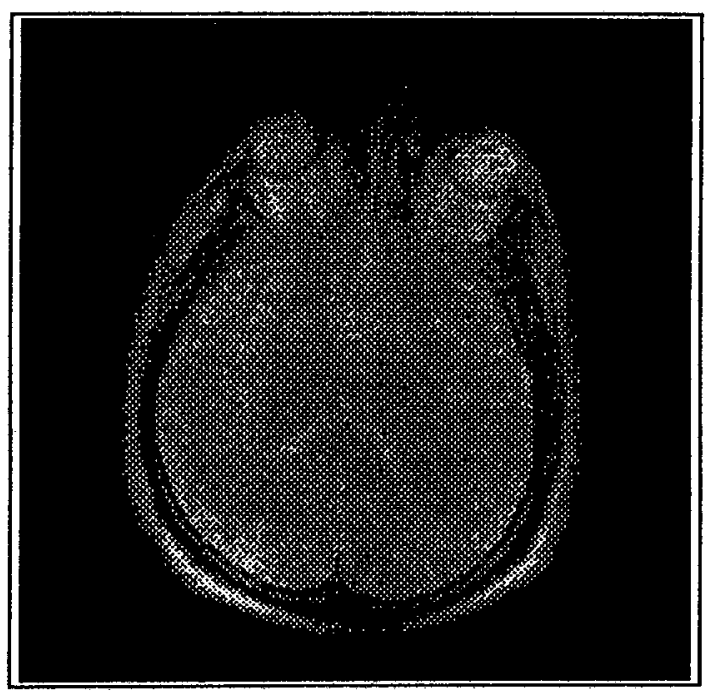

Imagem do tomógrafo do IFQSC

$$
\text { c81t5.pgm }-256 * 256
$$




\section{2 - Motivação}

A necessidade de compactar dados deve-se principalmente a dois fatores:

1) Imagens digitais são geralmente representadas por uma grande quantidade de dados. A quantidade de espaço requerido para a armazenagem dessas imagens deve ser minimizado, diminuindo o custo de armazenamento, e permitindo o uso desse, meio para acomodar mais imagens. Exemplificando: um exame com 9 planos de imagens tomográficas obtidas no tomógrafo do IFQSC, gera 9 imagens de 256 linhas por 256 colunas com um byte por pixel, o que perfaz 64 Kbytes por imagem e 576 Kbytes por conjunto. Uma banda de imagem de satélite é recortado em 1024 linhas por 1024 colunas por um byte por pixel o que resulta em 1 Mbyte de espaço de armazenamento. É importante notar que estas imagens se repetem ao longo do tempo. Um satélite tem várias bandas e passa várias vezes sobre o mesmo lugar, assim como as imagens tomográficas podem ser repetidas ao longo de dias ou semanas gerando grande quantidade de dados.

2) Muitas vezes, os sistemas que efetuam a coleta dos dados que serão apresentados como imagens digitais, precisam enviálas para sistemas que efetuarão sua apresentação. Porém estes últimos sistemas freqüentemente encontram-se em máquinas 
distintas das que efetuaram a aquisição. Então surge a necessidade de transferência desses dados usando linhas de comunicação entre equipamentos. Para esta comunicação, quanto menor, ou mais concentrados forem estes dados mais rápida será a transferência, o que aumentaria a performance e também. diminuiria os custos.

Hoje existem dois tipos básicos de compactação de informações:

1) compactação sem perda ("lossless"), - que é usada para comprimir arquivos de dados, programas executáveis, banco de dados, etc. Nessa técnica, não se pode perder um único bit da informação previamente comprimida, pois essa perda causaria problemas enormes (por exemplo um programa executável ficaria errado ou um texto correto teria letras trocadas).

2) (compactação com perda ("lossy") - que é usada para comprimir imagens e sons, onde a imagem reconstruída após a compactação não é exatamente a mesma de antes dessa, mas a perda de informações é mantida a uma quantidade que permita que o som reconstruído seja inteligível, bem como as imagens sejam (para o olho humano) extremamente parecidas com a imagem original, ou seja o erro imposto deve estar dentro de limites toleráveis pela aplicação. 
O enfoque desse trabalho é em técnicas onde as perdas sejam mínimas, pois a perda de informação numa tomografia, pode esconder alguma anormalidade que poderia prejudicar um diagnóstico ou mesmo mascarar anomalias que porventura existam. Mas para o armazenamento destas informações, pode-se perder algumas características, desde que sejam pequenas e imperceptiveis a olho nu. No caso de imagens dé satélite, a perda de definição pode resultar em cálculos errôneos de áreas, já que as imagens dos satélites comerciais tem problemas com definições (que são na ordem de 30 x 30 metros ou 10 x 10 metros nos satélites mais modernos), mas para o armazenamento e posterior apresentação destas imagens, a perda controlada pode ser útil, já que as imagens ficam armazenadas em espaço muito reduzido.

Pode-se colocar o início da área de compressão de dados, após os trabalhos de Claude Shannon nos laboratórios Bell, os quais deram origem à teoria da informação como um novo ramo da matemática na década de 40. Assim a compressão de dados surgiu como um ramo dessa teoria da informação, por tratar de eliminar redundâncias contidas nessas informações.

Nó década de 50 houveram dois trabalhos, que influenciaram a compactação de dados até a década de 70.0 primeiro é o trabalho de Huffman [HUF_52] e o segundo o 
trabalho de Shannon depois completado por Fano, e hoje popularmente conhecido como Shannon-Fano [NEL_92].

Em 1977 e 1978 uma dupla de israelenses publicaram dois trabalhos que mudaram o panorama de compressão de dados. Jacob Ziv e Abraham Lempel [ZIV_77] [ZIV_78] descreveram duas técnicas usando dicionários adaptativos que conseguiram novas taxas de compactação de dados. E diversos melhoramentos foram propostos para essas técnicas nas últimas décadas. 


\section{2 - Apresentação do Trabalho}

o presente trabalho apresenta diversos métodos de compactação de dados, bem como uma visão dos sistemas de compactação existentes para diversos sistemas computacionais. Apresenta também o sistema desenvolvido na linguagem 'C' para compressão das imagens digitais de tomografia e de satélites, usando técnicas sem perda de informação e técnicas aonde as perdas são controladas, e finalmente discute os resultados e propõe novas linhas de pesquisa nesta área.

No capitulo 2 apresenta-se os métodos de compressão de dados, explicando o processo de compressão e descrevendo-os na forma de algoritmos e compara os sistemas existentes de compressão de dados, para diversos sistemas.

No capitulo 3, discute-se o problema dos formatos de imagens, bem como apresenta o sistema desenvolvido, discutindo cada implementação.

Finalmente no capítulo 4, mostra as conclusões chegadas com este trabalho, bem como apresenta linhas futuras de pesquisa.

O capítulo 5 apresenta a bibliografia. 
O Apêndice A descreve o programa pgmbin.c.

O Apêndice B descreve o programa pgmtm.c.

O Apêndice C descreve os programas huf.h, chuf.c e uhuf.c.

O Apêndice D descreve os programas btc.c e ubtc.c.

O Apêndice E descreve os programas c4c.c e c4u.c.

O Apêndice $F$ descreve os programas c8c.c e c8u.c.

O Apêndice G descreve o programa mse.c. 


\section{Capítulo 2}

\section{2 - Métodos de Compressão de Dados}

Para compactar-se arquivos, normalmente utiliza-se um modelo para ser codificado, ou seja, dadas as cadeias de símbolos de entrada, usando 0 modelo calcula-se as probabilidades dos símbolos e essas informações são passadas para um codificador que gera a cadeia de saida. Veja o exemplo de um modelo para código de Huffman abaixo.

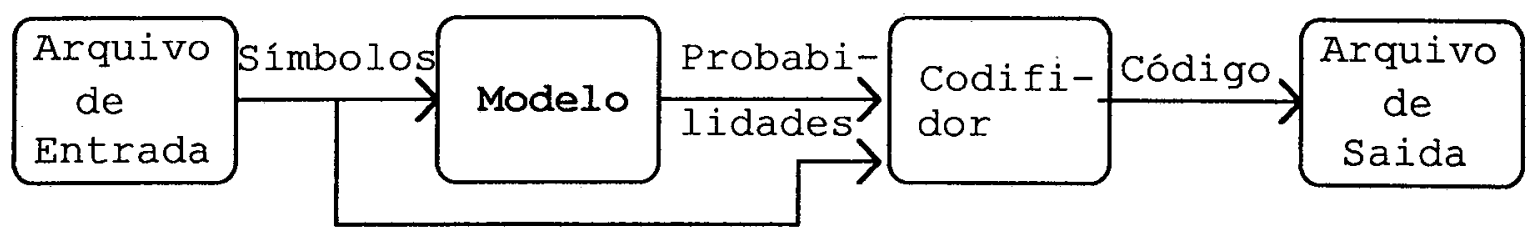

Figura 1 - modelo de um codificador

Note que nesse caso a probabilidade dos caracteres que compõem a mensagem deve ser conhecida a priori. No caso de transmissão de dados em uma linha de comunicação, ou mesmo da compactação de um arquivo, essa exigência significa que o arquivo de entrada deve ser lido pelo menos duas vezes: a primeira para calcular as probabilidades lou a frequência com que cada valor aparece) e a segunda para codificar. Outro modelo muito usado hoje é seguindo uma matriz de probabilidades já definida ou definindo-a gradativamente a 
medida em que os símbolos são utilizados, como é indicado no modelo abaixo [NEL_92]:

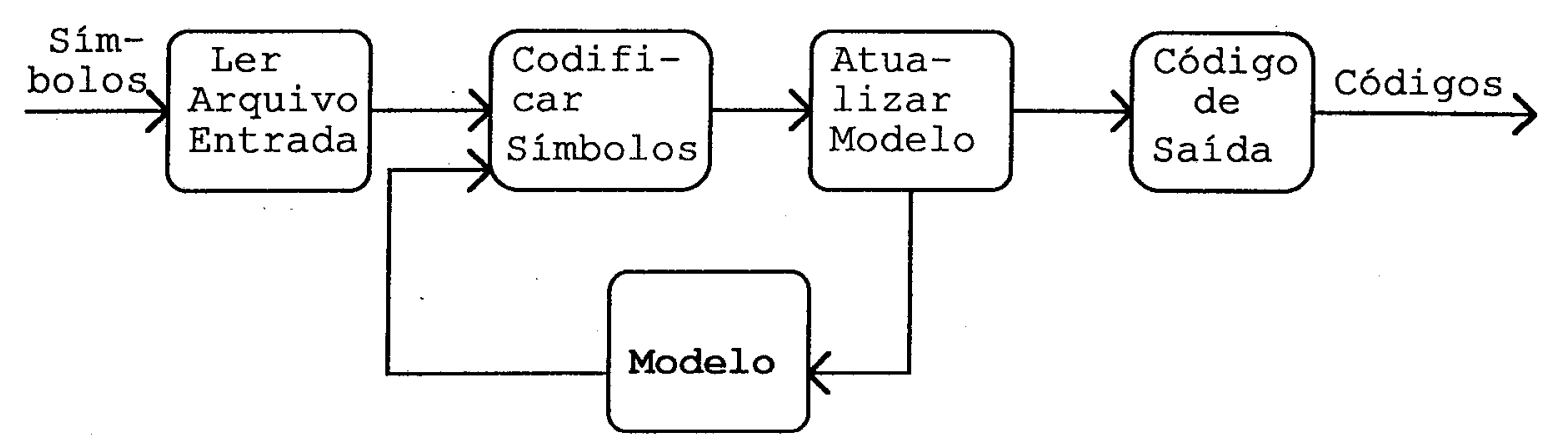

Figura 2 - modelo de compressão adaptativa

Pelo fato das probabilidades dos símbolos serem calculados no decorrer do processo de codificação, tais modelos são chamados de adaptativos. Os modelos de Lempel-ziv (ver seção 2.5 e 2.6) [ZIV_77] [ZIV_78] são sempre adaptativos. Esta característica facilita sua implementação em compressão, transmissão ou armazenamento de dados. No caso de imagens a existência prévia da matriz de probabilidades dos símbolos (que é a contagem dos valores existentes) pode ser descrita da mesma forma que os dados necessários para fazer o histograma dessa imagem. Neste caso a construção do histograma pode ser feito a priori pois a informação obtida pode ser vista como a matriz de probabilidades.

O Histograma de Intensidades indica para cada nível de cinza da imagem a quantidade de pontos mapeados em tal nível. 
Ele contém uma informação global sobre os "objetos" da imagem. Se todos os pontos da imagem são de um mesmo objeto, - histograma mostra a probabilidade condicional p(z/objeto) de um ponto possuir um dado nível de cinza $z$, sendo que 0 ponto pertence ao objeto [MAS_89.] . 


\section{1 - Codificação de Shannon-Fano}

o primeiro código de compressão bem conhecido é devido ao trabalho simultâneo de Claude Shannon dos Laboratórios Bell e de R. M. Fano do M.I.T., essa codificação é conhecida atualmente como Shannon-Fano [NEL_92]. o método de codificação constrói uma árvore binária baseada nas probabilidades de ocorrência dos caracteres, de modo a obter uma codificação que tenha as seguintes propriedades [GAI_93]:

- o número de bits para cada caracter distinto codificado, deve ser único.

- Os códigos de caracteres com maior probabilidade de acontecer, devem ser os menores possíveis.

- Apesar do código ter um número variável de bits, ele deve ser decodificado de apenas uma maneira (não ambigüidade) .

Para construir a árvore binária de Shannon-Fano use o seguinte algoritmo [GAI_93]: 
- Calcule as probabilidades dos símbolos e os ordene por esse peso.

- Divida a lista em duas partes, de forma que as duas sublistas restantes sejam proporcionalmente iguais.

- A sub-lista superior é designada arbitrariamente como sendo 0 , conseqüentemente a sub-lista inferior será designada com o valor 1 .

- Recursivamente aplique as duas regras anteriores para cada uma das sub-listas, até que termine a partição das sublistas.

Como exemplo, seja a seguinte cadeia de símbolos com suas probabilidades:

$\begin{array}{lllll}\text { A } & \text { B } & \text { C } & \text { D } & \text { E } \\ 15 & 7 & 6 & 6 & 5\end{array}$

A árvore binária usada nesse exemplo para a codificação de Shannon-Fano seria: 


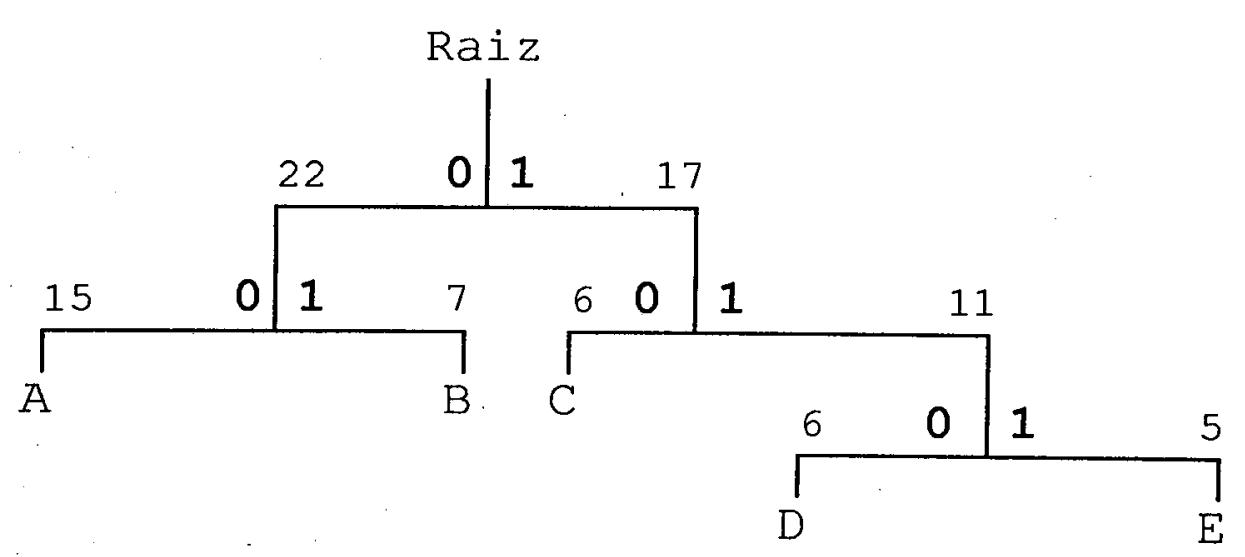

ou seja, a codificação para cada símbolo na tabela, seria a seguinte:
A $\quad 00$
B 01
C 10
D $\quad 110$
E 111

A fórmula para o conteúdo de informação (Info. - na tabela a seguir) para um símbolo dado é o negativo do logaritmo na base dois da probabilidade do símbolo. Para a mensagem acima o número de bits de informação (Bits Info.) é calculada multiplicando Freq. * Info,, bem como o número total de bits para os símbolos da mensagem (Bits $S F$ ) é calculado como sendo a Freq. vezes o número de bits em Shannon Fano, e é mostrada na tabela abaixo: 


\begin{tabular}{|l|l|l|l|l|l|}
\hline Símbolo & $\begin{array}{l}\text { Shannon } \\
\text { Fano }\end{array}$ & Freq. & Info. & $\begin{array}{l}\text { Bits } \\
\text { Info. }\end{array}$ & $\begin{array}{l}\text { Bits } \\
\text { SE }\end{array}$ \\
\hline A & 00 & 15 & 1,38 & 20,68 & 30 \\
\hline B & 01 & 7 & 2,48 & 17,35 & 14 \\
\hline C & 10 & 6 & 2,70 & 16,20 & 12 \\
\hline D & 110 & 6 & 2,70 & 16,20 & 18 \\
\hline E & 111 & 5 & 2,96 & 14,82 & 15 \\
\hline TOTAL & & 39 & & 82,25 & 89 \\
\hline
\end{tabular}

Com a codificação de Shannon-Fano conseguiu-se 89 bits, numa mensagem de 82,25 bits (calculado pela fórmula de entropia), e que teria 312 bits usando código ASCII de 8 bits $(8 \star 39)$.

Número_de_bits $=-\log _{2}$ (probabilidade $)$

Fórmula da Entropia 


\section{2 - Codificação de Huffman}

A codificação de Huffman é uma técnica de compressão estatística na qual há uma redução do tamanho médio do código usado para representar o alfabeto. O código de Huffman é uma solução ótima, quando todas as probabilidades de ocorrência de uma determinada letra for uma potência de 1/2 [HUF_52].

A codificação de Huffman cria código de tamanho variável para cada símbolo de entrada, sendo que os símbolos de entrada com maior probabilidade tem um código menor e os de maior probabilidade tem código maior.

Para fazer a árvore binária de codificação e decodificação do código de Huffman, usa-se uma técnica de baixo para cima ("bottom-up"), começando pelas folhas até atingir a raiz da árvore. Primeiramente ordena-se os códigos de entrada usando como peso a probabilidade de cada símbolo (conhecida a priori). Usa-se então o seguinte algoritmo: 
- Ordena-se os símbolos por ordem do peso e coloca-os numa lista de nós livres;

- Os dois nós com menor peso são encontrados;

- Um nó pai desses dois nós é criado. O peso dele é a soma dos pesos dos nós filhos;

- O nó pai é adicionado na lista dos nós livres. Os dois filhos são removidos da mesma lista;

- Um dos nós filhos é designado pelo caminho vindo do nó pai a ter o valor de decodificação arbitrado em 0 , o outro filho fica com o valor 1 ;

- Execute os 4 últimos passos, repita-os até que só exista um nó livre. Esse é designado como a raiz da árvore binária.

Se tivéssemos a seguinte cadeia de símbolos com suas probabilidades:

$\begin{array}{lllll}\text { A } & \text { B } & \text { C } & \text { D } & \text { E } \\ 15 & 7 & 6 & 6 & 5\end{array}$

A árvore binária usada nesse exemplo para a codificação de Huffman seria: 


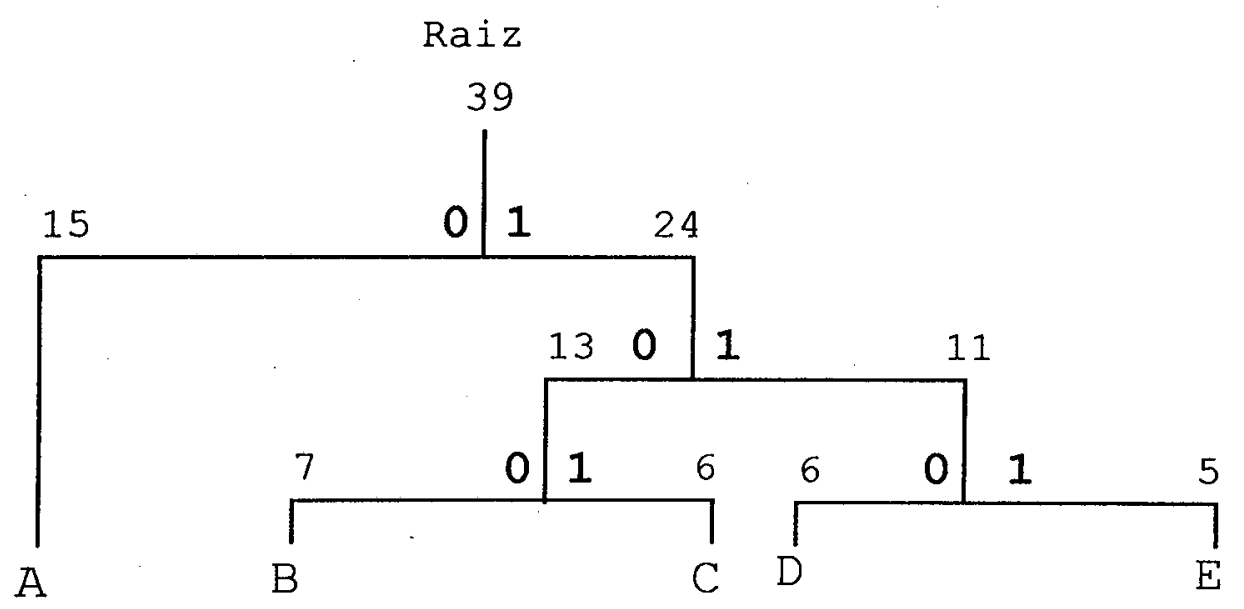

Percorrendo-se a árvore acima para cada símbolo na tabela, teria-se a seguinte codificação:

\begin{tabular}{|l|l|l|l|l|l|}
\hline Símbolo & Huffman & Freq. & Info. & $\begin{array}{l}\text { Bits } \\
\text { Info. }\end{array}$ & $\begin{array}{l}\text { Bits } \\
\text { Huf. }\end{array}$ \\
\hline A & 0 & 15 & 1,38 & 20,68 & 15 \\
\hline B & 100 & 7 & 2,48 & 17,35 & 21 \\
\hline C & 101 & 6 & 2,70 & 16,20 & 18 \\
\hline D & 110 & 6 & 2,70 & 16,20 & 18 \\
\hline E & 111 & 5 & 2,96 & 14,82 & 15 \\
\hline TOTAL & & 39 & & 82,25 & 87 \\
\hline
\end{tabular}

Com a codificação de Huffman conseguiu-se 87 bits, numa mensagem de 82,25 bits (calculado pela fórmula de entropia) dois bits a menos que a codificação de Shannon-Fano, vista na seção anterior. 
Como pode-se notar, o código de Huffman tem a propriedade de ter um único prefixo, então ele pode ser decodificado sem problemas de ambigiidade no momento da chegada dos dados no decodificador.

Um dos problemas da codificação de Huffman é que para decodificar, a tabela de entrada necessariamente precisa estar disponivel, e para isto é necessário transmitíla junto com os dados, o que aumenta o tamanho do arquivo compactado. Diversas técnicas tem sido usadas para manter essa informação mínima, usando por exemplo, escalonamento para colocar todos os códigos dentro de uma unidade de informação do tamanho de um caracter.

Outro problema é que o arquivo de dados deve ser lido pelo menos duas vezes: uma para calcular as probabilidades; e outra para fazer a codificação. Nesse caso outras técnicas podem ser usadas na codificação de Huffman para evitar esse problema, como por exemplo, construir a tabela interativamente tanto na compressão como na descompressão dos dados, mas lembrando-se que neste caso, usando uma tabela de Huffman adaptativa, o resultado não é igual ao anterior. 


\section{3 - Codificação Aritmética}

Os códigos de Huffman e Shannon-Fano são ótimos, no sentido de ter o melhor rendimento, quando as probabilidades dos símbolos são potências de $1 / 2$, o que geralmente não é o caso. A técnica conhecida como codificação aritmética não tem essa restrição e consegue então comprimir até o limite da entropia do texto usado [NEL_92].

A melhor forma para representar a codificação aritmética é representando um código por intervalos de números reais de 0 a 1 . Com 0 aumento de caracteres na mensagem o intervalo para representá-10 fica menor, e o número de bits para sua representação aumenta. Sucessivos símbolos na mensagem reduzem esse intervalo de acordo com a probabilidade de cada símbolo. Os símbolos que aparecem muito reduzem menos o intervalo, e portanto adiciona apenas poucos bits na mensagem .

Como exemplo da codificação aritmética, vamos considerar os símbolos $X$ e $Y$, com probabilidades 0,66 e 0,33 respectivamente. Para codificar examinamos o primeiro símbolo: se ele é $X$ escolhemos a partição inferior, se for $Y$ a partição superior. Para três símbolos, conseguiremos a seguinte tabela. 
1

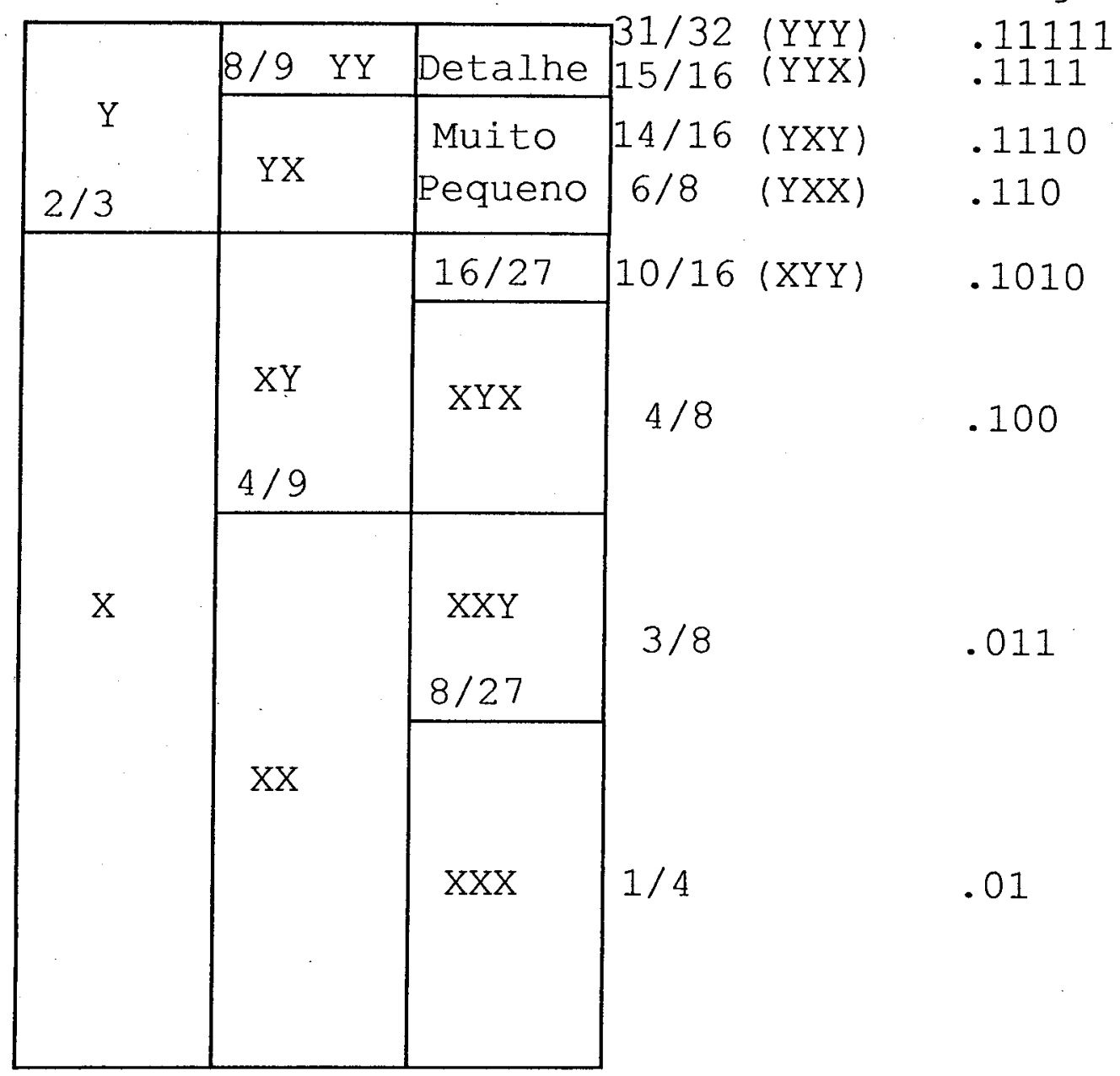

. 11111

Código

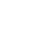


em relação à memória e unidade central de processamento, o que a torna muita lenta nos computadores convencionais. 


\section{4 - Codificação Usando Dicionários}

Uma forma de comprimir texto seria a de ter um dicionário codificado com todas as palavras numeradas seqüencialmente e substituir no arquivo texto os nomes pelo número da palavra no dicionário [NEL_89]. O problema para esse contexto, é que tanto o software codificador como o decodificador necessita do mesmo dicionário e esse dicionário não é pequeno. Outro ponto é que esse método é aplicável apenas em arquivos de texto e não em arquivos binários como imagens, códigos executáveis, etc, pois esses arquivos são sequências de bytes, ou instruções de máquina, e estes padrões não estão comumente no dicionário. 


\section{5 - Codificação LZ77}

Em 1977 J. Ziv, e A. Lempel, publicaram um trabalho na IEEE Transactions on Information Theory entitulado "A. Universal Algorithm for Sequencial Data Compression" que usa um dicionário criado conforme o texto é codificado e conhecido popularmente como Lz77 [ZIV_77] (não é explicado a causa da troca dos nomes dos autores nas referências):

O algoritmo Lz77 usa o texto lido previamente como entrada para um dicionário dinâmico (inicialmente este dicionário contém apenas as letras do código usado, normalmente os caracteres ASCII). Ele troca frases no arquivo de entrada por ponteiros no arquivo de saída, permitindo compressão dos dados. A quantidade de compressão depende do tamanho das frases no dicionário e do tamanho da janela de texto visto previamente.

A estrutura do algoritmo do $L 277$ é uma janela de texto, dividida em duas partes. A primeira consiste de um grande bloco de dados de texto recentemente decodificado. A segunda é um registro de caracteres já lidos do arquivo de entrada, mas ainda não codificados no arquivo de saída.

Esse método tem sido codificado usando diversas variações, a mais comum é conhecida por LZSS, descrita por 
James Storer e Thomas Szymanski em 1982 [LEL_87]. Nesse caso - compressor mantém uma janela de $\mathrm{N}$ caracteres e um registro de caracteres já lidos em que se busca esse registro na janela, de forma a maximizar $\circ$ número de caracteres encontrados. O algoritmo simplificado é o seguinte:

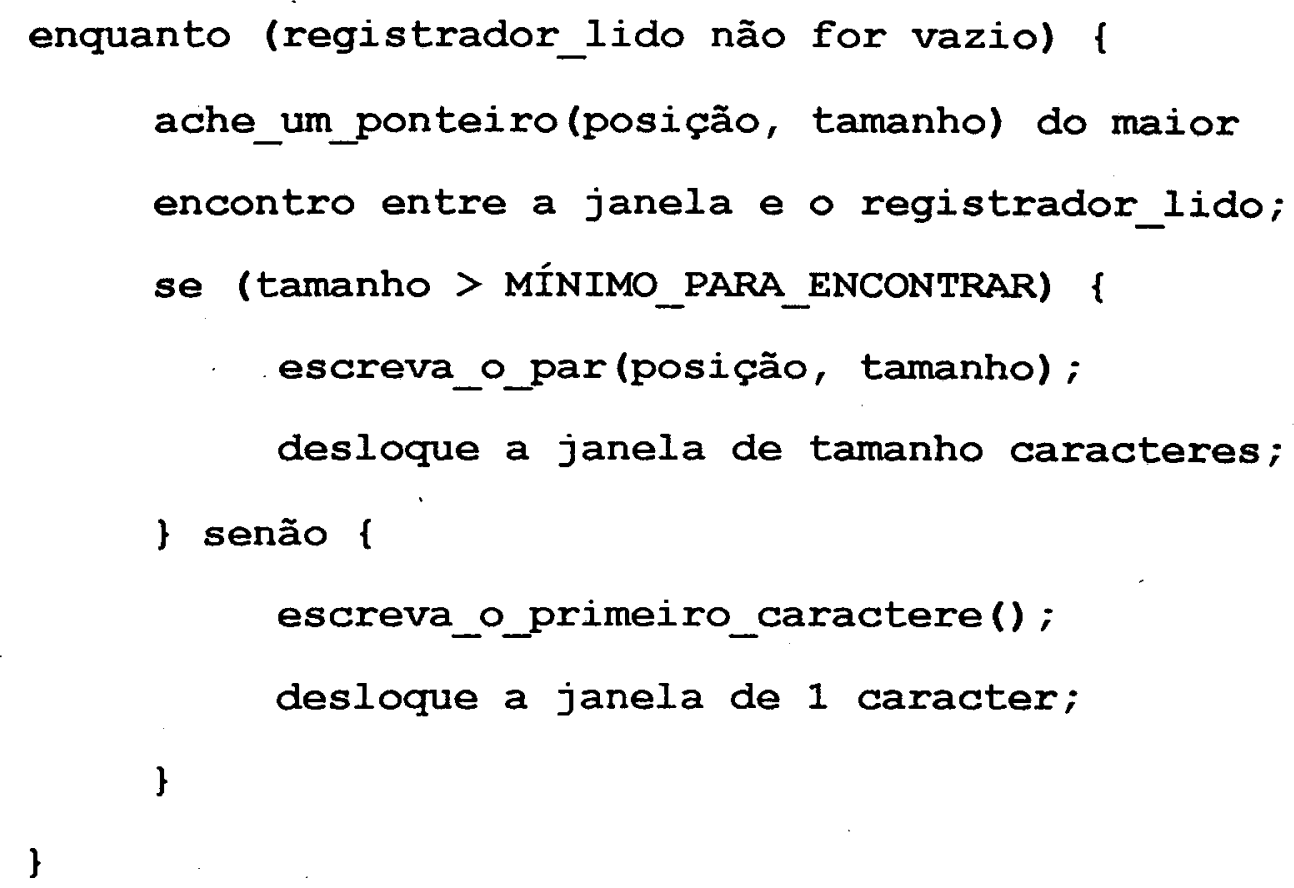

A decodificação é também muito simples e rápida: Sempre que encontrar o par (posição, tamanho), vá para a (posição) na janela e copie (tamanho) caracteres para a saída.

Esses algoritmos podem ser simplificados podendo-se usar uma janela módulo $\mathrm{N}$ (no sentido matemático de módulo - ou seja, o resto da divisão inteira por N), criando um "buffer" 
circular. Variantes desse método podem ainda usar compressão redundante ao LZSS usando um simples código de tamanho variável na saída (LZB) [LEL_87], código de Huffman dinâmico (LZH) [NEL_92], e código de Shannon-Fano (ZIP 1.X) [LEL_87], - que melhora significativamente o resultado do método. 


\section{6 - Codificação Lz78}

O esquema proposto por Ziv \& Lempel em 1978, popularmente chamado de Lz78 [ZIV_78], atua da seguinte forma: as frases são colocadas no dicionário, e depois quando uma ocorrência repetida dessa frase for encontrada, escrevese o Indice do dicionário ao invés da frase. Existem diversas variações desse algoritmo baseados nesse princípio e diferindo principalmente na maneira de manejar o dicionário.

O mais conhecido desses compressores é o definido por Terry Welch em 1984 [WEL_84], e popularmente conhecido por LZW. Este compressor é preconizado por seu autor, a ser usado (em hardware ou em software) para melhorar a performance dos controladores de disco e fita. Somente em 1992 apareceram produtos baseados nessa idéia de comprimir todo o disco como o STACKER [STA_92], e o DOS 6.0 [MIC_93].

o algoritmo básico do Lzw é colocado a seguir: 


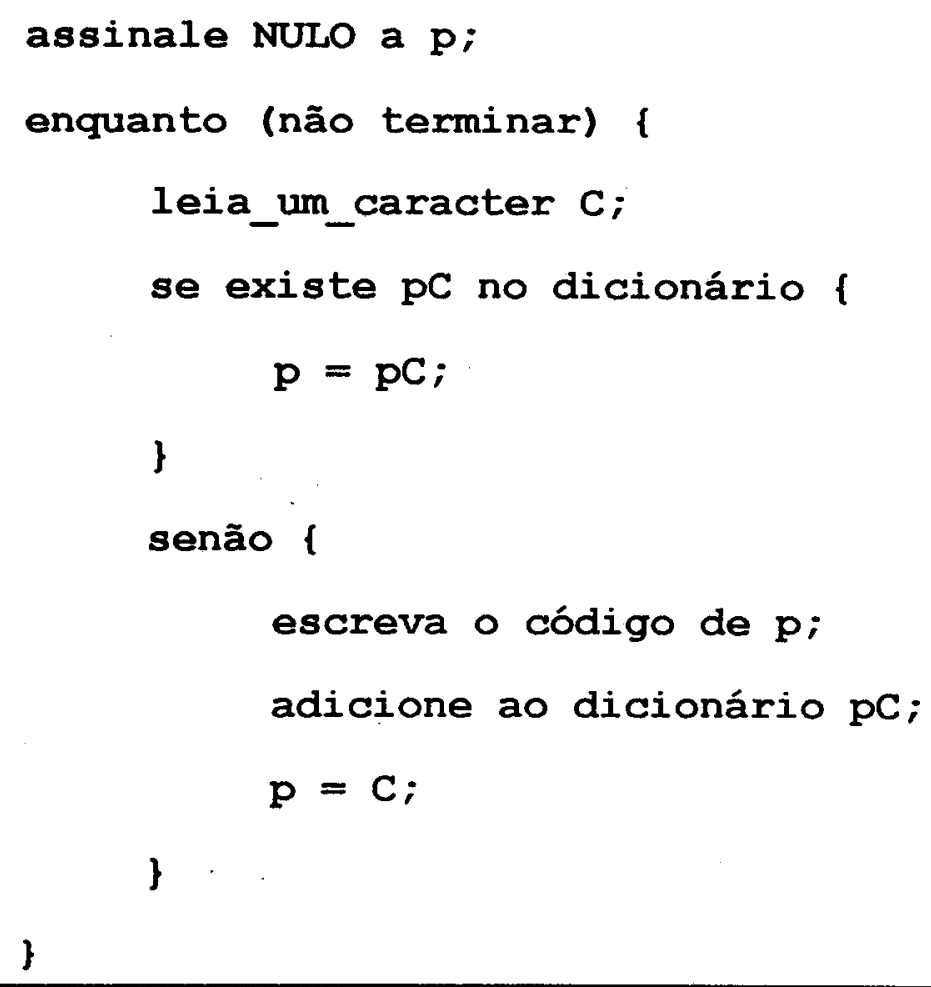

Para a decodificação o programa lê os caracteres, construindo o dicionário e cada vez que achar o índice no dicionário, substitui pelo seu valor. O notável desse método é que o dicionário não é enviado junto com o texto, mas sim reconstruído.

o algoritmo mais encontrado atualmente é uma variante do LZW chamado de LZC, que é implementado no comando "compress" do Unix [GAI_93]. Nessa variante os ponteiros não tem tamanho fixo, mas começam com 9 bits, e crescem vagarosamente para o tamanho máximo possível (normalmente 16 bits em máquinas Unix), quando todos os ponteiros de um determinado tamanho já foram usados. Mas o dicionário não é congelado quando ele 
fica cheio, pois o programa monitora a performance da compressão, e quando essa começa a decrescer, o dicionário é descartado e começa a criação de um novo dicionário. Outros métodos usados mais recentemente, usam algoritmos do tipo LRU (menos usado recentemente) para descartar frases poucos usadas, no lugar de jogar fora o dicionário e começar de novo.

A especificação V42bis do CCITT (Comitê Consultivo Internacional para Telegrafia e Telefonia) para compressão de dados em uma. Iinha de comunicações [BLA_91] usa o algoritmo LZW, que é coberto por uma patente da Unisys, a qual exige uma licença para que os fabricantes de "modens" usem esse algoritmo. Patentes (inclusive conflitantes) é uma constante nesse campo de compressão de dados. 


\section{7 - Joint Photographic Experts Group - JPEG}

Um grupo criado pela CCITT, e pela ISO para padronizar compressão de imagens terminou uma proposta em 1991, e definiu o padrão de compressão de imagens fotográficas [WAL_91]. O JPEG é um pàdrão para compressão de imagens coloridas ou em níveis de cinza, mas não comprime imagens de dois níveis (preto e branco) que é tratado por outro grupo chamado JBIG - Joint Bi-level Image Experts Group [GAI_93].

Existem diversos parâmetros no processo de compressão do JPEG. Ajustando esses parâmetros, podemos trocar qualidade de imagem reconstruída por tamanho, ou seja, se perdemos qualidade da imagem original, ganhamos mais espaço de armazenamento e se mantivermos qualidade, 0 ganho de armazenamento não é tão grande.

O JPEG define um algoritmo básico com perdas, mais extensões opcionais para codificação progressiva e hierárquica. Há também um modo de compressão sem perdas que tipicamente consegue razão de compressão de 2:1. A maioria dos softwares e hardwares disponíveis para a proposta do JPEG, usam somente o modelo básico. 
Vamos apresentar (sem entrar em detalhes técnicos) a proposta do JPEG básica [GAI_93]:

1 - Transforme a imagem num espaço de cores adequado. Isto é uma operação nula em imagens em níveis de cinza o que é de interesse deste trabalho, mas para imagens coloridas é bom mudar da codificação RGB (vermelho, verde, azul) para um espaço YUV de luminância (Y) e crominância (UV). O componente luminância está agora em níveis de cinza e as duas outras dimensões, relativas a crominância, nos dão informações das cores.

2 - (Opcional) Deixe o nível de luminância inalterado e reduza a dimensão dos outros dois componentes na proporção 2:1 horizontalmente e 2:1 ou 1:1 verticalmente. Nos termos de JPEG isto é definido como amostragem $2 \mathrm{~h} 2 \mathrm{v}$ ou $2 \mathrm{~h} 1 \mathrm{v}$. Essa compressão diminui o tamanho dos arquivos para arquivos coloridos.

3 - Agrupe os valores dos pixels para cada componente em blocos de $8 \times 8$. Transforme cada bloco de $8 \times 8$ através de uma transformada de cosenos discreta (DCT).

4 - Em cada bloco, divida cada uma das 64 componentes de frequências por um "coeficiente de quantização" (CQ) separado, e arredonde os valores para inteiro. Esse é o passo 
fundamental na perda de informação. Um $\mathrm{CQ}$ de 1 perde um mínimo de informação, $\mathrm{CQ}^{\prime} \mathrm{s}$ maiores perdem sucessivamente mais informações.

5 - Codifique os coeficientes reduzidos usando codificaçăo de Huffman ou codificação aritmética. Na prática usa-se a codificação de Huffman, pois a codificação aritmética usada no JPEG é patenteada e é necessário pagar taxas de licença.

6 - Coloque as informações iniciais (cabeçalhos) e grave os resultados. Em um arquivo universal JPEG, todos os parâmetros de compressão estão armazenados nos cabeçalhos. Para aplicações especializadas, é possível a omissão desses parâmetros, mas isto significa que 0 descompressor tem de conhecer os parâmetros do compressor. 


\title{
2.8 - QuadTrees
}

\begin{abstract}
QuadTrees são estruturas de dados que permitem codificar uma informação em forma de imagem [SAM_89].
\end{abstract}

Uma QuadTree é aplicada em imagens de tamanho múltiplos de $2^{\mathrm{n}}$ lou imagens que possam ser colocadas em quadros desse tamanho) e é subdividida em 4 partes iguais chamadas de Noroeste, Nordeste, Sudoeste e Sudeste. Cada uma dessas partes pode por sua vez ser subdivida por quatro partes formando uma estrutura em forma de árvore quaternária.

Exemplo de Subdivisão de uma imagem:

$\begin{gathered}\text { QuadTree } \\
\text { Imagem } \\
\text { Original } \\
\text { Divisão }\end{gathered}$
\begin{tabular}{|l|l|l|l|l|}
\hline NO & NE \\
& SO & SE & No & NE \\
\hline & & So & SE \\
& & So & SE \\
\hline
\end{tabular}

Apesar de ser uma técnica de particionamento e organização de imagens, os QuadTrees normalmente comprimem uma imagem, pois na sua divisão incessante, grupos com valores homogêneos acabam sendo formados. 
Outra propriedade das Quadtrees é a de que pode-se perder definição de uma imagem ao cortar-se os últimos níveis da árvore. 


\section{9 - Outros Métodos}

Existem outros métodos de compressão de imagens, como por exemplo a teoria de "wavelet", fractais, etc, que são usadas apenas em situações especiais e não serão tratados nesse trabalho. 


\subsection{0 - Comparação Entre Sistemas de Compressão de Dados Existentes}

Existem diversos programas para compressão de dados no mercado, para diversas plataformas de trabalho. Apresentaremos os principais produtos para PC/MSDOS, estações de trabalho operando com o sistema Unix, Macintosh e VAX sob VMS, pois esses são os equipamentos usualmente mais usados.

Normalmente esses arquivos comprimidos tem o seu tipo de arquivo terminado por.$x x x$, onde $x \times x$ é o nome escolhido pelo programa compressor. Veja abaixo o significado das siglas dos métodos de compressão. A maior parte destes compressores usa o método LzW ou variações. 


\begin{tabular}{|l|l|l|l|l|l|}
\hline $\begin{array}{l}\text { Tipo do } \\
\text { arquivo }\end{array}$ & Método & MS/DOS & UNIX & Mac & VAX/VMS \\
\hline .arc & LZW & pkarc & arc & arcmac & arc \\
\hline .arj & $\begin{array}{l}\text { LZ77+ } \\
\text { Huf }\end{array}$ & arj & unarj & unarj & \\
\hline gif & LZW & cshow & xv & & \\
\hline $\begin{array}{l}\text {.lha } \\
\text { lhz }\end{array}$ & LZ77 & lha & lharc & lha & lharc \\
\hline .sit & & unsit & unsit & stuffit & \\
\hline .tar & I & tarread & tar & tar & tar \\
\hline zoo & LZ77 & zoo & zoo & zoo & zoo \\
\hline. F & $\begin{array}{l}\text { LZ77+ } \\
\text { Huf }\end{array}$ & pkzip & $\begin{array}{l}\text { zip } \\
\text { unzip }\end{array}$ & $\begin{array}{l}\text { zip } \\
\text { unzip }\end{array}$ & $\begin{array}{l}\text { zip } \\
\text { unzip }\end{array}$ \\
\hline Y & LZ78 & yabba & yabba & yabba & yabba \\
\hline .Z & LZW & compress & compress & compress & compress \\
\hline .z & $\begin{array}{l}\text { LZ77+ } \\
\text { Huf }\end{array}$ & gzip & gzip & gzip & gzip \\
\hline
\end{tabular}

Huf - Código de Huffman.

LZ77 - codificação LZ77.

1 - Tar não é um método de compressão mas sim um sistema de arquivamentos de dados. Como sistemas como o MSDOS não tem um sistema de arquivamento de dados, normalmente os programas de compactação também manejam os arquivos. 
LZ78 - codificação LZ78.

LZW - codificação LZ-Welch.

A maioria desses programas tem implementação já de domínio público, alguns são "shareware", e outros são vendidos comercialmente. 


\subsection{1 - Conclusões}

A apresentação dos diversos métodos de compressão de dados mostra que esse campo é vasto, e que para cada tipo de arquivo (binário, dados, imagens, etc) existe uma forma de compressão que mostra resultados melhores do que outras técnicas.

Por outro lado é bom lembrar que não pode existir um compressor universal, que comprime todos os arquivos em pelo menos um único bit. É fácil demonstrar por um processo de contagem, que se existisse esse compressor universal, poderíamos ter todos os arquivos mapeados para zero bits.

o algoritmo do. JPEG tem restrições na criação e uso do DCT (que por sua natureza perde informações no arredondamento dos valores obtidos), mas é hoje largamente empregado, inclusive com implementações em máquinas dedicadas. 


\section{Capítulo 3}

\section{3 - O Sistema Desenvolvido}

\section{1 - O problema do Formato de Imagem}

Normalmente as imagens tomográficas geradas no tomógrafo do IFQSC, tem o seguinte formato de arquivo (.pac): os quatro primeiros bytes contém o tamanho do arquivo, definido como sendo dois bytes para o número de colunas e dois bytes para o número de linhas, colocados no arquivo na ordem de byte do computador tipo PC. Os bytes seguintes armazenam a imagem propriamente dita linha por linha. Já as imagens de satélite, tem um formato mais complicado, por exemplo no SITIM (Sistema de Tratamento de Imagens - desenvolvido pelo Instituto de Nacional de Pesquisas Espaciais - INPE), a imagem é dividida em um arquivo de cabeçalho (header) (que contém informações como data da passagem, coordenadas de latitude e longitude, hora da passagem, etc) e outro arquivo que contém somente a imagem, em ordem de linha.

Até há pouco tempo atrás não havia uma preocupação entre os desenvolvedores de aplicativos que produzem imagens, em uniformizar o formato de produção de suas imagens. Assim, cada um apresentava o seu, e quem viesse depois teria de se adaptar ao que já existia. Porém, nem sempre os formatos 
previamente fornecidos se adaptavam às necessidades dos novos usuários das imagens.

Atualmente já existe uma tendência em se produzir imagens que estejam de acordo com padrões gráficos e sistemas gráficos grandemente utilizados. Assim, houve a preocupação de construir um módulo de conversão entre formatos de imagens utilizadas nos sistemas pac e SITIM para formatos mais usados, e para isso escolheu-se uma familia de formatos portáteis.

Para ter um formato comum, resolvemos usar a familia de formatos definidos por. Jeff Poskanzer, chamado de PBM (Portable BitMap format) , PGM (Portable GrayMap format) e PPM (Portable PixMap format). Esse formato é simples, e é definido para ser portátil através de equipamentos e sistemas operacionais diferentes. No nosso caso o formato escolhido é - .PGM (Portable GrayMap format) binário que pode representar arquivos preto e branco com até 256 níveis de cinza lo caso dos dois tipos de imagens trabalhadas).

Definimos então programas para converter do formato inicial para o formato PGM. O formato adotado usa a seguinte definição: 
Os primeiros bytes tem de ser a cadeia "P5", depois de espaços (podem ser brancos, tabs ou novas-linhas - $(n)$.

Pode-se ter linhas de comentário começado por '\#' no primeiro caracter da linha laté o caracter nova-linha no fim) .

Tem-se a dimensão da imagem como dois inteiros ASCII separados por espaços. O primeiro é a largura, ou o número de colunas, (y) e o segundo a quantidade de linhas $(x)$.

Finalmente tem-se o máximo nível de cinza que aparece na imagem (de 1 a 255). Esse valor tem depois dele um espaço, que é normalmente o caracter nova-linha ( $(n)$.

Após a informação do máximo nível de cinza seguem-se os dados (em bytes) na ordem das linhas, ou seja, a primeira linha (todas as colunas) segue-se a segunda linha (todas as colunas), etc. até o fim.

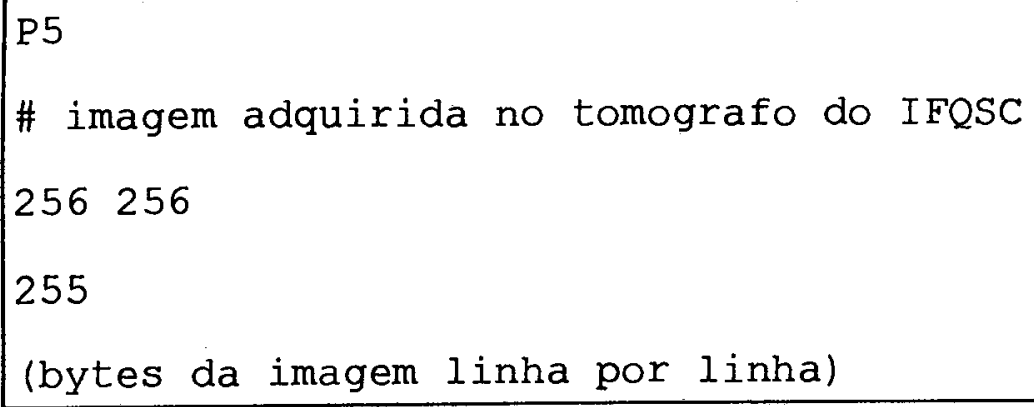


Foram feitos 2 programas "pgmbin" (listagem no apêndice A) e "pgmtm" (listagem no apêndice B) para converter arquivos para o formato PGM binário.

o programa pgmbin transforma uma imagem pura (linhas e Colunas armazenados diretamente) em uma imagem .pgm usando a seguinte sintaxe (veja o apêndice $A$ a definição destes parâmetros):

pgmbin imagem.img imagem.pgm y x "comentário"

Já o programa pgmtm transforma a imagem do formato (.pac) do tomógrafo do IFQSC para .pgm. O comentário é fixo: "imagem adquirida pelo tomografo do IFQSC" e a sintaxe para a chamada é:

pgmtm imagem.pac imagem.pgm 


\section{2 - O Sistema de Compressão de Imagens}

Foram desenvolvidos 4 programas para compressão de imagens, além de usar o software de domínio público "xv" para visualizar os arquivos de imagens, bem como para verificar sua compressão usando o algoritmo LzW (que pode ser codificado nos arquivos tipo .TIFF) e JPEG (que é definido pelo consórcio de desenvolvimento do padrão) .

A idéia é usar esses codificadores como filtro, ou seja, os dados são recebidos pela entrada padrão e a saída também é padrão (usa-se redirecionamento para ler arquivos), isso permite usar linhas de montagem para esses programas. 


\section{3 - Compressão de Huffman}

O primeiro programa chuf.c (ver apêndice C) implementa o código de Huffman. Seu programa para descomprimir chama-se uhuf.c. (ver apêndice C) O formato do arquivo de saída é definido pela cadeia tpo como os primeixos caracteres, e todo - resto do arquivo .PGM é comprimido. A taxa de compressão conseguida nos exemplos testados é de aproximadamente 2:1, ou seja de cada 2 caracteres de entrada é gerado 1 caracter de saída.

Este método apesar de não ser dos mais eficientes em termos de taxa de compressão, comprime os arquivos sem perda. Neste caso como a matriz de probabilidades de ocorrência dos caracteres é conhecida a priori, este método comprime próximo da entropia da imagem. 


\section{4 - Compressão de Truncagem de Bloco - BTC}

Esta técnica chamada de compressão de truncagem de bloco (BTC - Block Truncation Compression) é baseado em [KRU_92], e comprime imagens na proporção de $4: 1$ (exceto o cabeçalho) com perdas na imagem. A idéia central deste método é usar blocos de 4 por 4 pixels e manter o primeiro e o segundo momento do bloco. o primeiro momento é a média e o segundo momento é a média dos quadrados deste mesmo bloco. É implementada por um compactador btc.c (ver apêndice D) e um descompactador ubtc.c (ver apêndice D) .

Deve-se calcular para cada bloco as seguintes equações:

$$
\begin{aligned}
& m_{1}=\frac{1}{n} \sum_{i=0}^{n-1} p_{i} \\
& m_{2}=\frac{1}{n} \sum_{i=0}^{n-1} p_{i}^{2} \\
& d=\sqrt{\frac{q}{n-q}} \\
& \sigma=\sqrt{m_{2}-m_{1}} \\
& a=m_{1}-d \sigma \\
& b=m_{1}+\frac{\sigma}{d}
\end{aligned}
$$


Onde $\mathrm{m}_{1}$ é a média, $\mathrm{m}_{2}$ é a média dos quadrados, $\mathbf{p}_{\mathbf{i}}$ são os elementos do bloco a serem analizados, $\mathbf{n}$ é o número de elementos no bloco $(16=4 * 4)$ e $\mathrm{q}$ é o número de pixels no bloco que é maior que a média.

Após o cálculo destes elementos, calcula-se a e b, que serão colocados como resultado no arquivo de saída, seguido de 16 bits ( 2 bytes) dizendo que elemento é maior ou igual a média (com valor 1) ou menor que a média (com valor 0 ). Estes quatro bytes são gravados no arquivo de saída para cada bloco, o que perfaz a compressão de $16: 4$ ou seja $4: 1$.

$\mathrm{Na}$ descompressão lê-se os 4 bytes do bloco e analisa-se - mapa de bits. Para cada bit 1 coloca-se o valor de b e para os bits 0 o valor de a.

Apesar de ser uma compressão com perdas, a imagem gerada após a descompressão é bastante similar a original dependendo da imagem. Em alguns casos as bordas da imagem ficam serrilhadas, quando comparadas as imagens originais.

O formato desta imagem é definida a seguir:

Na primeira linha o cabeçalho tP1; copia então as duas linhas seguintes do formato .pgm los comentários e a definição de 
colunas e linhas); a seguir vem os dados (4 bytes para cada bloco de $4 * 4$ bytes).

tP1

\# imagem adquirida no tomografo do IFQSC 256256

(bytes da imagem compactadas por BTC, bloco a bloco) 


\section{5 - Compressão Usando DCT}

Uma técnica muito usada atualmente é a de usar o DCT (Discrete Cosine Transform), ou seja, transformada discreta dos cosenos. Isto deve-se ao fato que uma imagem transformada por DCT consegue ótima compressão e a transformada inversa, leva a uma imagem bastante próxima à original.

- método definido em JPEG usa DCT para conseguir comprimir uma imagem.

Vamos usar um método aproximado do JPEG, para conseguir imagens compactadas com fator de 4:1 fixo. Os programas c4c.c (ver apêndice E) e c8c.c (ver apêndice F) baseados nos programas desenvolvidos em [EMB_91], são usados para comprimir e os programas c4u.c (ver apêndice E) e c8u.c (ver apêndice F) para descomprimir os arquivos de imagens.

A implementação baseia-se em usar blocos ( 4 por 4 em c4c.c e 8 por 8 em c8c.c) para comprimir a imagem. Para calcular DCT, usamos as seguintes fórmulas:

$$
\begin{aligned}
& F[u, v]=\frac{1}{N^{2}} \sum_{m=0}^{N-1} \sum_{n=0}^{N-1} f[m, n] \cos \left(\frac{(2 m+1) u \pi)}{2 N}\right) \cos \left(\frac{(2 n+1) v \pi)}{2 N}\right) \\
& \hat{f}[m, n]=\sum_{u=0}^{N-1} \sum_{v=0}^{N-1} c[u] c[v] \cos \left(\frac{(2 m+1) u \pi)}{2 N}\right) \cos \left(\frac{(2 n+1) v \pi)}{2 N}\right)
\end{aligned}
$$


onde:

u, v são variáveis discretas de frequência $10,1,2$, $\ldots, \mathrm{N}-1)$.

$f[m, n]$ imagem $N^{*} N$ pixels $(0,1,2, \ldots, N-1)$

$F[u, v]$ é o resultado do DCT.

$\mathrm{Na}$ função inversa f chapéu, as variáveis são:

$\mathbf{m}, \mathbf{n}$ indices dos pixels resultantes $10,1,2, \ldots$, $\mathrm{N}-1)$.

$\mathbf{F}[\mathrm{u}, \mathrm{v}]$ é a DCT $\left(\mathrm{N}^{\star} \mathrm{N}\right)$ para obter o resultado inverso.

$c[k]$ é definido como 1 se $k=0,2$ se $k=1,2,3, \ldots$, $\mathrm{N}-1$.

Para cada bloco na imagem $(4 * 4$ se em c4c e $8 * 8$ se em c8c), calcula-se a matriz DCT. Ela tem uma propriedade interessante, que é possuir muitos zeros nos elementos inferiores a diagonal secundária. Portanto precisa-se armazenar apenas os elementos superiores a diagonal secundária da matriz. Além disto os elementos na diagonal 
superior são mais relevantes na reconstrução da imagem do que os elementos diagonais inferiores [EMB_91].

No caso do c4c.c, calcula-se a matriz coseno's (note-se que esta matriz pode ser calculada a priori). Usa-se o fato de que as equações acima podem ser representadas por:

$$
\begin{aligned}
& D C T\{A\}=\frac{C A C^{T}}{N^{2}} \\
& c[u, n]=\cos \left(\frac{(2 n+1) u \pi)}{2 N}\right)
\end{aligned}
$$

Após os cálculós a matriz DCT $4 * 4$ é armazenada com menos bits para cada componente. Veja o mapa de bits usado nesta matriz:

$\begin{array}{llll}8 & 3 & 3 & 2 \\ 3 & 3 & 2 & 0 \\ 3 & 3 & 0 & 0 \\ 2 & 0 & 0 & 0\end{array}$

ou seja guarda-se o primeiro byte intacto $[0,0]$ e depois grava-se três bytes compostos de 3,3 , e 2 bits cada um lou 8 bits), usando os seguintes indices: $[0,1],[0,2]$ e $[0,3]$ no segundo byte, $[1,0],[2,0]$ e $[3,0]$ no terceiro byte, e $[1,1]$, $[2,1]$ e $[1,2]$ no último byte. O restante da matriz é considerada zero. Para usar 3 bits os resultados são 
normalizados para o intervalo $[-4,-3, \ldots, 3]$ e os de 2 bits para o intervalo $[-2,-1,0,1]$

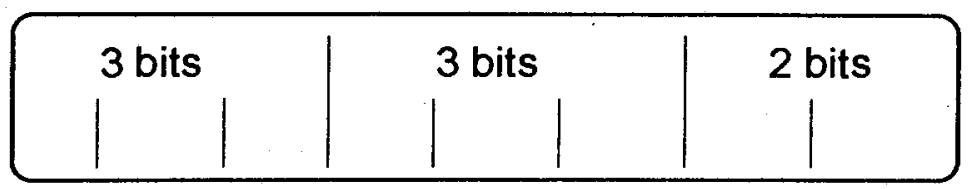

um Byte dividido em tres campos de 3, 3, e 2 bits

Para o decodificador c4u.c, usa-se o processo inverso: ler a matriz de DCT armazenada, perfazendo o contrario em relação ao armazenamento, e multiplica pela matriz de cosenos transposta e cosenos, para obter o bloco, próximo ao original.

Apesar deste método conseguir compressão na ordem de 4:1 - resultado das imagens de satélite e de tomografia compactados, visualmente (ao nível de olho nu) não difere significativamente). Mas ao ampliarmos a imagem verifica-se efeitos de serrilhamento em alguns pontos. 
No caso do c8c.c a matriz número de bits muda para:

$\begin{array}{llllllll}8 & 8 & 4 & 4 & 4 & 4 & 4 & 4 \\ 8 & 8 & 4 & 4 & 4 & 4 & 0 & 0 \\ 4 & 4 & 4 & 4 & 0 & 0 & 0 & 0 \\ 4 & 4 & 4 & 4 & 0 & 0 & 0 & 0 \\ 4 & 4 & 0 & 0 & 0 & 0 & 0 & 0 \\ 4 & 4 & 0 & 0 & 0 & 0 & 0 & 0 \\ 4 & 0 & 0 & 0 & 0 & 0 & 0 & 0 \\ 4 & 0 & 0 & 0 & 0 & 0 & 0 & 0\end{array}$

ou seja armazena-se ou bytes inteiros ou meio bytes. Mas alguns valores são escalados (divididos por um valor) antes de ser convertido para o arquivo de saída. A matriz de escalonamento é:

$$
\begin{array}{llllllll}
1 & 1 & 3 & 3 & 2 & 2 & 1 & 1 \\
1 & 1 & 2 & 1 & 1 & 1 & 0 & 0 \\
3 & 2 & 2 & 1 & 0 & 0 & 0 & 0 \\
3 & 1 & 1 & 1 & 0 & 0 & 0 & 0 \\
2 & 1 & 0 & 0 & 0 & 0 & 0 & 0 \\
2 & 1 & 0 & 0 & 0 & 0 & 0 & 0 \\
1 & 0 & 0 & 0 & 0 & 0 & 0 & 0 \\
1 & 0 & 0 & 0 & 0 & 0 & 0 & 0
\end{array}
$$


Aonde divide-se cada elemento da matriz original por esta matriz definida acima, exceto no caso dos zeros, aonde o resultado é zerado na matriz original. Na descompressão (c8u.c) ao ler os dados baseados na matriz de bits, faz-se a multiplicação elemento a elemento com a matriz acima, antes de multiplicar pela matriz de cosenos transposta e cosenos.

o arquivo de saída é similar ao do BTC, só que na primeira linha a cadeia para o programa c4c.c é tP2 e a cadeia para o programa c8c.c é tP3.

tP2

\# imagem adquirida no tomografo do IFQSC

256256

(bytes da imagem compactadas por c4c, bloco a bloco)

Formato do arquivo gerado pelo c4c.c 
tP3

\# imagem adquirida no tomografo do IFQSC

$128 \quad 128$

(bytes da imagem compactadas por c8c, bloco a bloco)

Formato do arquivo gerado pelo c8c.c 


\section{6 - Conclusão}

- sistema de compressão de imagens desenvolvido é subdivido em 4 módulos de compressão, 4 módulos de descompressão, 2 módulos de mudança de formato e 1 módulo de teste do erro quadrado médio. Cada um dos módulos de compressão e descompressão implementa uma técnica de compactação apresentada no capitulo 2. É importante frisar que esses módulos podem ser agrupados e utilizados em outros sistemas de processamento de dados, dependendo das necessidades apresentadas. 


\section{Capítulo 4}

\section{4 - Conclusões e Linhas de Futuras Pesquisas}

\section{1 - Conclusões Gerais}

Os objetivos deste trabalho foram alcançados plenamente no desenvolvimento de um sistema modular de compressão de imagens, onde buscou-se a portabilidade, para que as imagens de sensoreamento remoto e médicas fossem comprimidas em diversas plataformas computacionais.

Várias técnicas de compressão de dados foram avaliadas, sendo que as principais foram implementadas como módulos do sistema de compressão de imagens. Através do MSE (Mean Squared Error) pode-se medir o grau de deterioração de uma imagem original, em comparação com a imagem comprimida e reconstruída (descomprimida) (ver apêndice G) .

O MSE é definido por:

$$
M S E=\frac{1}{N^{*} M} \sum_{i=0}^{N-1} \sum_{j=0}^{M-1}\left(p_{i j}-q_{i j}\right)^{2}
$$


Onde:

\author{
$p_{i j}$ e $q_{i j}$ são os valores da imagem original e da \\ imagem reconstruída no ponto ( $i, j)$. \\ $\mathbf{N}$ e $\mathbf{M}$ definem a dimensão da imagem.
}

Para conseguir altas taxas de compressão (de $4: 1$ ou mais) é necessário recorrex a técnicas de compressão com perdas de imagens. Apesar destas imagens reconstruidas não serem exatamente iguais às imagens originais, normalmente para o olho humano esta diferença é imperceptível. Há diversas pesquisas na área de compressão de dados a fim de diminuir a quantidade de operações necessárias para cálculo de DCT, que é a base de um dos principais métodos de compressão atual.

Um padrão que emerge como de "facto" nessa área é o JPEG, que nas suas implementações permite compressões com perda controlada de resolução (um número de $100 \%$ a 0\%), onde $100 \%$ são as perdas decorrentes apenas de arredondamento de valores e $0 \%$ perda total. $75 \frac{\circ}{8}$ é muito usado, onde perde-se $25 \%$ de qualidade, mas ganha-se em torno de 4:1 em compactação. Taxas como $50 \%$ já começam a apresentar mesmo a olho nu diferenças da imagem original, mas todavia consegue- 
se taxas de mais de 6:1. Essa perda pode ser tolerada em algumas aplicações, como por exemplo sequências de animação.

Apresentamos a tabela abaixo com dados das imagens testadas para o nosso sistema, bem como das constantes no software xv. 


\begin{tabular}{|c|c|c|c|c|c|c|}
\hline Imagem & pgm & btc & $\begin{array}{l}c 4 c \\
c 8 c \\
\end{array}$ & huf & $\begin{array}{l}j p g \\
758 \\
\end{array}$ & $\begin{array}{l}\text { tif } \\
\text { (LZW) }\end{array}$ \\
\hline b5bsb & 262205 & 65594 & 65594 & 173031 & 32964 & 179311 \\
\hline$c 81 t 1$ & 65595 & 16440 & 16440 & 37064 & 7364 & 37627 \\
\hline c81t2 & 65595 & 16440 & 16440 & 42339 & 11200 & 45123 \\
\hline c81t3 & 65595 & 16440 & 16440 & 43362 & 12600 & 47363 \\
\hline c81t4 & 65595 & 16440 & 16440 & 44087 & 12567 & 48061 \\
\hline c81t5 & 65595 & 16440 & 16440 & 43091 & 11682 & 46651 \\
\hline c81t6 & 65595 & 16440 & 16440 & 42523 & 12018 & 46077 \\
\hline c81t7 & 65595 & 16440 & 16440 & 39859 & 10812 & 42783 \\
\hline c81t8 & 65595 & 16440 & 16440 & 37234 & 10178 & 39571 \\
\hline c81t9 & 65595 & 16440 & 16440 & 31189 & 10209 & 33651 \\
\hline c82s1 & 65595 & 16440 & 16440 & 38853 & 8910 & 38455 \\
\hline C82s 2 & 65595 & 16440 & 16440 & 38825 & 6595 & 38209 \\
\hline c82s3 & 65595 & 16440 & 16440 & 46474 & 12039 & 49951 \\
\hline$c 82 s 4$ & 65595 & 16440 & 16440 & 45904 & 12117 & 49499 \\
\hline c82s5 & 65595 & 16440 & 16440 & 45129 & 11215 & 48691 \\
\hline c82s 6 & 65595 & 16440 & 16440 & 44784 & 12904 & 49889 \\
\hline $\mathrm{c} 82 \mathrm{~s} 7$ & 65595 & 16440 & 16440 & 43772 & 12269 & 48677 \\
\hline C82s 8 & 65595 & 16440 & 16440 & 46211 & 12309 & 50857 \\
\hline c82s9 & 65595 & 16440 & 16440 & 40854 & 10106 & 43975 \\
\hline cps5 & 262205 & 65594 & 65594 & 211127 & 51322 & 254595 \\
\hline jor $256 \mathrm{~s}$ & 65595 & 16440 & 16440 & 54400 & 12983 & 59007 \\
\hline pan & 4147 & 1073 & 1073 & 2946 & 1145 & 2558 \\
\hline
\end{tabular}


onde:

Imagem é o nome da imagem; b5bsb e cps5 são imagens de sensoreamento remoto de $512 * 512$ pixels; pan é uma foto digitalizada de $64 * 64 ;$ c81t[1-9] são imagens obtidas pelo tomógrafo do IFQSC sendo sequências de cortes transversais de uma cabeça humana de 256*256; c82s[1-9] e jor256s são sequências de cortes sagitais de uma cabeça humana. As imagens c81t[1-9] e c82s[1-9] são de um mesmo paciente.

pgm é o tamanho em bytes da imagem no formato .pgm, ou seja o tamanho original da imagem antes de comprimir.

btc é o tamanho da imagem comprimida usando o método BTC;

c4c é o tamanho da imagem comprimida usando 0 DCT de $4 * 4$ (c4c.c);

c8c é o tamanho da imagem comprimida usando o DCT de 8 * 8 (c8c.c) ;

huf é o tamanho da imagem comprimida usando o programa huf.c; 
jpg é o tamanho do arquivo comprimido pelo método JPEG usando - programa de domínio público xv e ganho de 75\%;

tif é o tamanho do arquivo comprimido usando LzW dentro do formato .tif, usando o software $x v$. 


\section{2 - Iinhas de Futuras Pesquisas}

Futuros trabalhos nessa área podem ser feitos na área de aquisição de vídeo, que usa outro padrão de compressão para imagens em movimento conhecido como MPEG (Motion Picture Expert Group), apesar de já haver vídeos comerciais que usam o JPEG como padrão para comprimir cada imagem.

Na área das imagens tomográficas desenvolvidos no IFQSC, pode-se aplicar o JPEG (existe uma versão de domínio público do JPEG que vem junto Com o software $x v$ ) ou DCT nas imagens antes dela ser transformada do domínio da frequência para o domínio do espaço.

Outra sugestão é a de que os arquivos gerados no tomógrafo do IFQSC, já venham em algum formato conhecido. Proponho o pgm binário (usado neste trabalho), e na linha de comentário, deste formato seja colocado informações sobre o paciente, ou um índice que permita acessar os dados do paciente, bem como data e horário da tomografia, ou outras informações usuais aos exames tomográficos.

A utilização do sistema de compressão de imagens é fundamental como suporte ao sistema de armazenamento e classificação de imagens de tomografia, atualmente em desenvolvimento neste instituto (ICMSC). 
A alteração deste sistema de compressão de imagens para trabalhar com imagens de 3D poderá também ser realizada, para permitir o armazenamento destas imagens nos sistemas de visualização tridimensional sendo desenvolvidos neste instituto. 


\section{5 - Bibliografia}

[BAR_88] - Barnsley, M. F, ; Sloan, A. D.: A Better way to Compress Images, Byte, Janeiro de 1988, pp. 215-223.

[BEN_91] - Bender, Paul E.; Wolf, Jack K.: New Asymptotic Bounds and Improvements on the Lempel-Ziv Data Compression Alghorithm, IEEE Transactions on Inf. Theory, Vol. 37, No. 3, Maio de 1991, pp. 721-729.

[BLA_91] - Black, Uyless: The $V$ Series Recommendations, McGraw-Hill Inc, 1991.

[BRI_91] - Bridges, John: Differencial Image Compression, Dr. Dobbs Journal, Fevereiro de 1991, pp. 38-51.

[DEE_94] - Deel, Ernie F.: Adaptatve Block Coding, Dr. Dobbs Journal, Março de 1994, pp. 127-130.

[EMB_91] - Embree, Paul M. \& Kimble, Bruce: C Language Algoritmhms for Digital Signal Processing, Prentice Hall, 1991

(4)GAI_93] - Gailly, Jean-loup: comp.compression Frequently Asked Questions, Internet compression-faq/part[1-3], 9 Fevereiro de 1993. 
[HEL_91] - Held, Gilbert: Data Compression, John Wiley \& Sons LTD, 1991, 3a. Ed.

[HUF_52] - Huffman, David: A Method for the Construction of Minimum Redundancy Codes, Proceedings of the I.R.E., Vol. 40, No. 9, Setembro de 1952,pp. 1098-1101

[JOH_93] - Johnson, Eric E \& Reichard, Kevin: Professional Graphics Programming in the X Window System, Mis:Press, 1993

[LAN_93] - Lane, Tom: JPEG image compression: FrequentIy Asked Questions, Internet jpeg-faq, 6 Fevereiro de 1993.

[LEL_87] - Lelewer, D. A.; Hirschberg, D. S. Data Compression, ACM Computing Surveys,Vol. 19, No. 3, Setembro de 1987, pp. 261-296.

[KRU_92] - Kruger, Anton: Block truncation compression,Dr. Dobbs Journal, Abril de 1992, pp. 48-52.

๑[MAS_89] - Mascarenhas, N.D.A.; Velasco, R.D.: Processamento Digital de Imagens, IV Escola Brasileiro Argentina de Informática, Janeiro de 1989.

[MIC 93] - Microsoft MS-DOS 6 User's guide, 1993. 
[NEL_89] - Nelson, Mark: LZW Data Compression, Dr. Dobbs Journal, Vol. 14, No. 10, Outubro de 1989, pp. 29-37.

[NEL_91] - Nelson, Mark: DDJ Data Compression Contest Results, Dr. Dobb's Journal, Novembro de 1991, pp. 62-64.

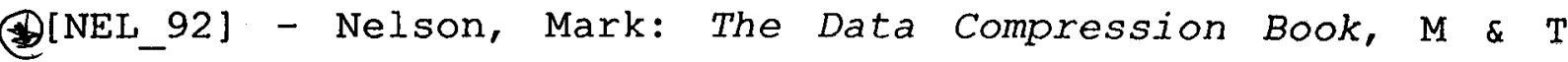
Books, 1992 .

[PAN_85] - Panepucci, H; Donoso, J. P, ; Tannus, A; Beckmann, N.; Bonagamba, T: Novas imagens do Corpo, Ciência Hoje, Vol. 20, Número 4, Setembro/Outubro 1985, pp. 45-56.

[PEC_82] - Pechura, Michael: File Archival Techniques Using Data Compression, Communications of $A C M$, Vol. 25, Número 9, Setembro de 1982, pp. 605-609.

[RUB_76] - Rubin, Frank: Experiments in Text File Compression, Communications of ACM, Vol. 19, no. 11, Novembro de 1976, pp. 617-623.

[SAM_89] - Samet, Hanan: Applications of Spatial Data Structures, Addison-Wesley Pub. Co., 1989.

[SAM_90] - Samet, Hanan: The Design and Analysis of Spatial Data Structures, Addison-Wesley Pub. Co., 1989. 
[STA_92] - Stac Eletronics: Stacker 2.0 - User's guide, 1993

[THO_91] - Thomas, Kas: Entropy, Dr. Dobb's Journal, Fevereiro de 1991, pp. 32-34, 110.

[TRA_92] - Traina, Agma J. M.: Processamento digital de imagens, notas didáticas do ICMSC/USP - Computação Gráfica, 1992.

[WAL_91] - Wallace, Gregory K.: The JPEG still Picture Compression Standard, Vol. 34, No. 4, abril de 1991, pp.3144 .

[WEL_84] - Welch, Terry: A technique for High Performance Data Compression, IEEE Computer, Vol. 17, No. 6, Junho de 1984, pp. 8-19.

[WEG_92] - Wegner, Tim: Image Lab, Waite Group Press, 1992

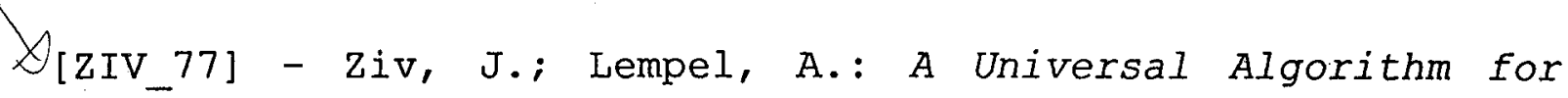
sequential Data Compression, IEEE Transactions on Information Theory, Vol. 23, No. 3, Maio de 1977, pp. 337-343.

[ZIV_78] - Ziv, J.; Lempel, A.: A Compression of Individual Sequences via Variable-Rate Coding, IEEE Transactions on 
Information Theory, Vol. 24, No. 5, Setembro de 1978, pp.530536. 


\section{Apêndice $\mathrm{A}$}

Listagem do programa pgmbin.c:

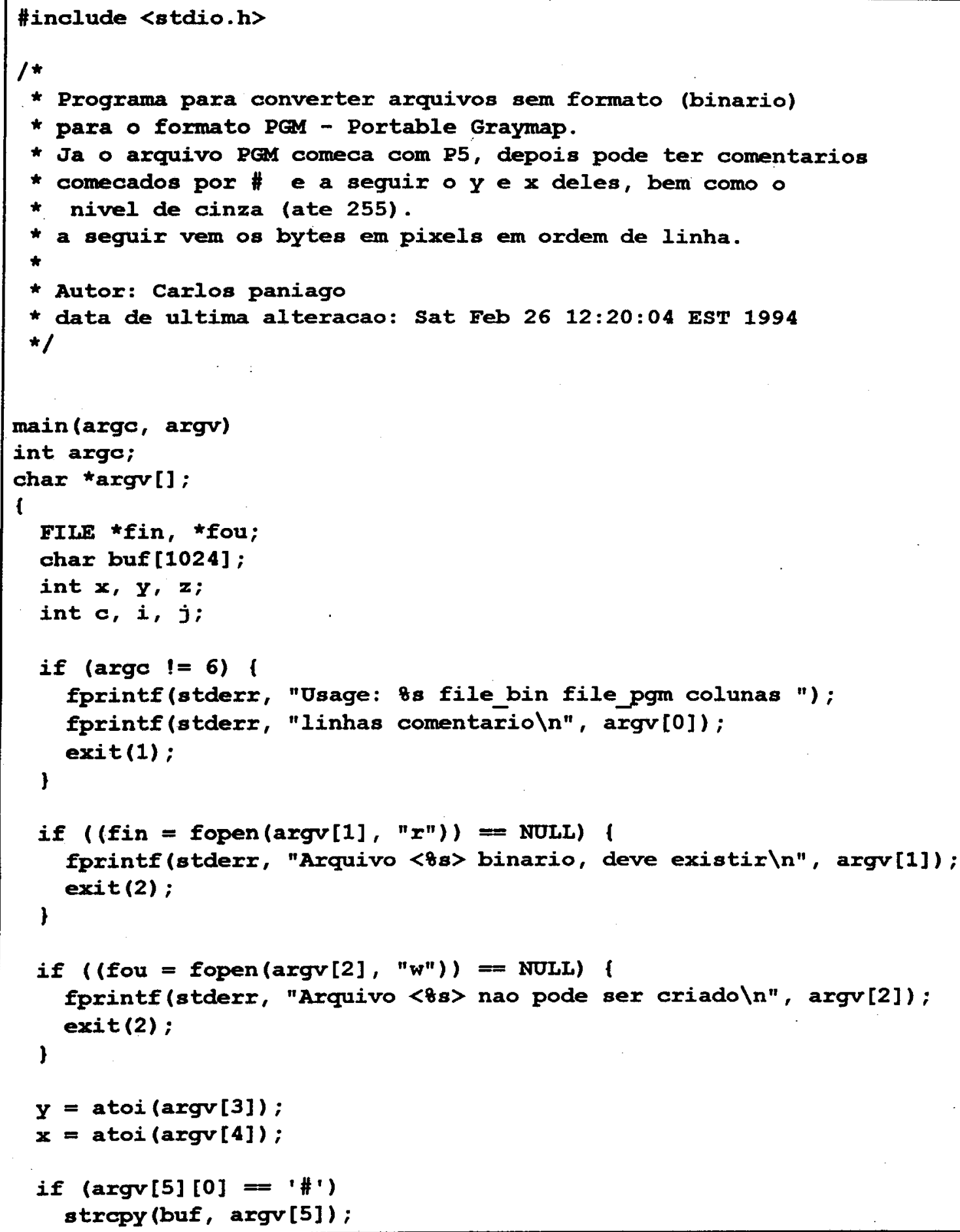




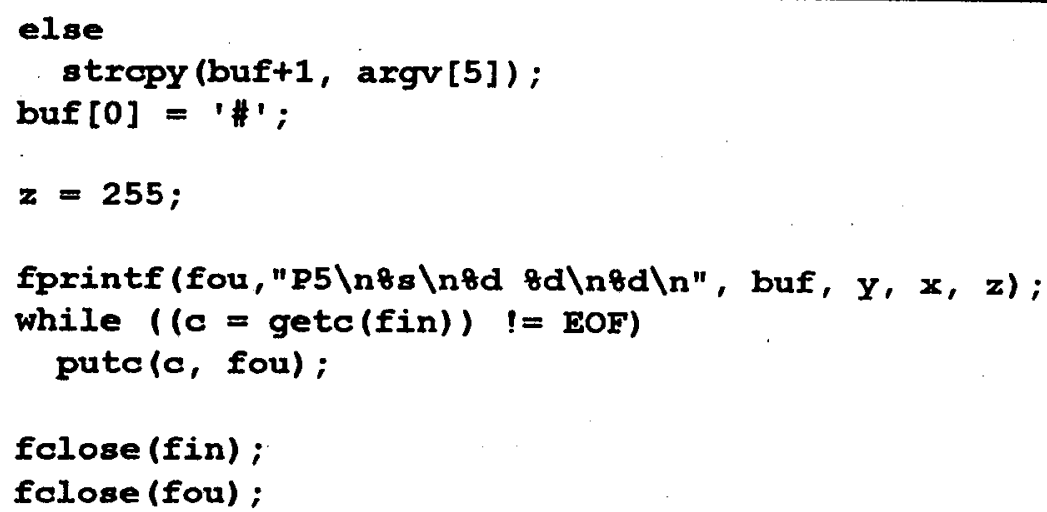

Para usá-lo:

pgmbin arquivo.img arquivo.pgm $y \times$ "comentário"

onde arquivo.img é o nome do arquivo no formato de imagem puro, ou seja, apenas linhas de uma imagem, para entrada (o arquivo a ser convertidol e arquivo.pgm é o arquivo de saida (em formato pgm). Os valores de $\boldsymbol{y}$ e $\boldsymbol{x}$ são o número de colunas e linhas da imagem e "comentário" é o comentário a ser colocado na imagem. 


\section{Apêndice B}

Listagem de pgmtm.c:

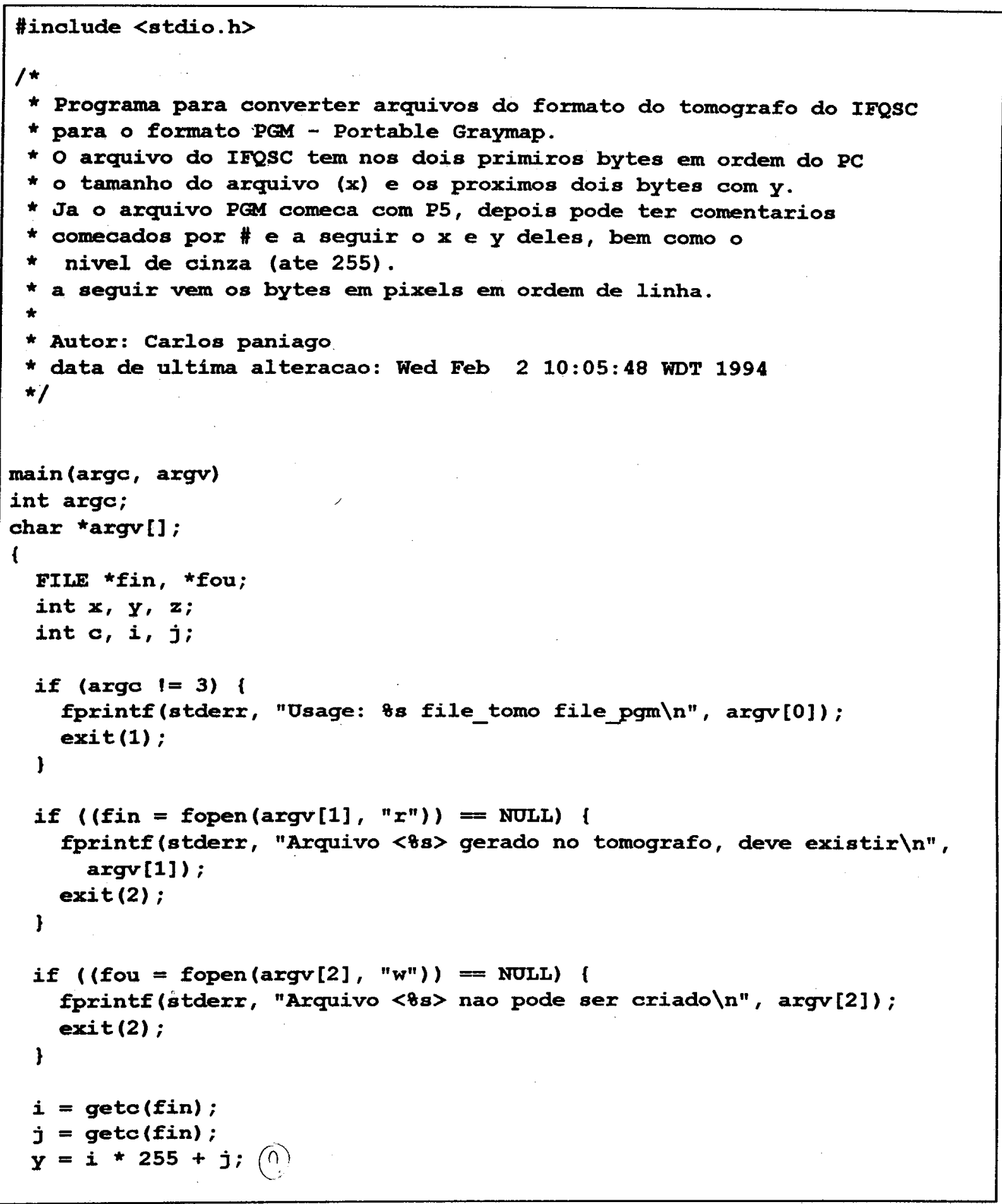




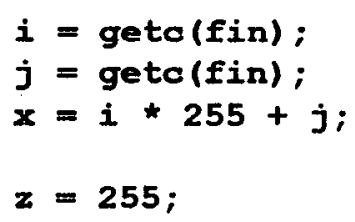

Para usá-lo:

pgmtm arquivo.pac arquivo.pgm

onde arquivo.pac é o nome do arquivo no formato de imagem do tomógrafo do IFQSC (o arquivo a ser convertido) e arquivo.pgm é o arquivo de saída (em formato pgm). 


\section{Apêndice C}

Listagem do programa huf.h:

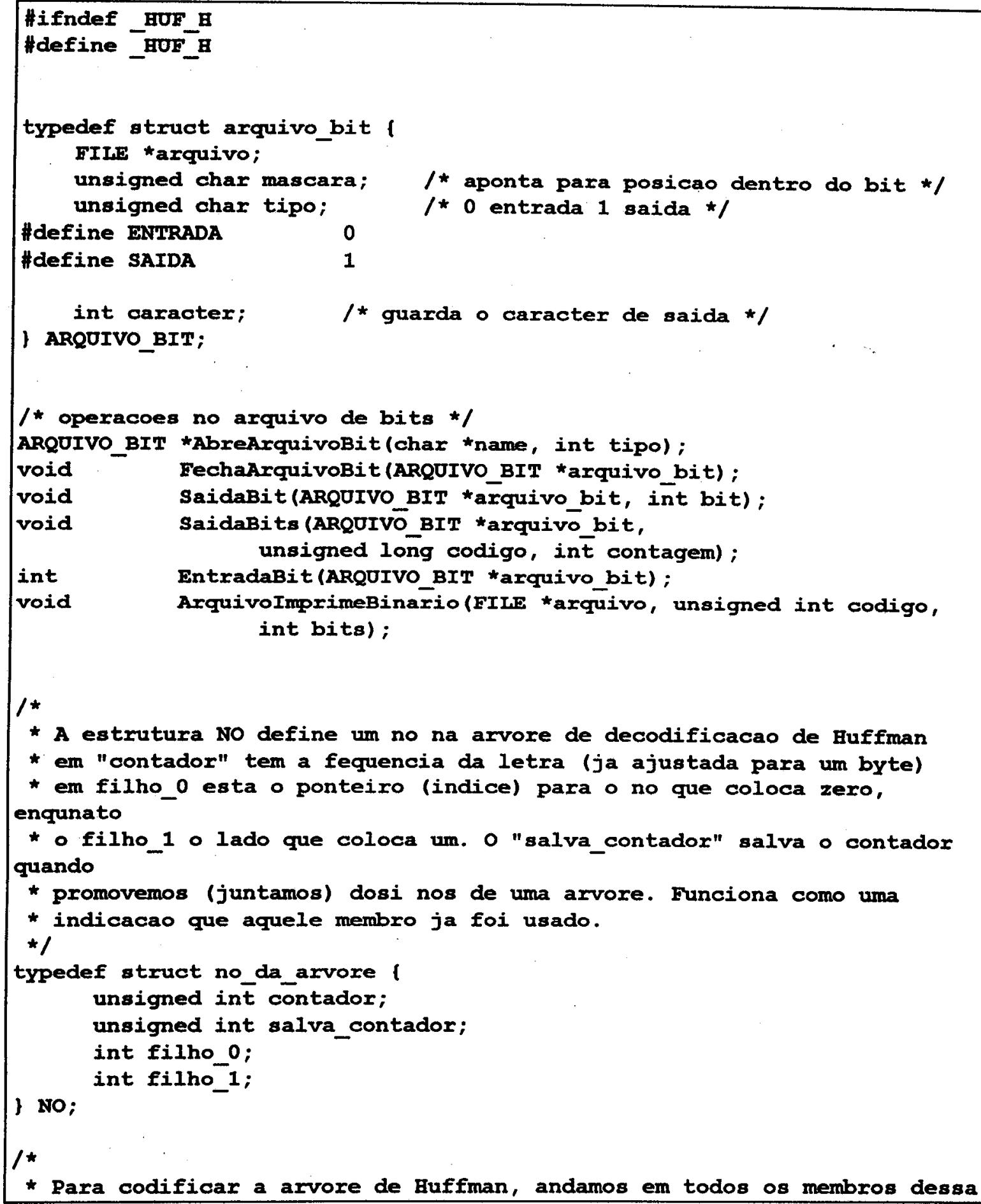




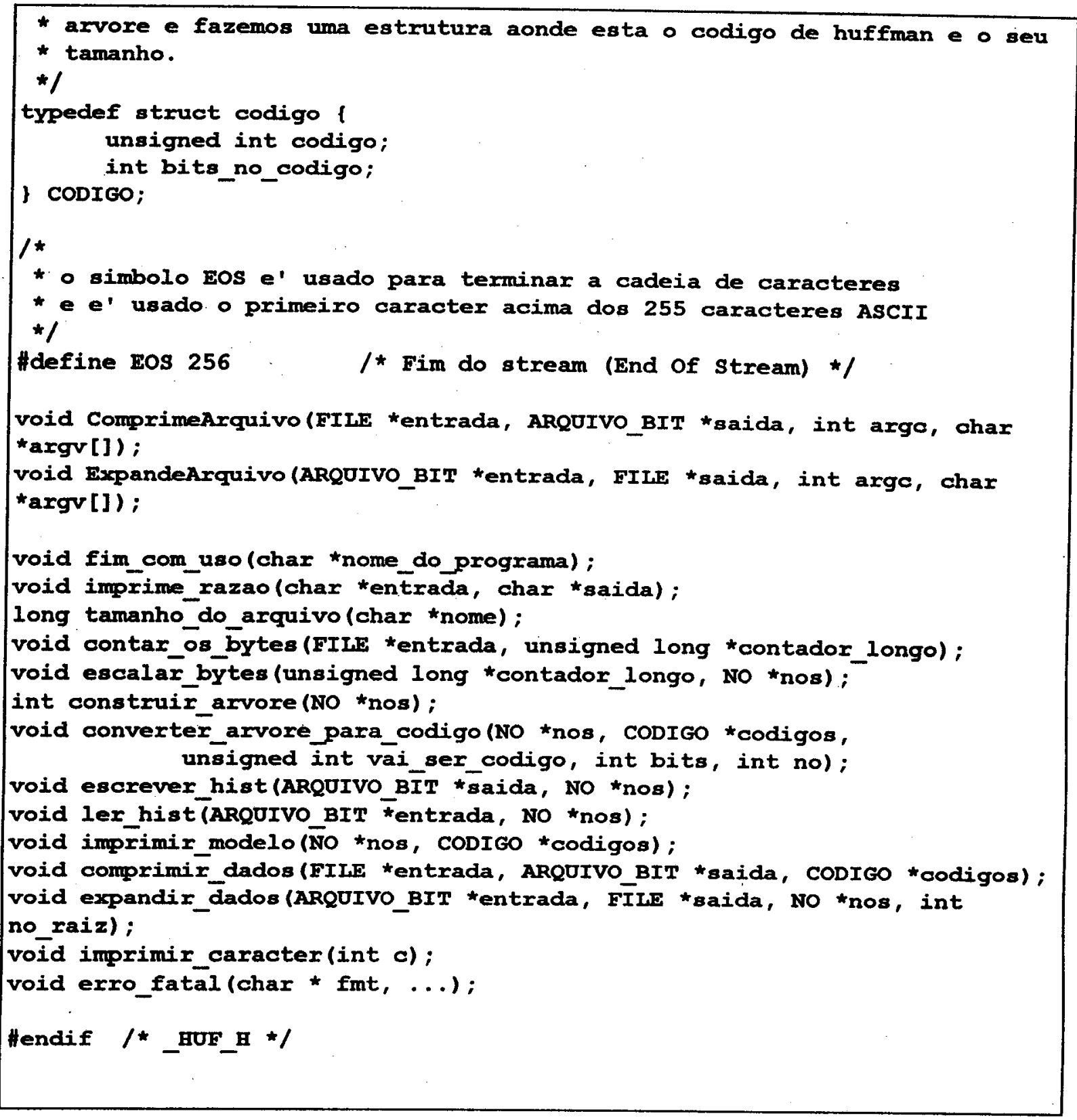


Listagem do programa chuf.c:

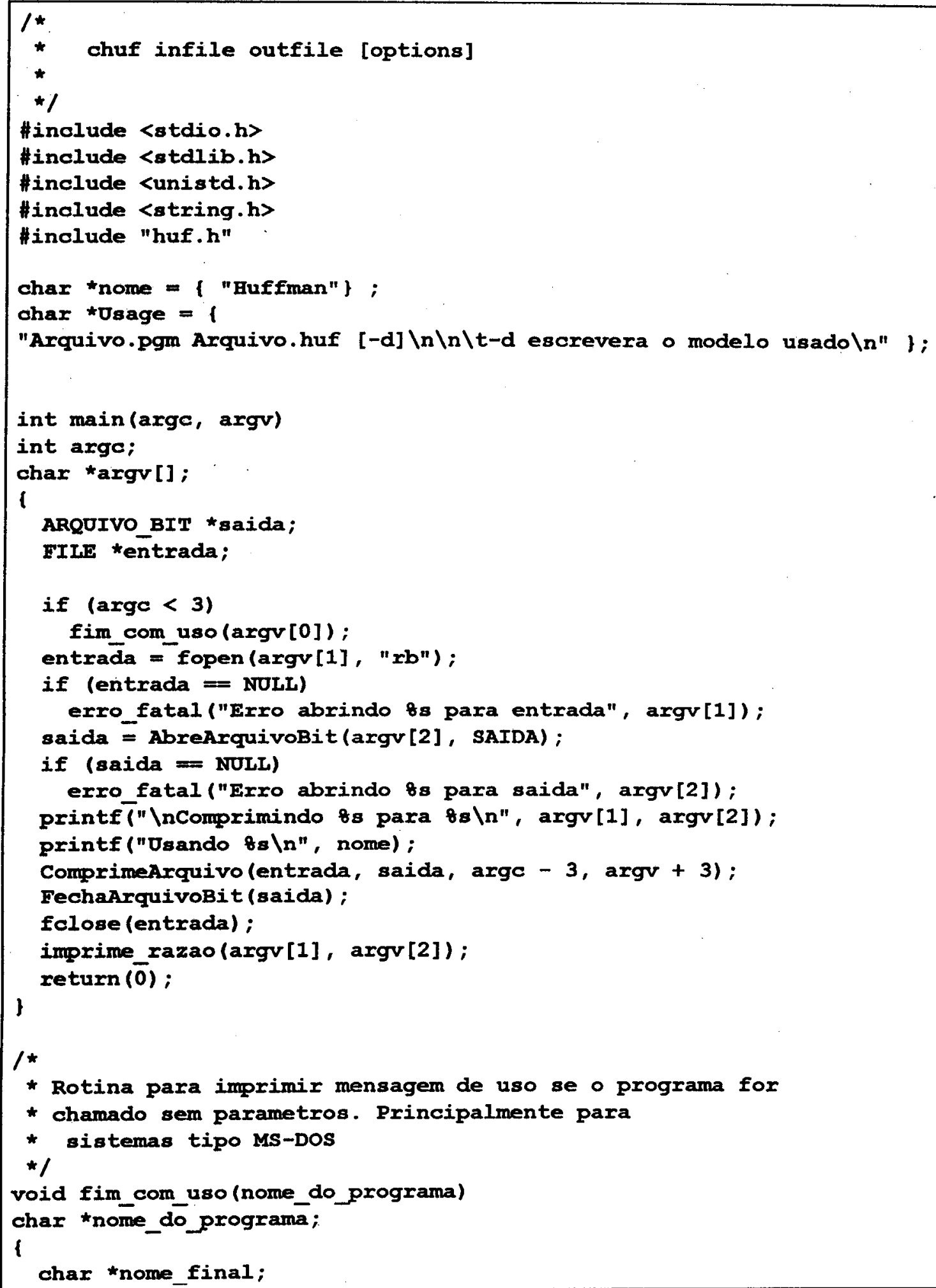




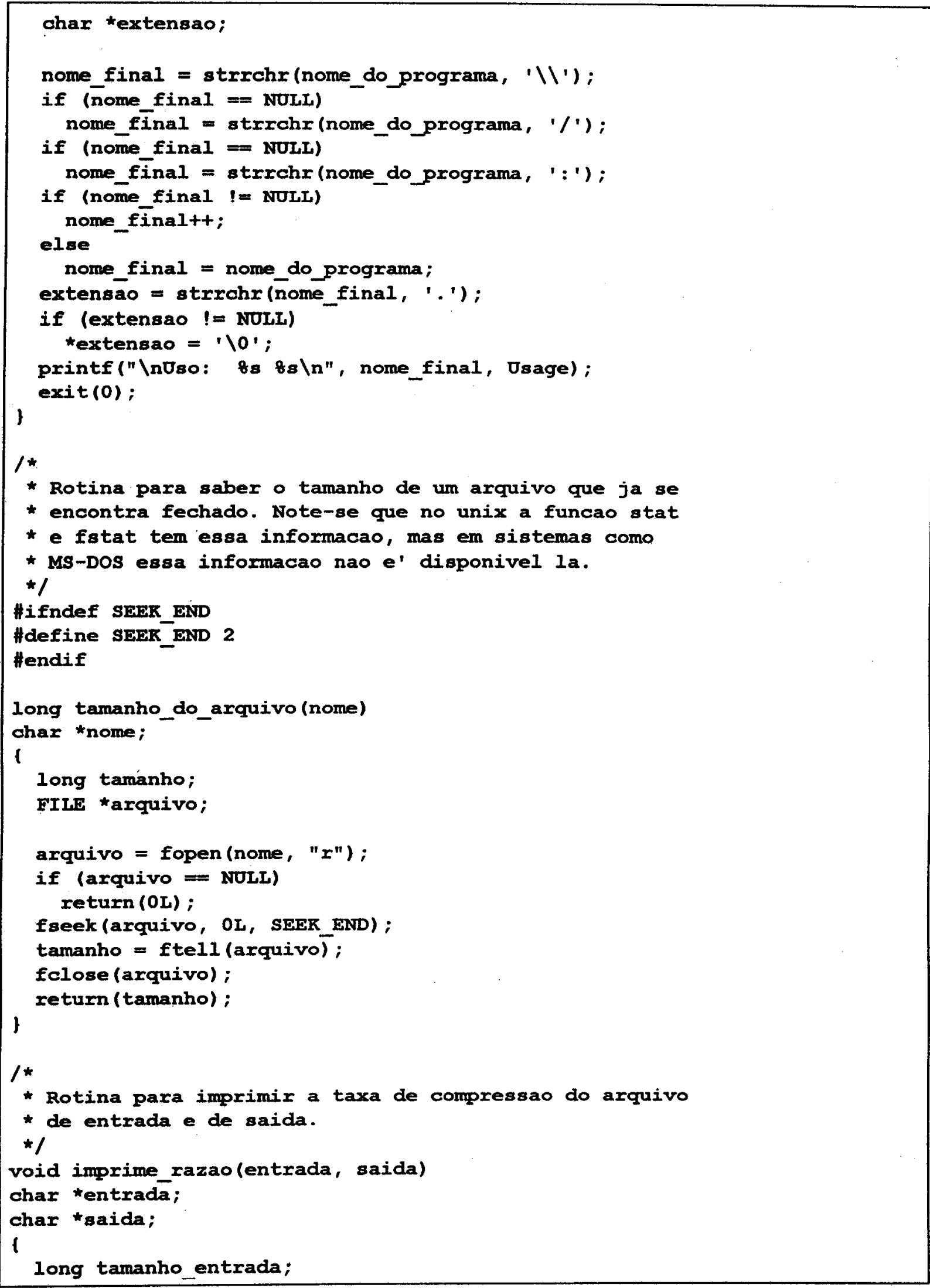




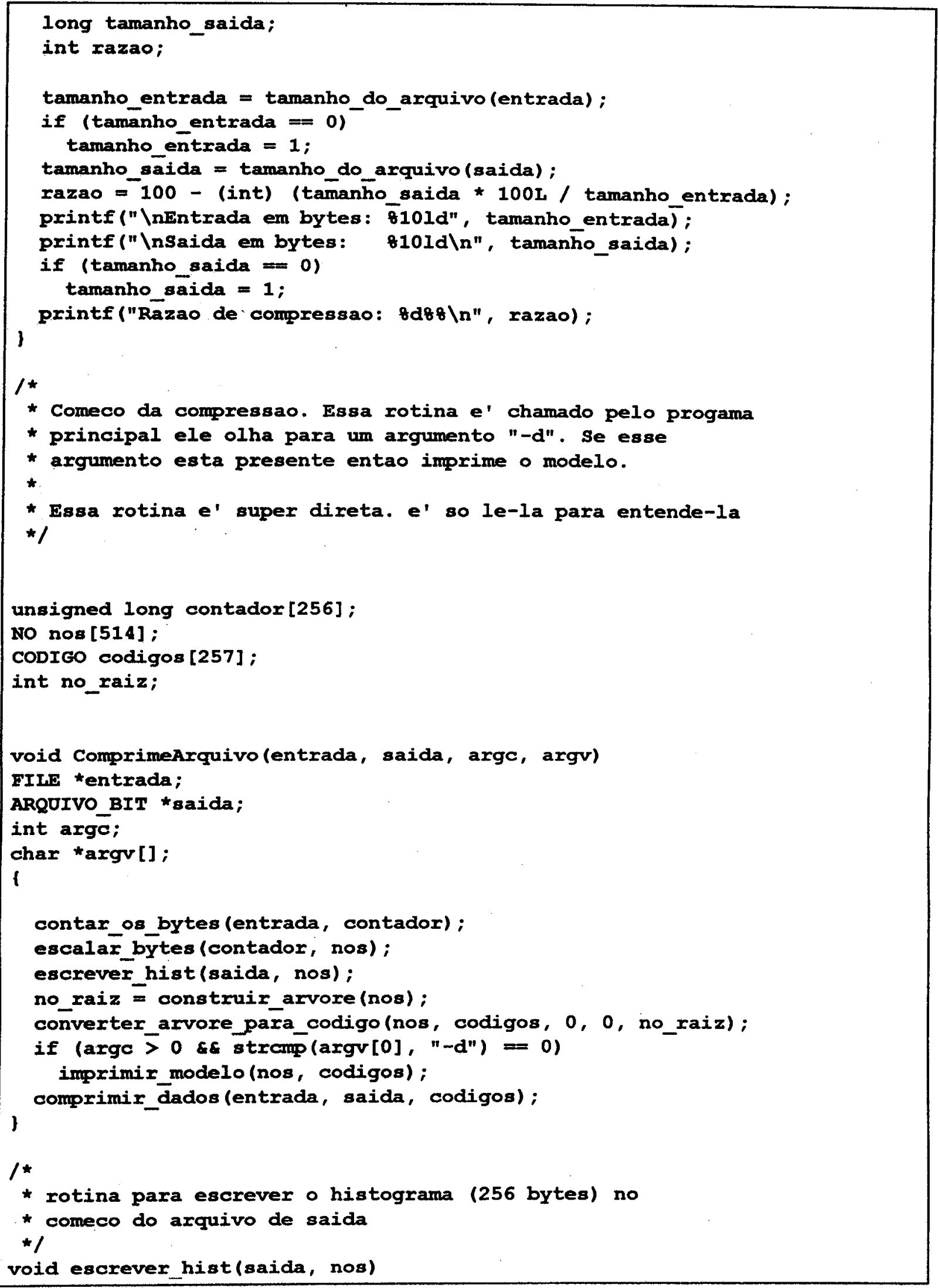




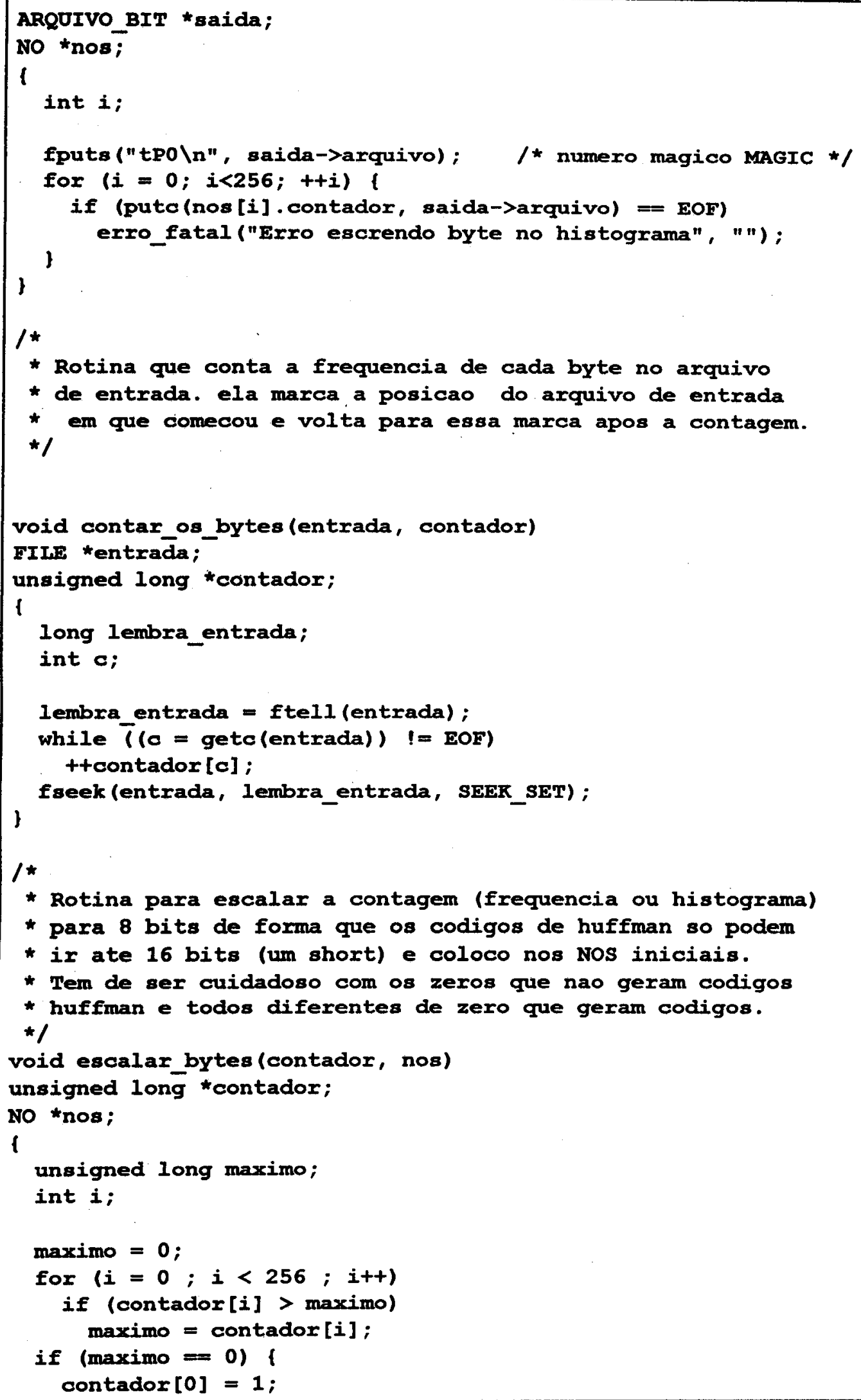




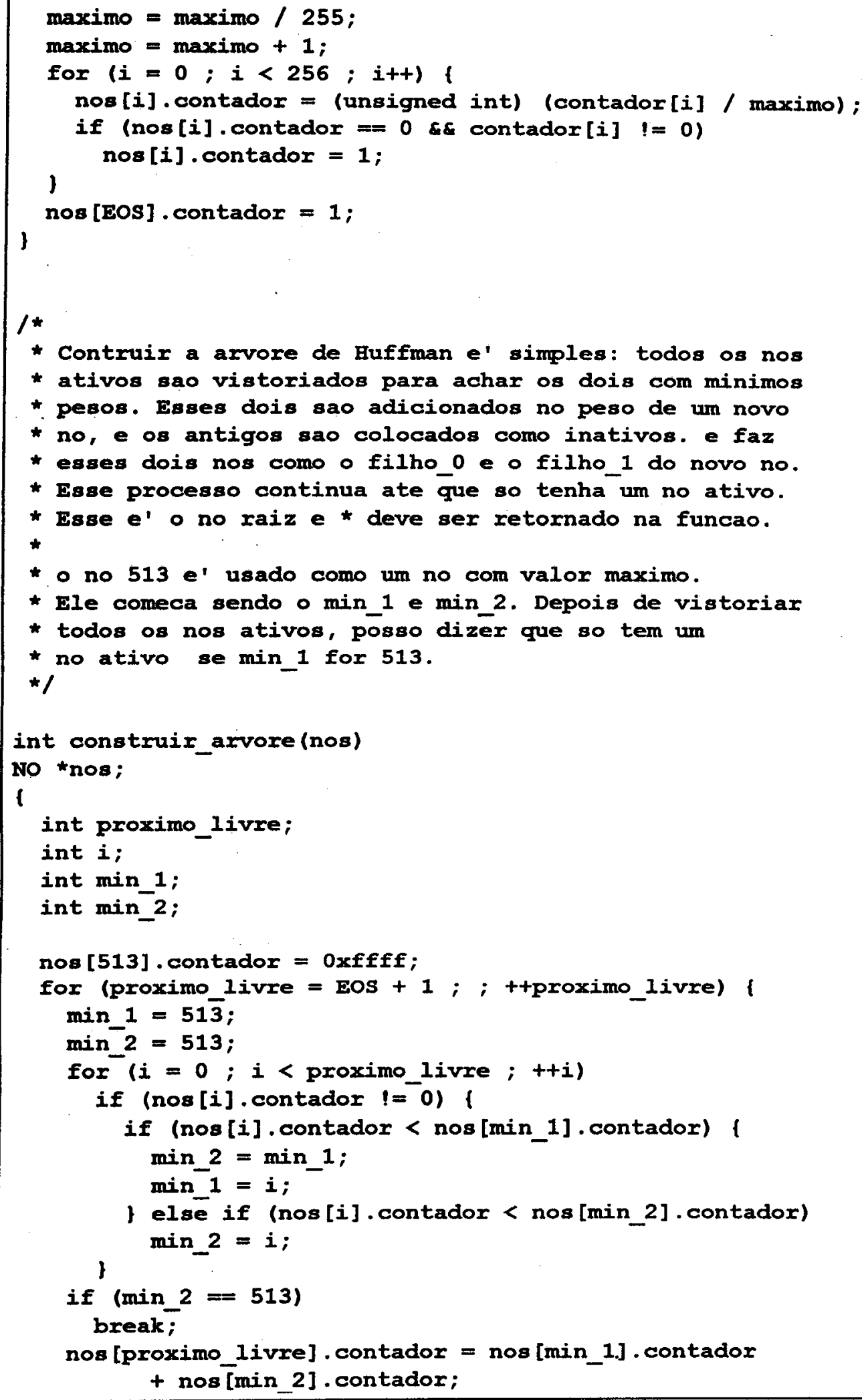




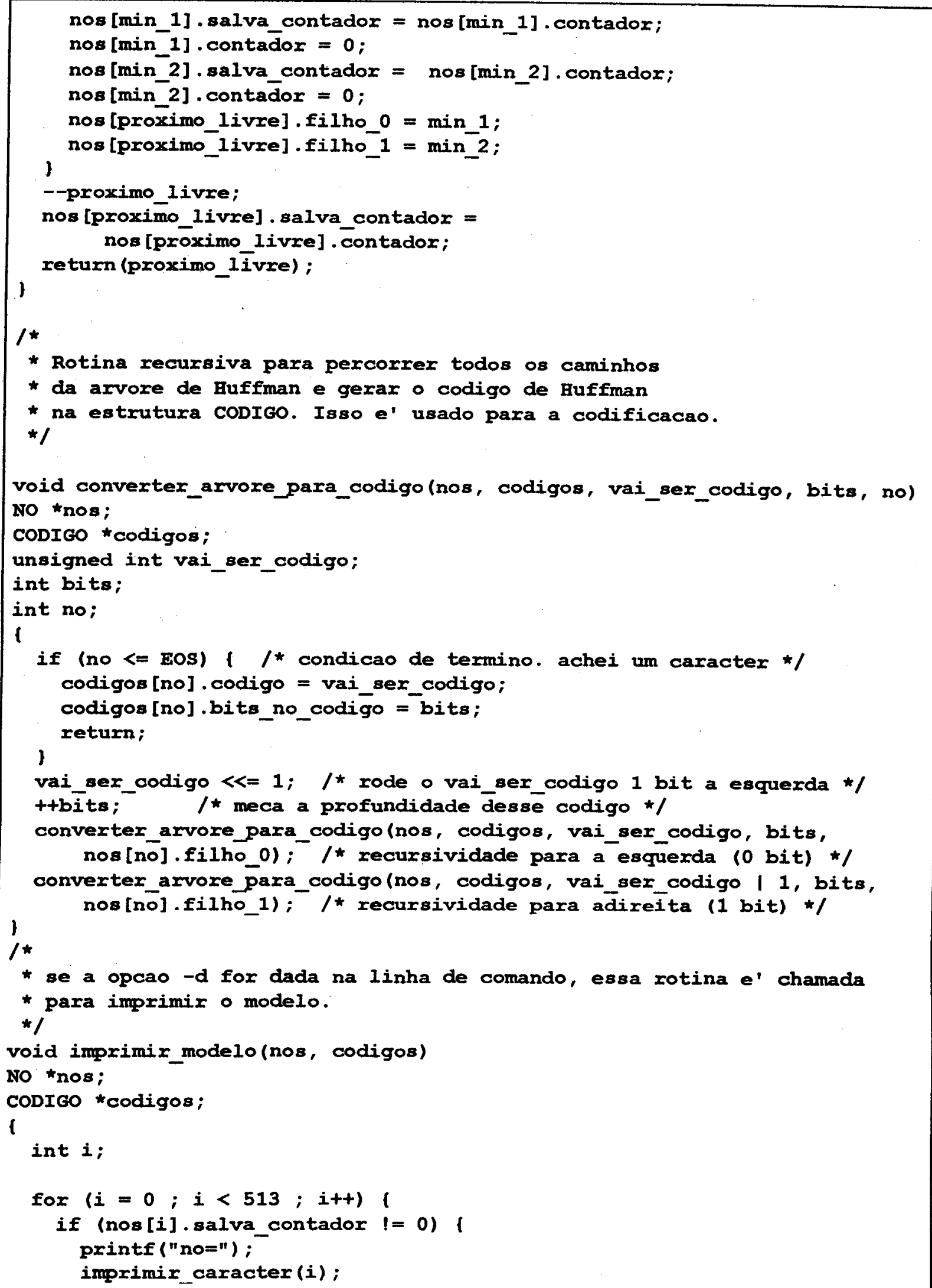




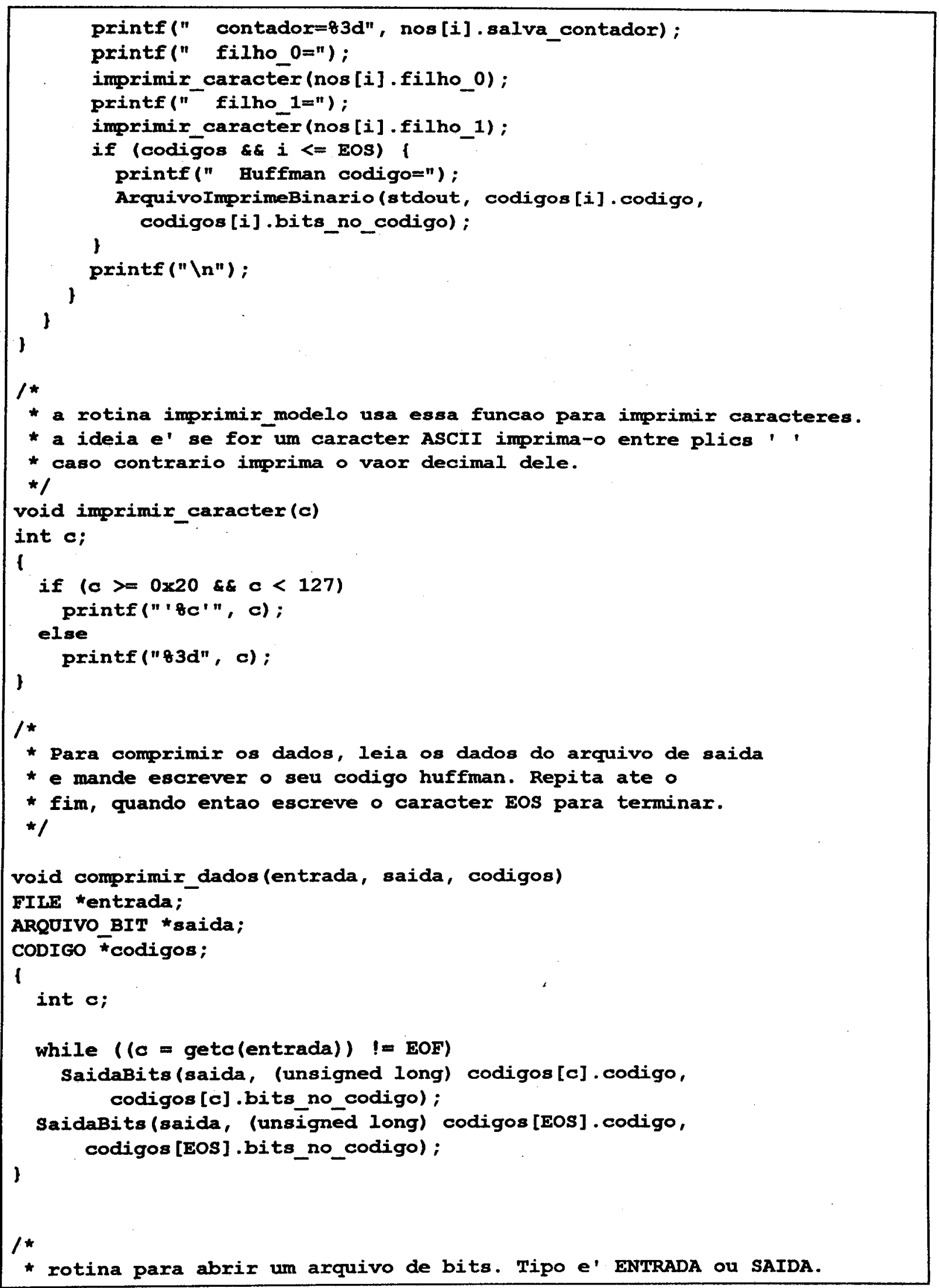




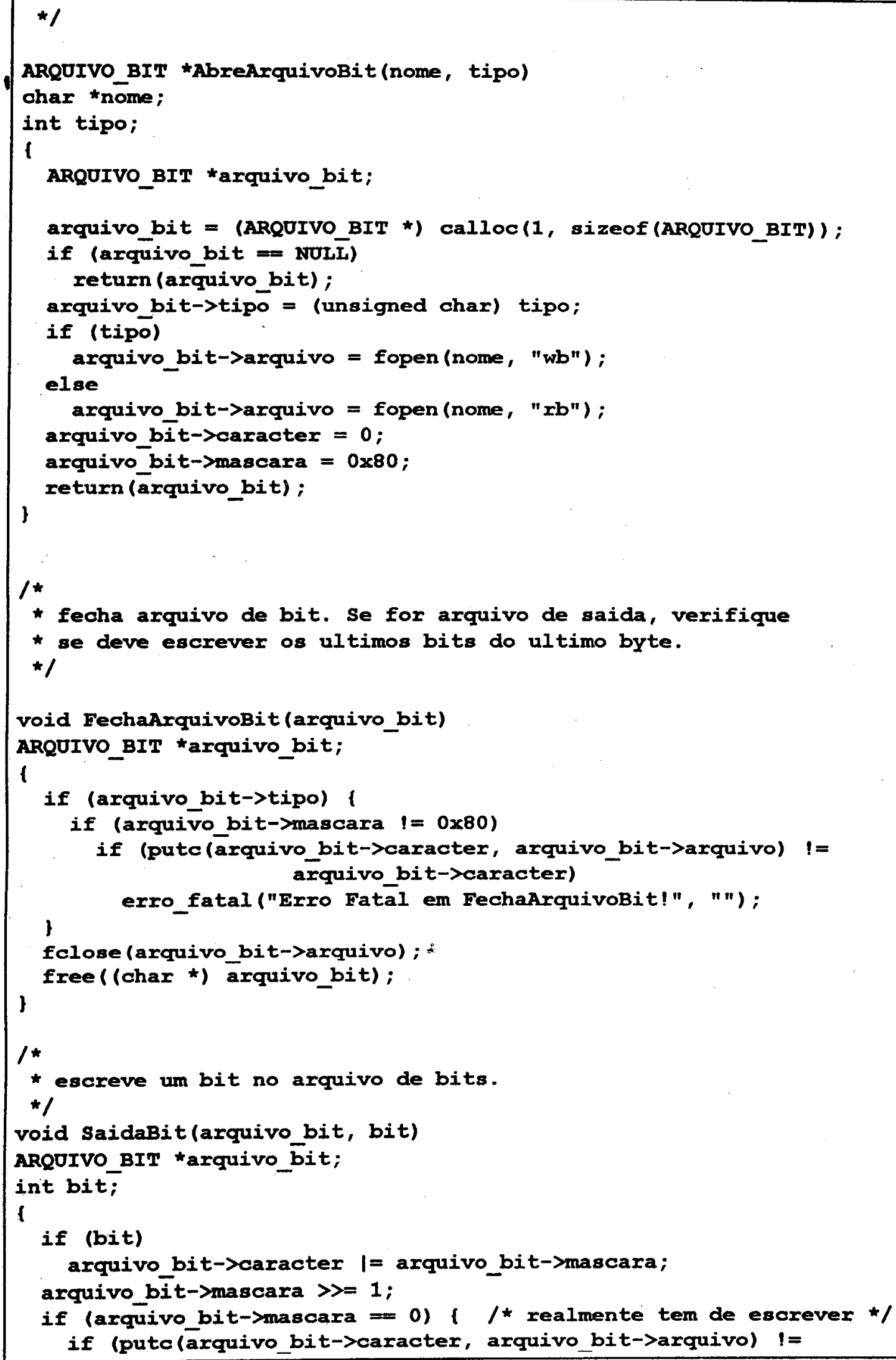




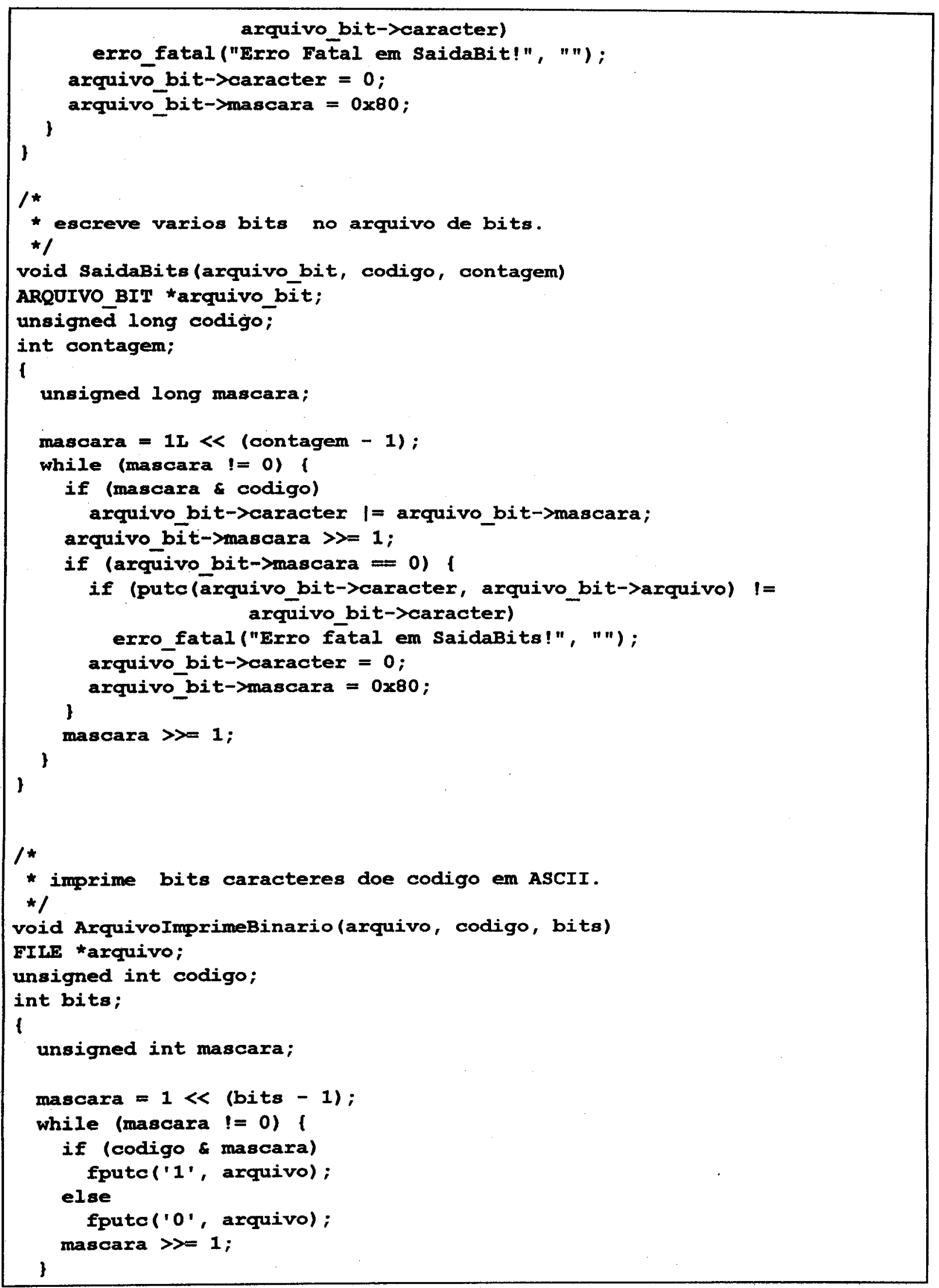




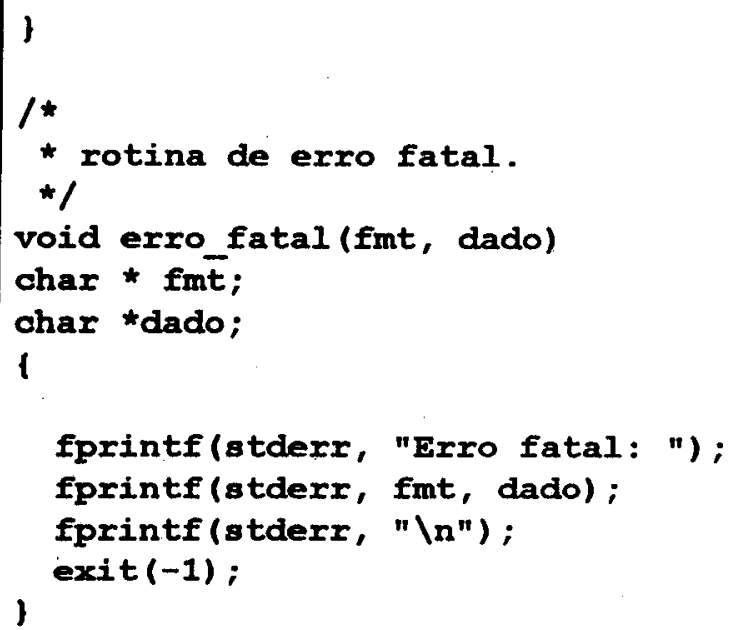

Para usá-1o:

chuf arquivo.pgm arquivo.huf [-d]

onde arquivo.pgm é o nome do arquivo no formato .pgm para entrada (o arquivo a ser comprimido) e arquivo.huf é o arquivo de saída (em formato de código de Huffman). A opção -d é opcional e imprime a árvore do código de Huffman. 
Listagem do programa uhuf.c:

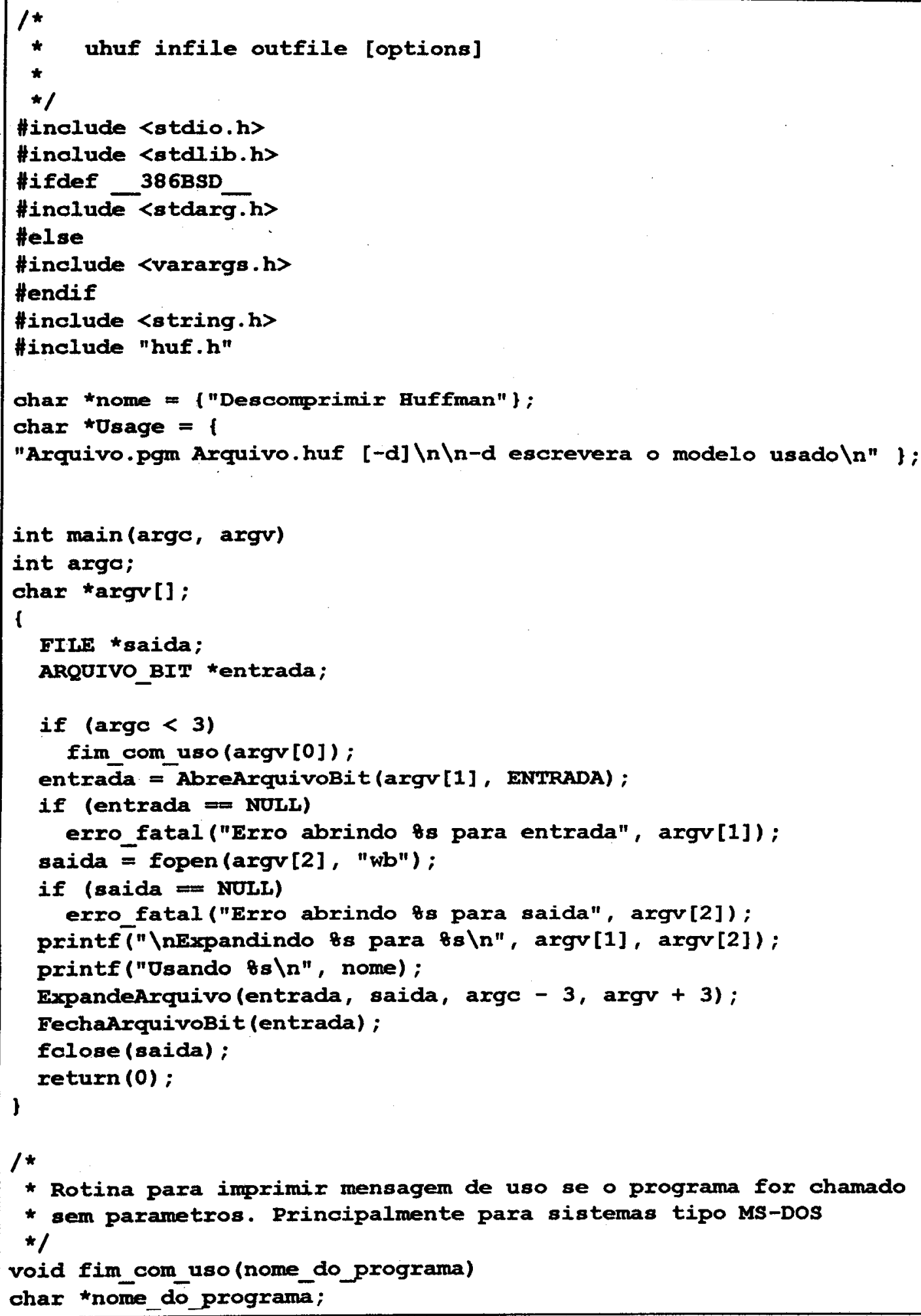




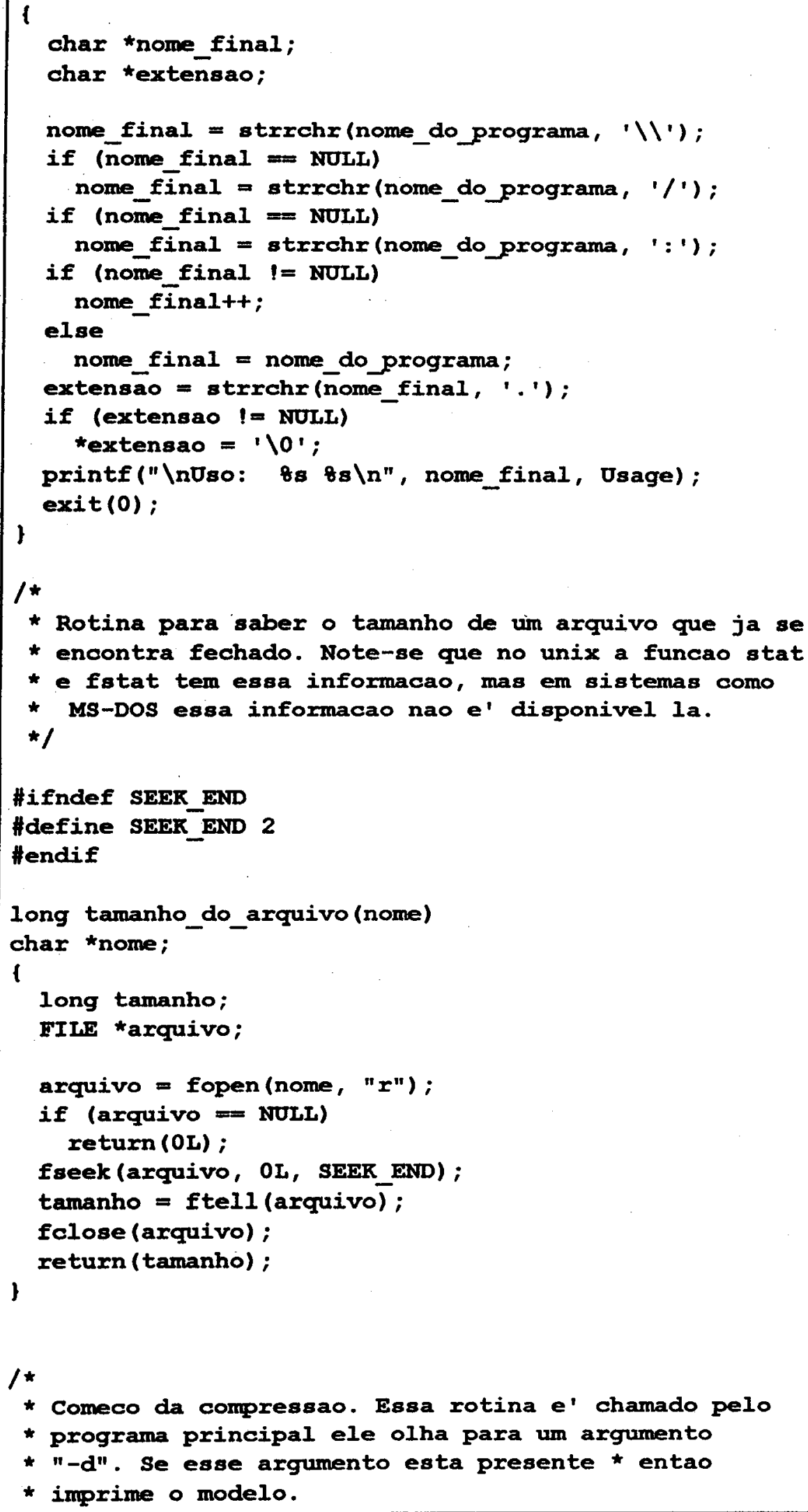




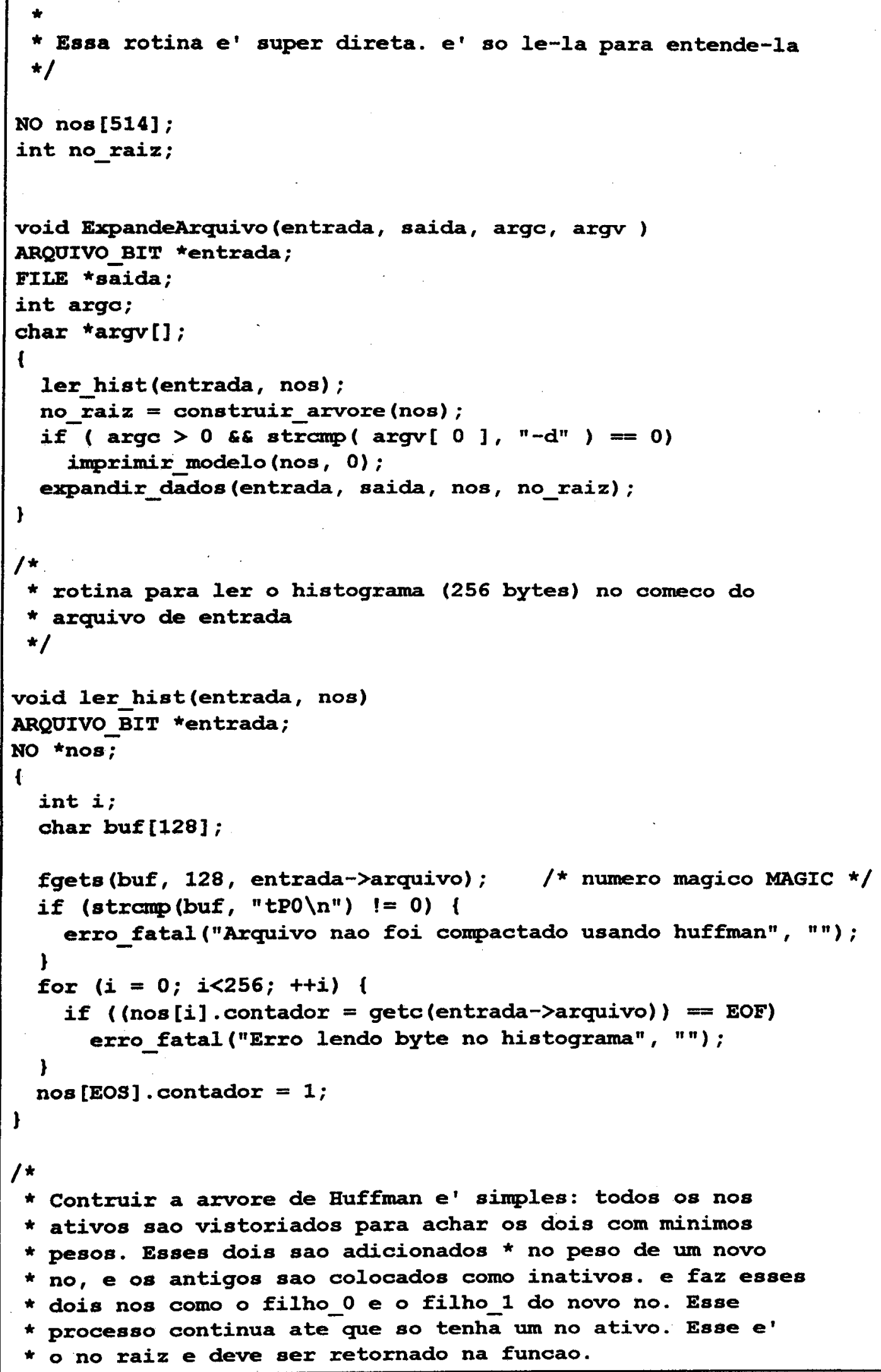




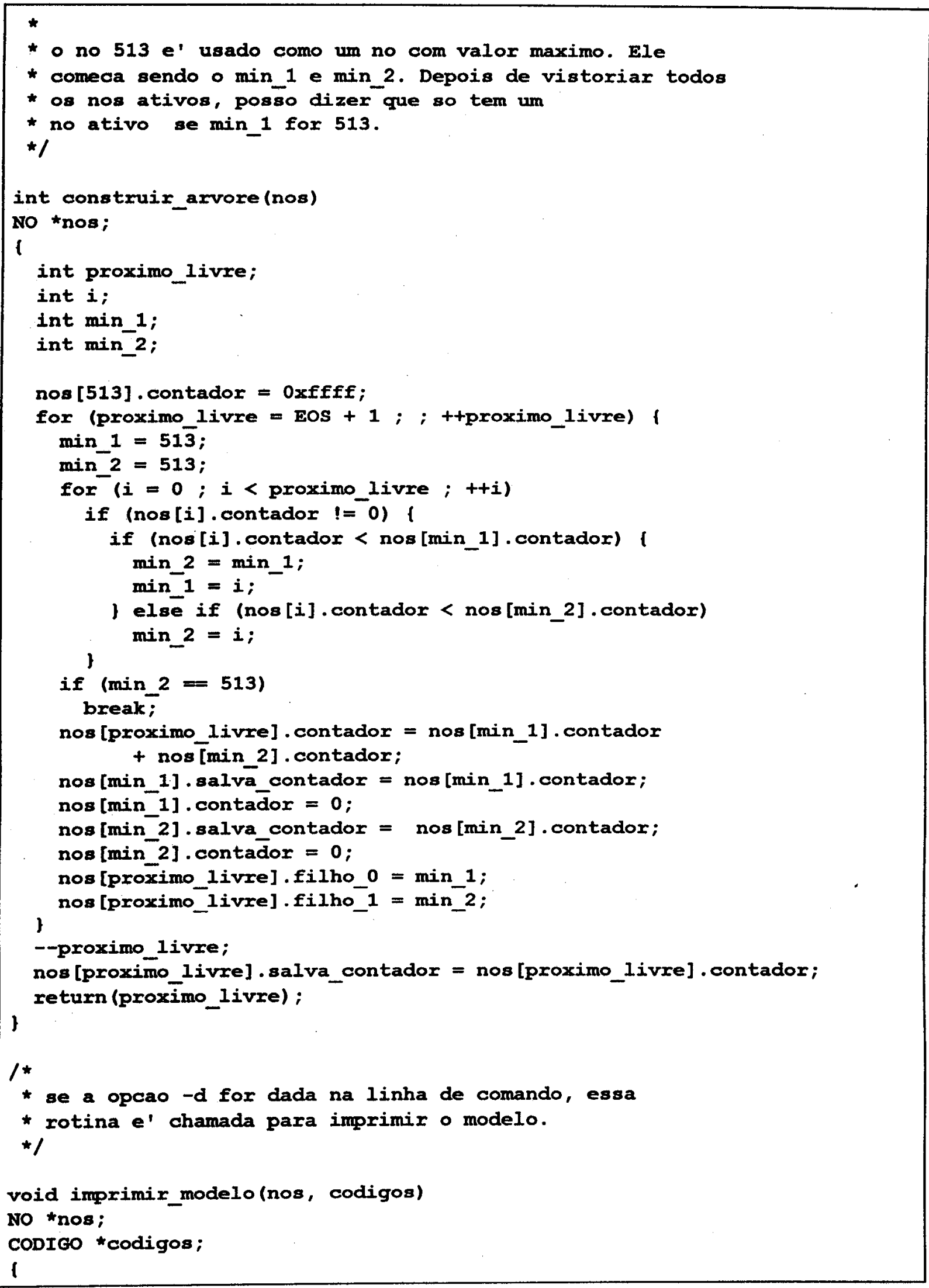




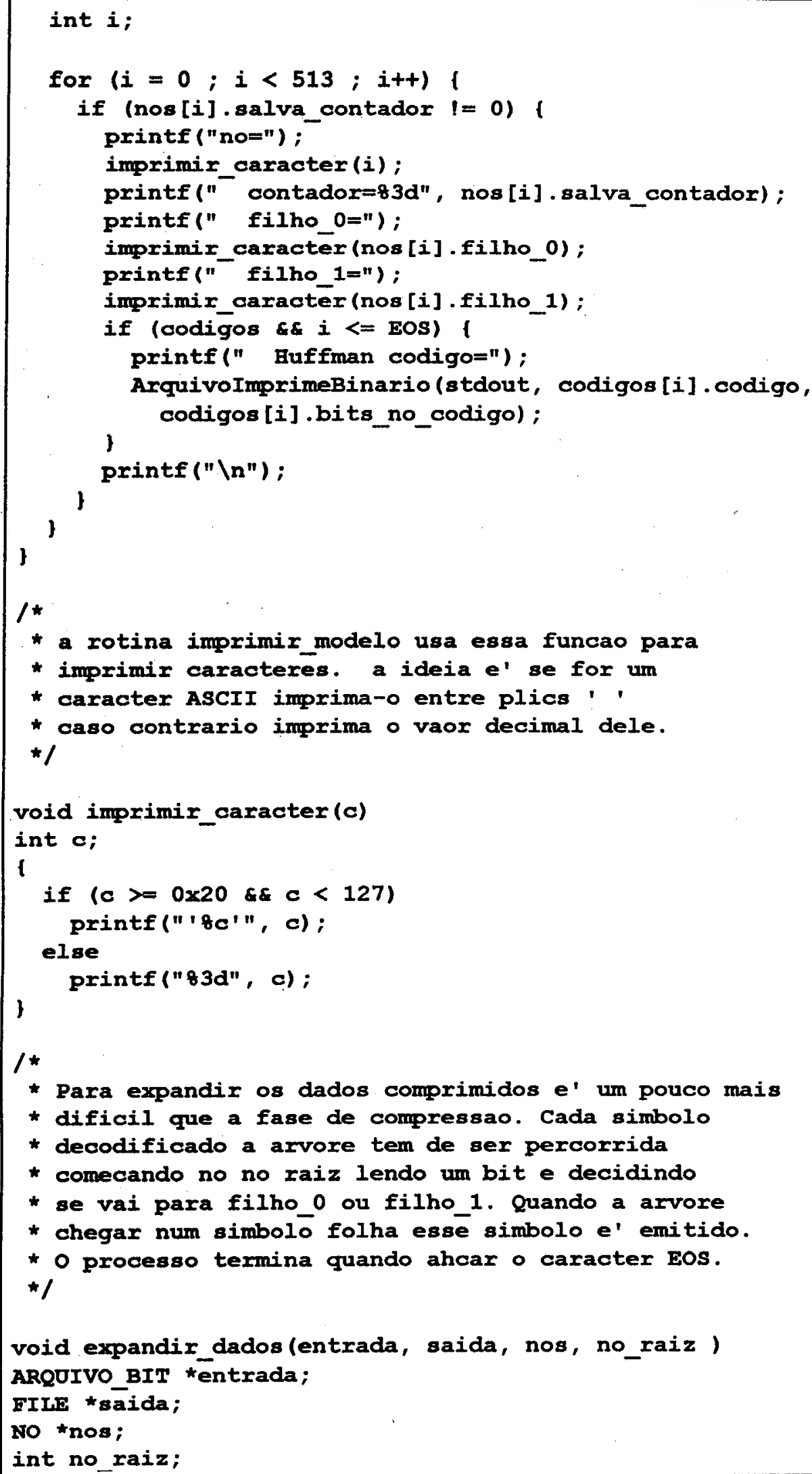




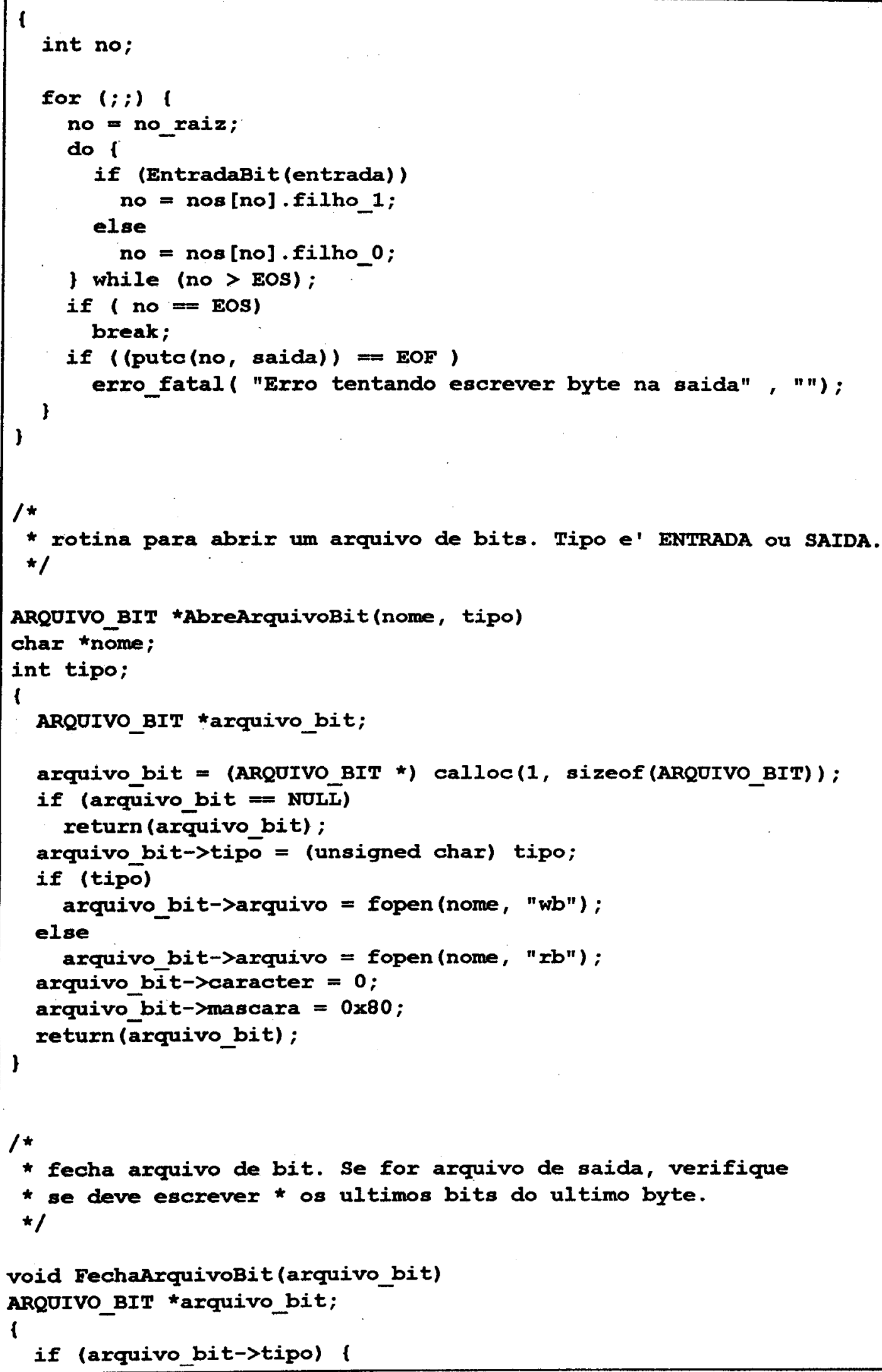




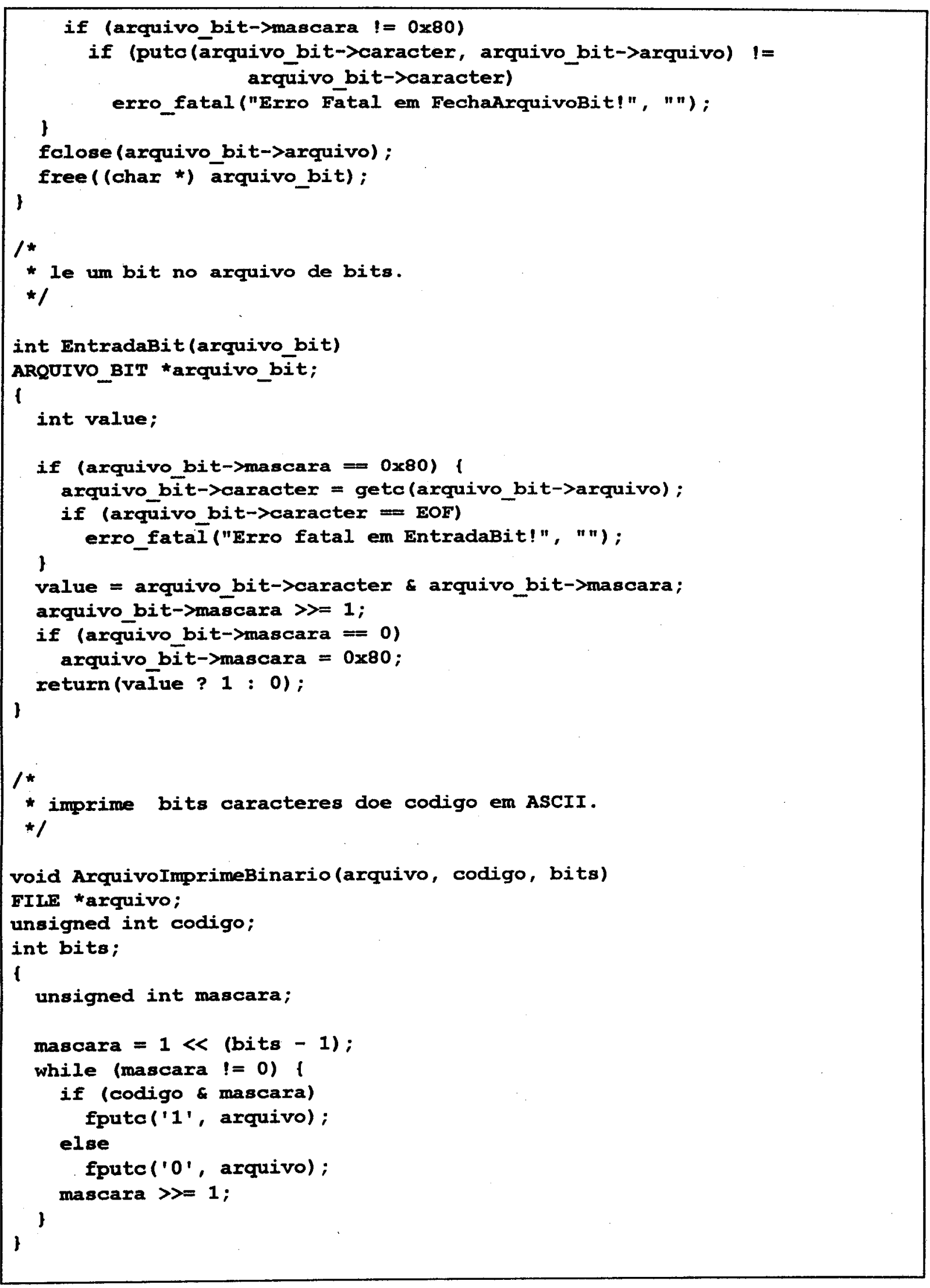




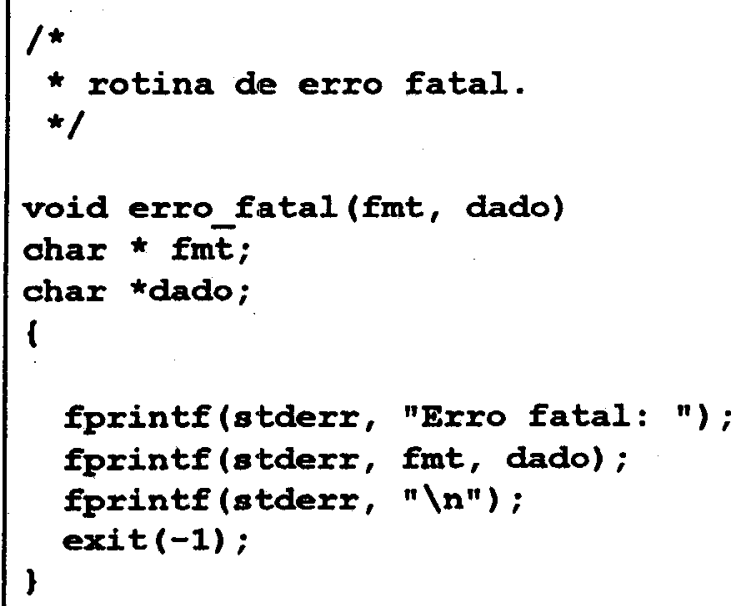

Para usá-1o:

uhuf arquivo.huf arquivo.pgm [-d]

onde arquivo.huf é o nome do arquivo no formato Huffman para entrada (o arquivo a ser descomprimido) e arquivo.pgm é o arquivo de saída (em formato pgm). A opção $-d$ é opcional e imprime a árvore do código de Huffman. 


\section{Apêndice D}

Listagem de btc.c:

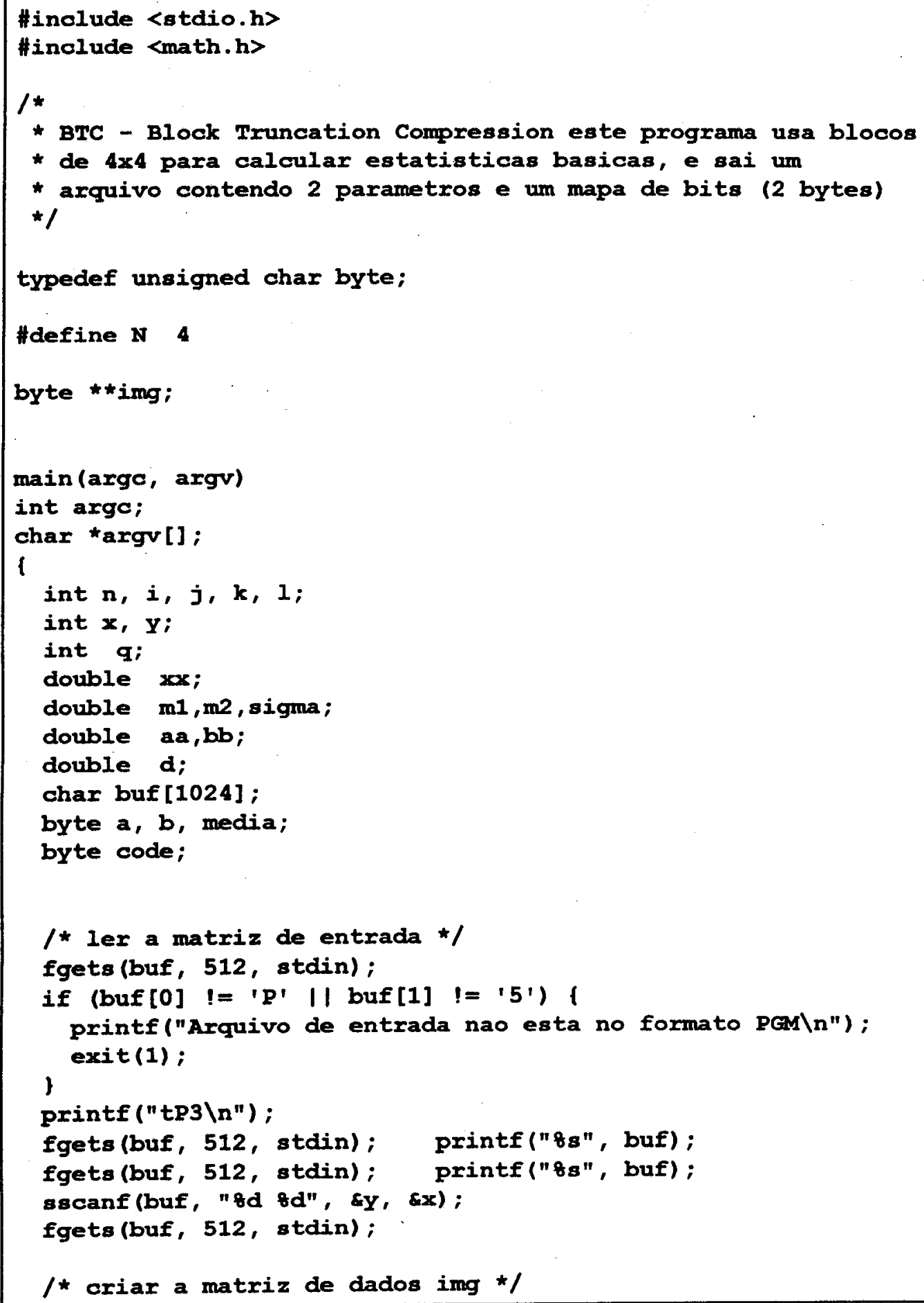




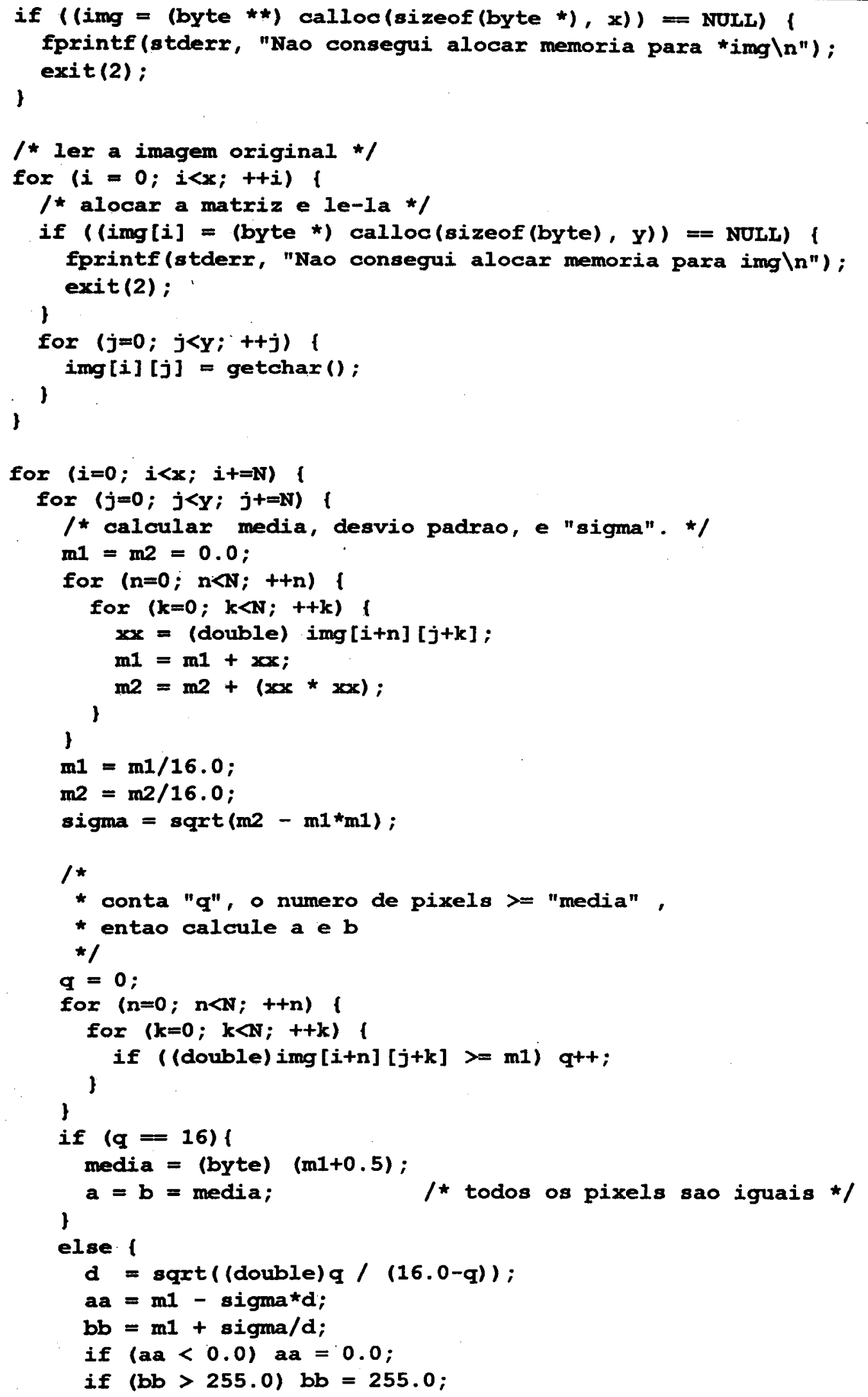




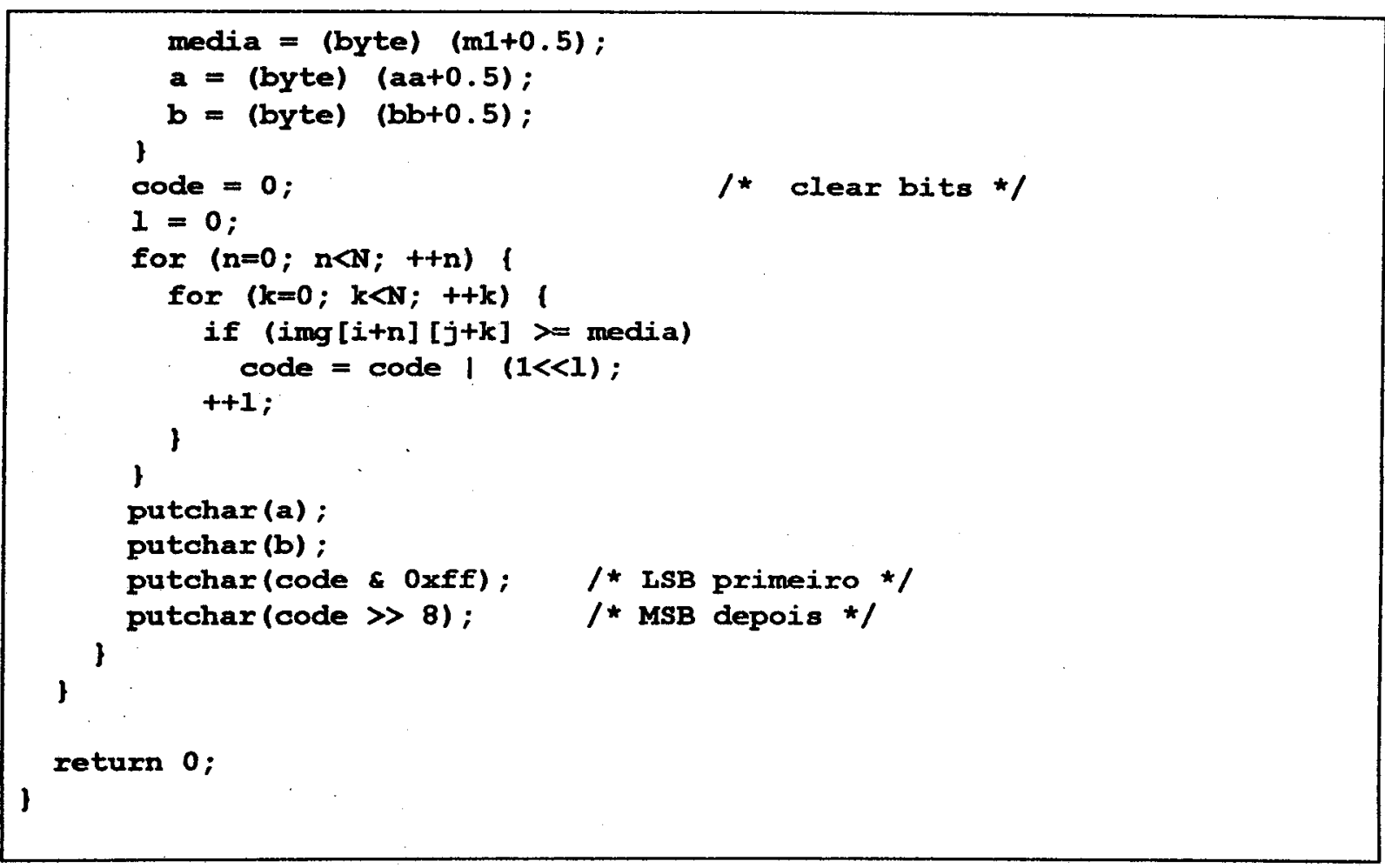

Para usar o programa btc:

btc <arquivo.pgm >arquivo.btc

Onde arquivo.pgm é o arquivo formato .pgm a ser comprimido e arquivo.btc é o arquivo comprimido usando BTC. 
Listagem do programa ubtc.c:

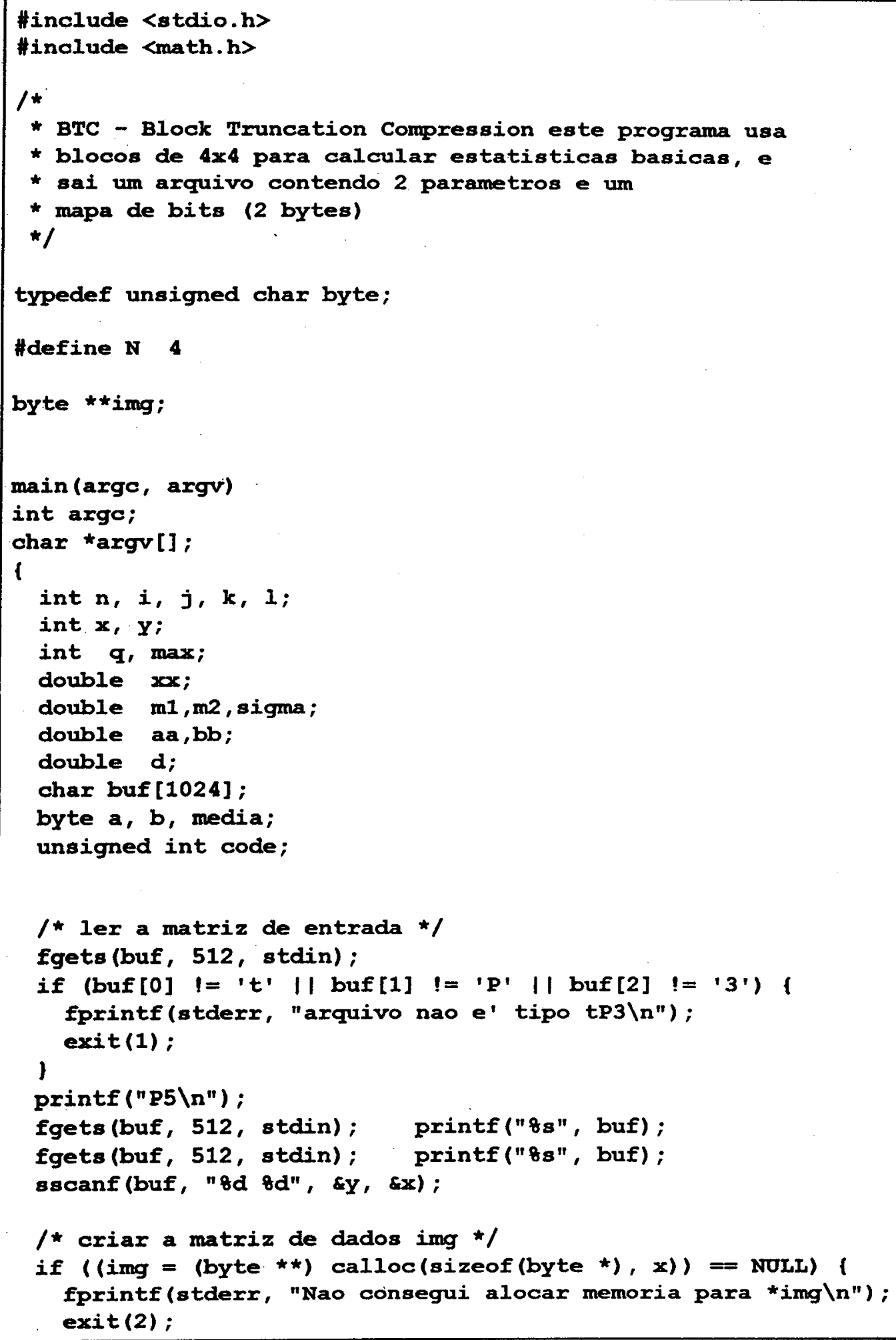




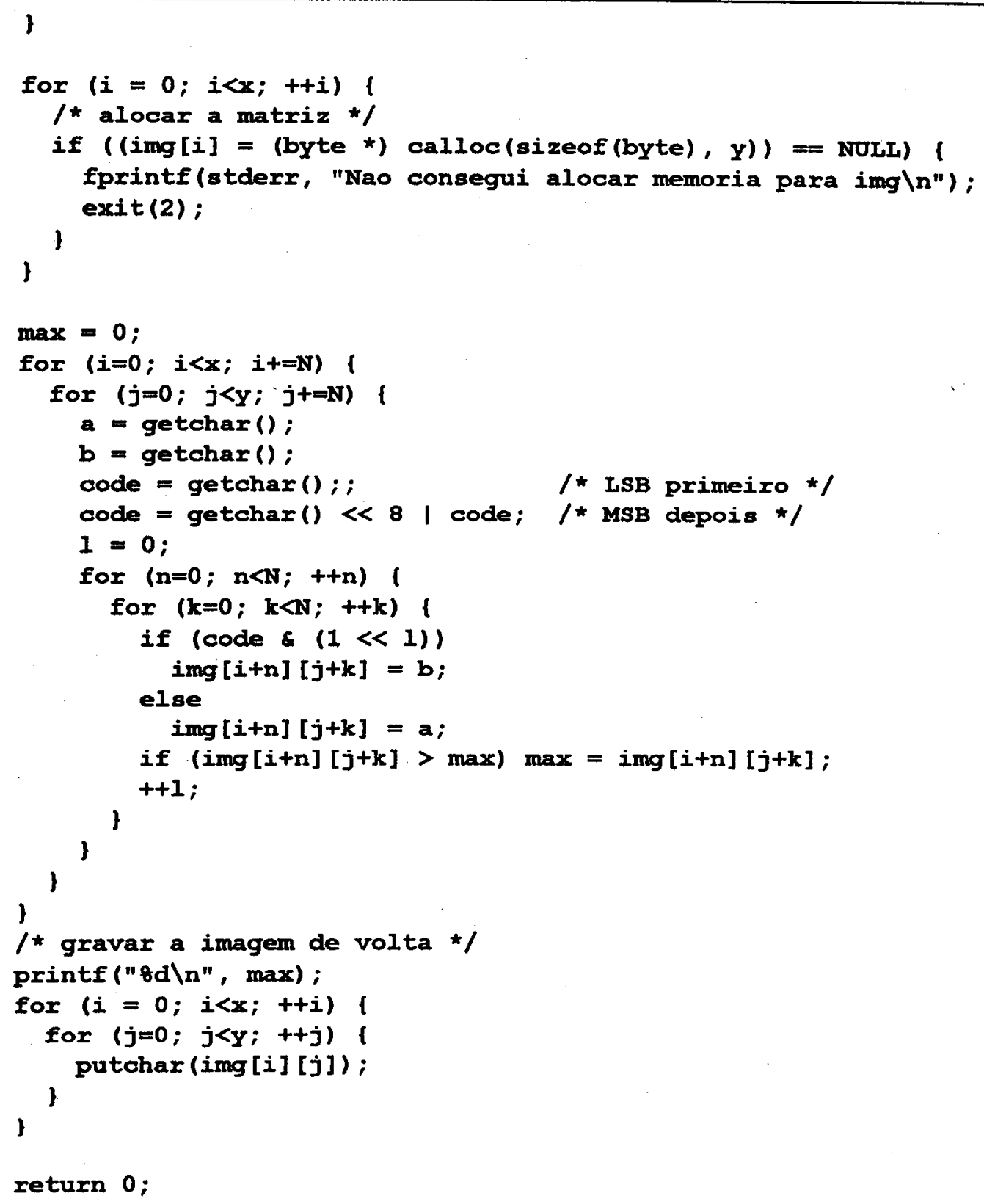


Para usar o descompressor ubtc:

ubtc <artquivo.btc >arquivo.pgm

Onde arquiro.btc é o arquivo já comprimido pelo programa btc. Arquivo.pgm é o arquivo saída formato .pgm. 


\section{Apêndice E}

Listagem de c4c.c:

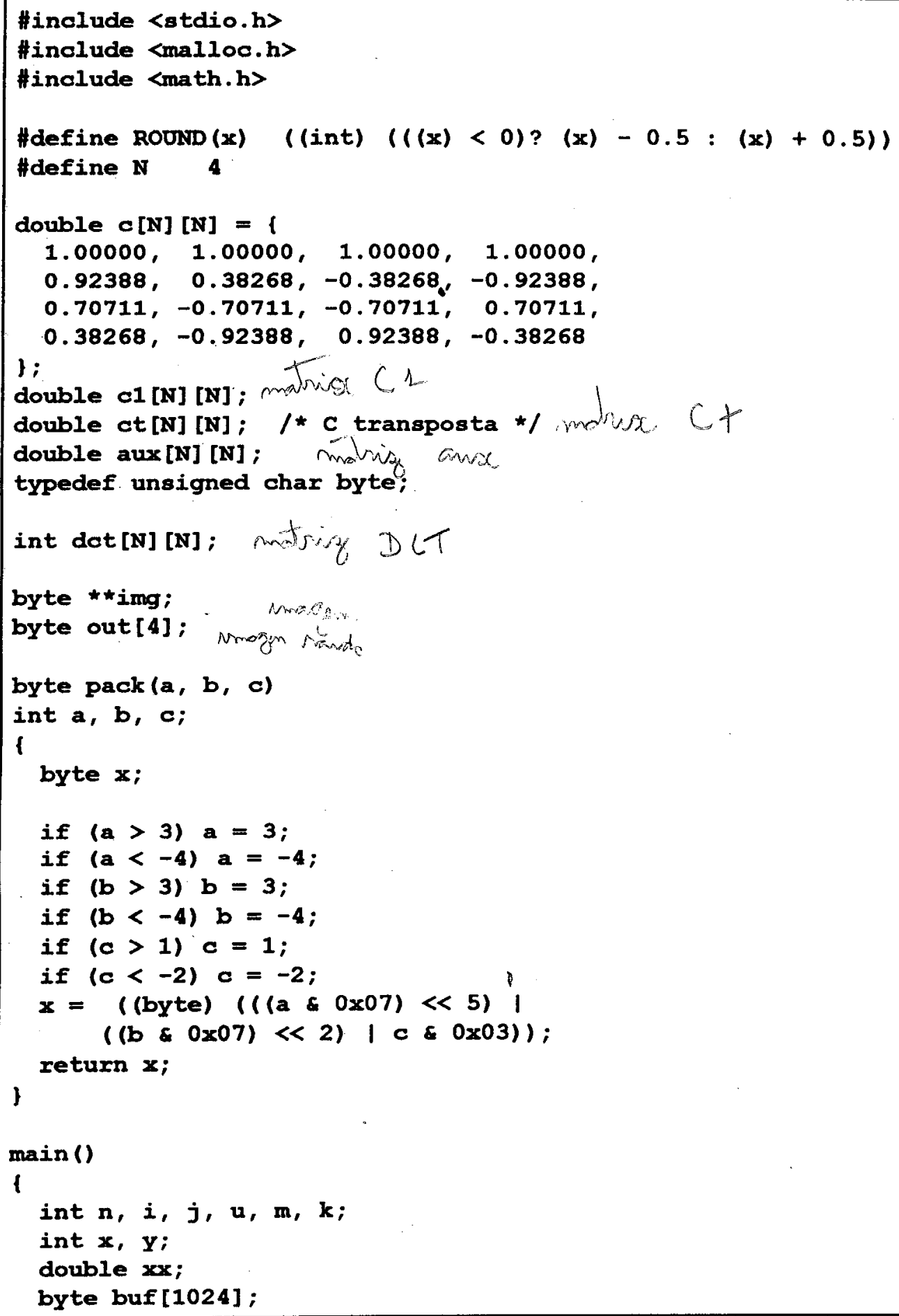




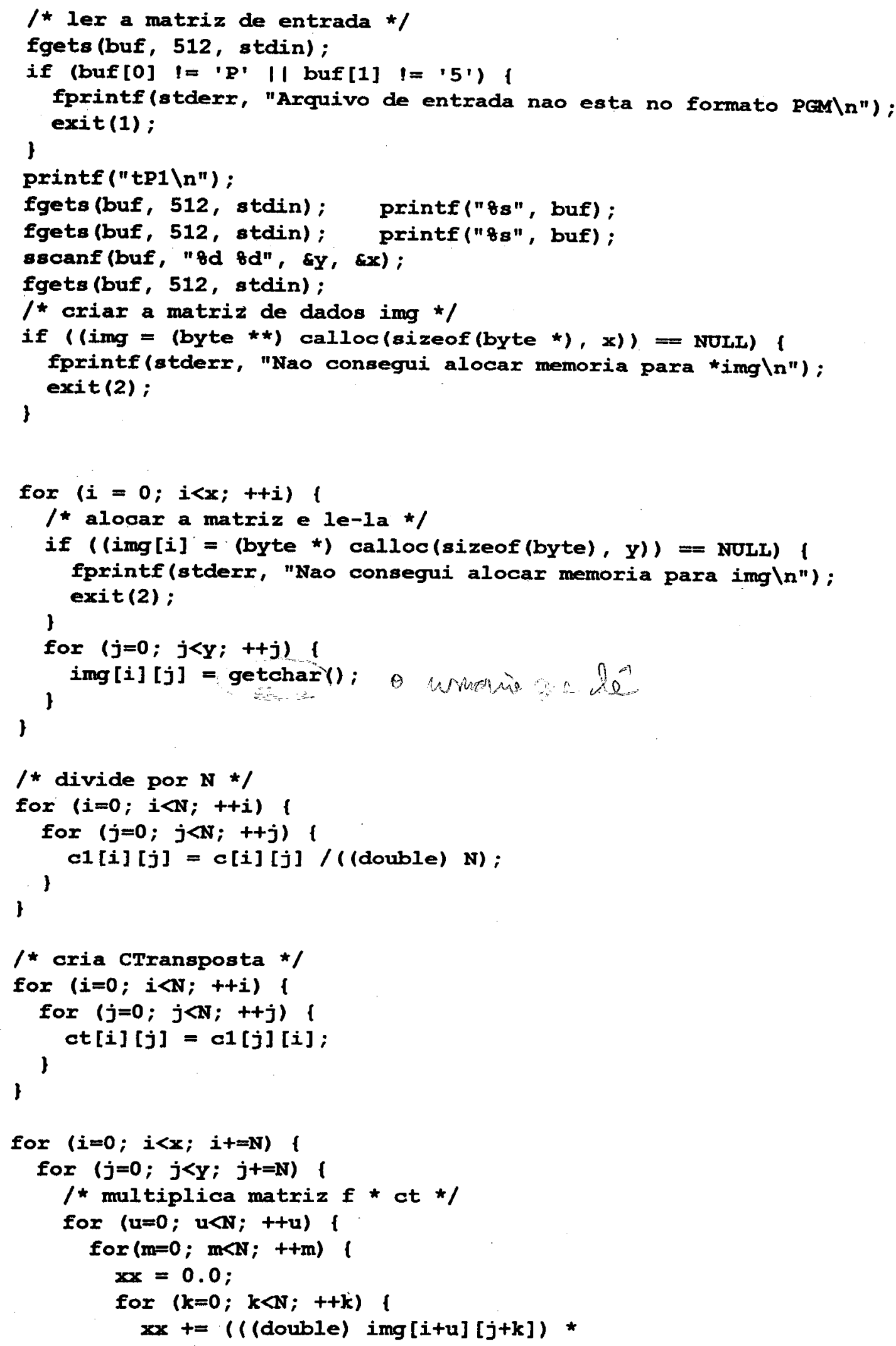




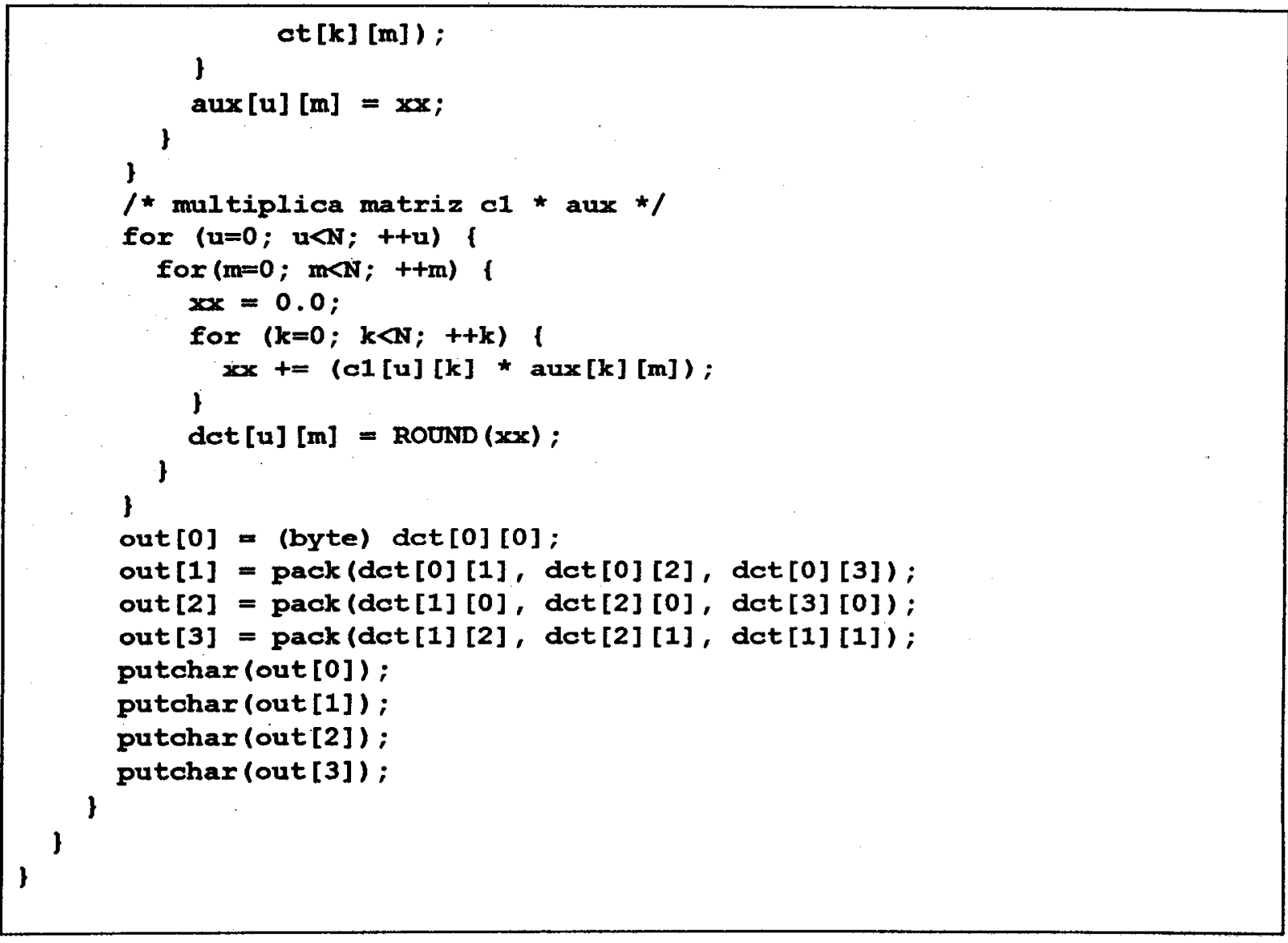

Para usar o programa c4c:

c4c <arquivo.pgm >arquivo. c4c

Onde arquivo.pgm é o arquivo formato .pgm a ser comprimido e arquivo.c4c é o arquivo comprimido usando DCT $4 * 4$. 
Listagem do programa c4u.c:

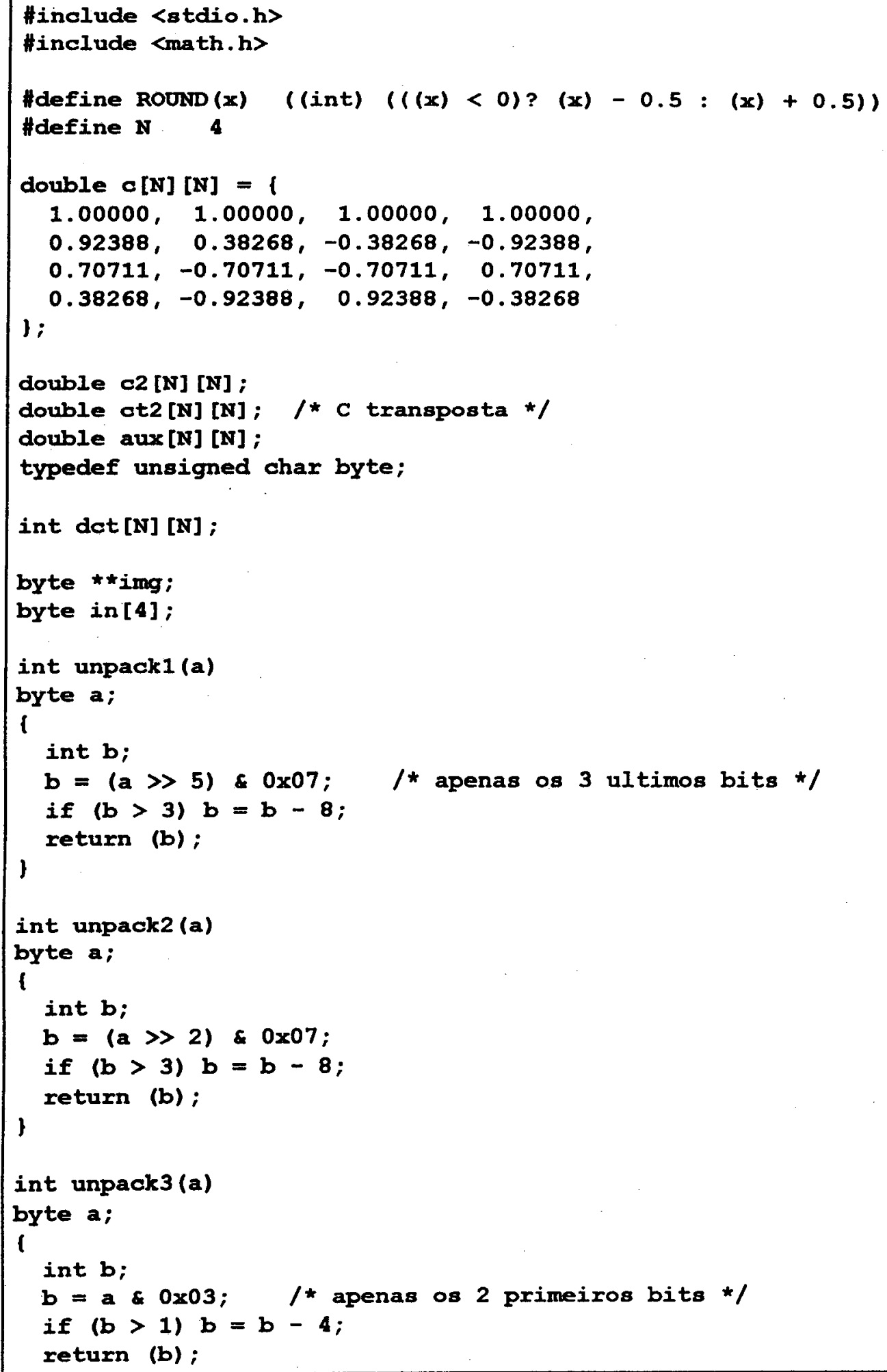




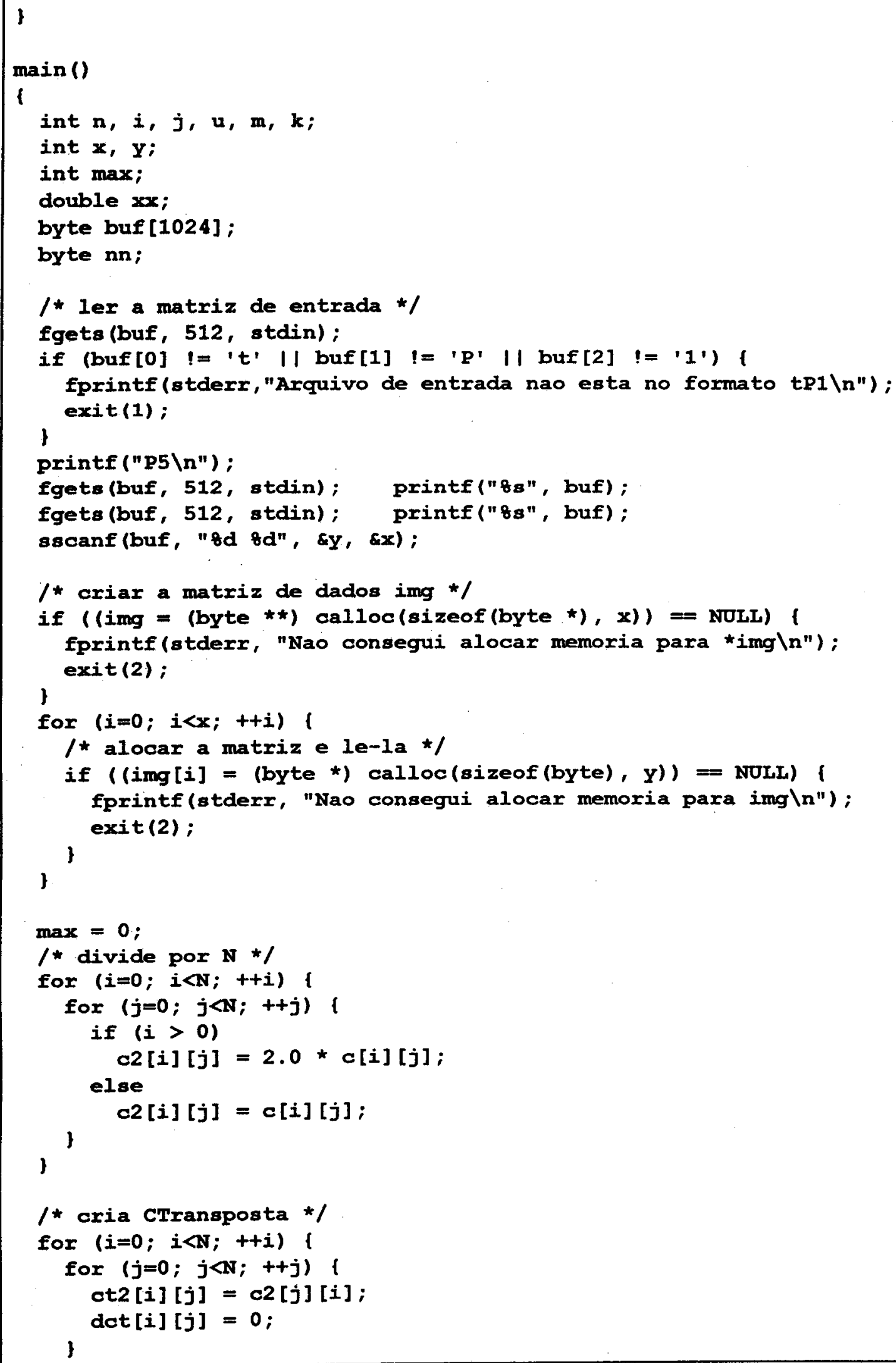




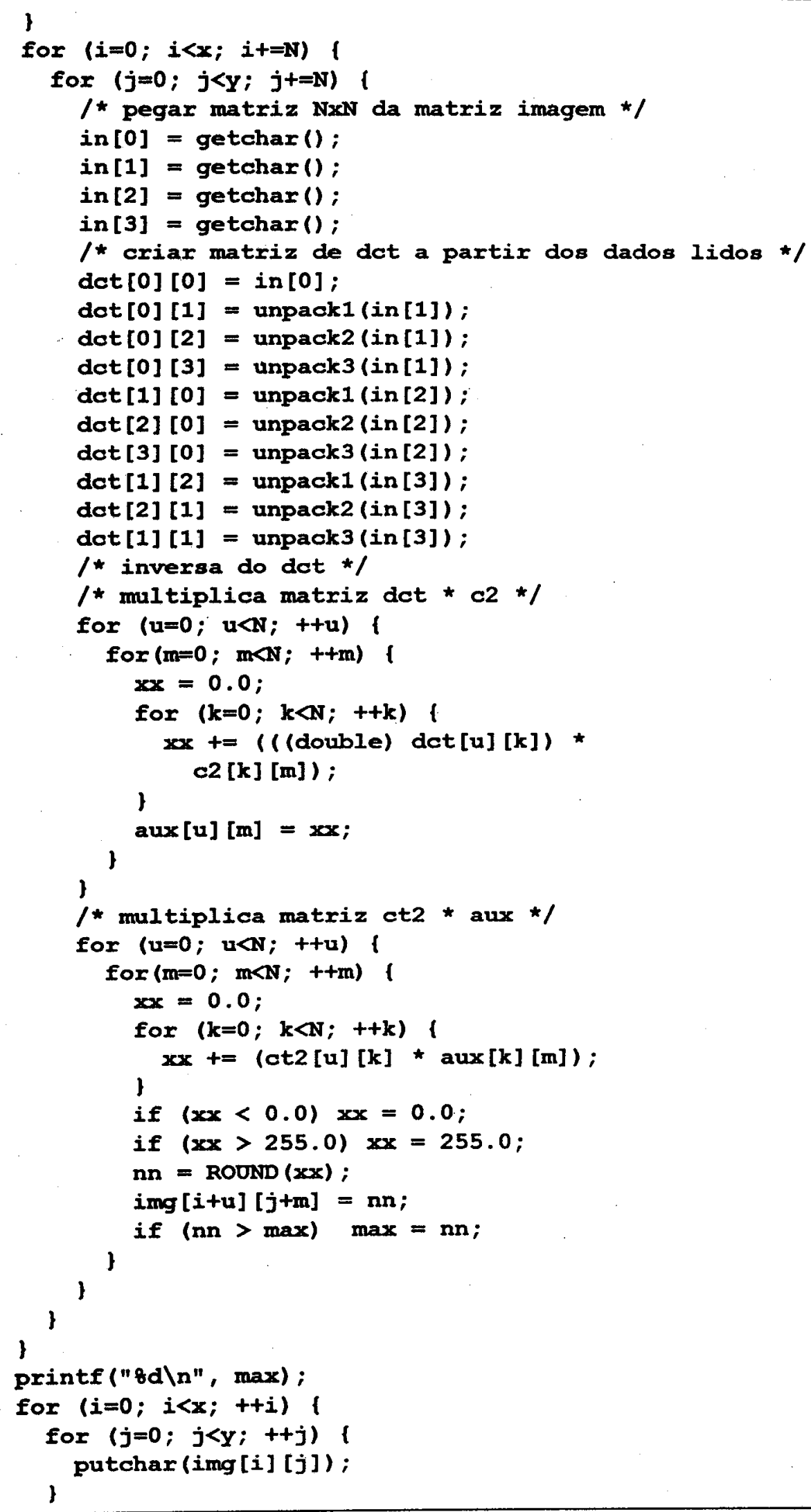


了

1

Para usar o descompressor c4u:

c4u <artquivo.c4c >arquivo.pgm

Onde arquivo.c4c é o arquivo já comprimido pelo programa c4c. Arquivo.pgm é o arquivo saida formato .pgm. 


\section{Apêndice F}

Listagem de c8c.c:

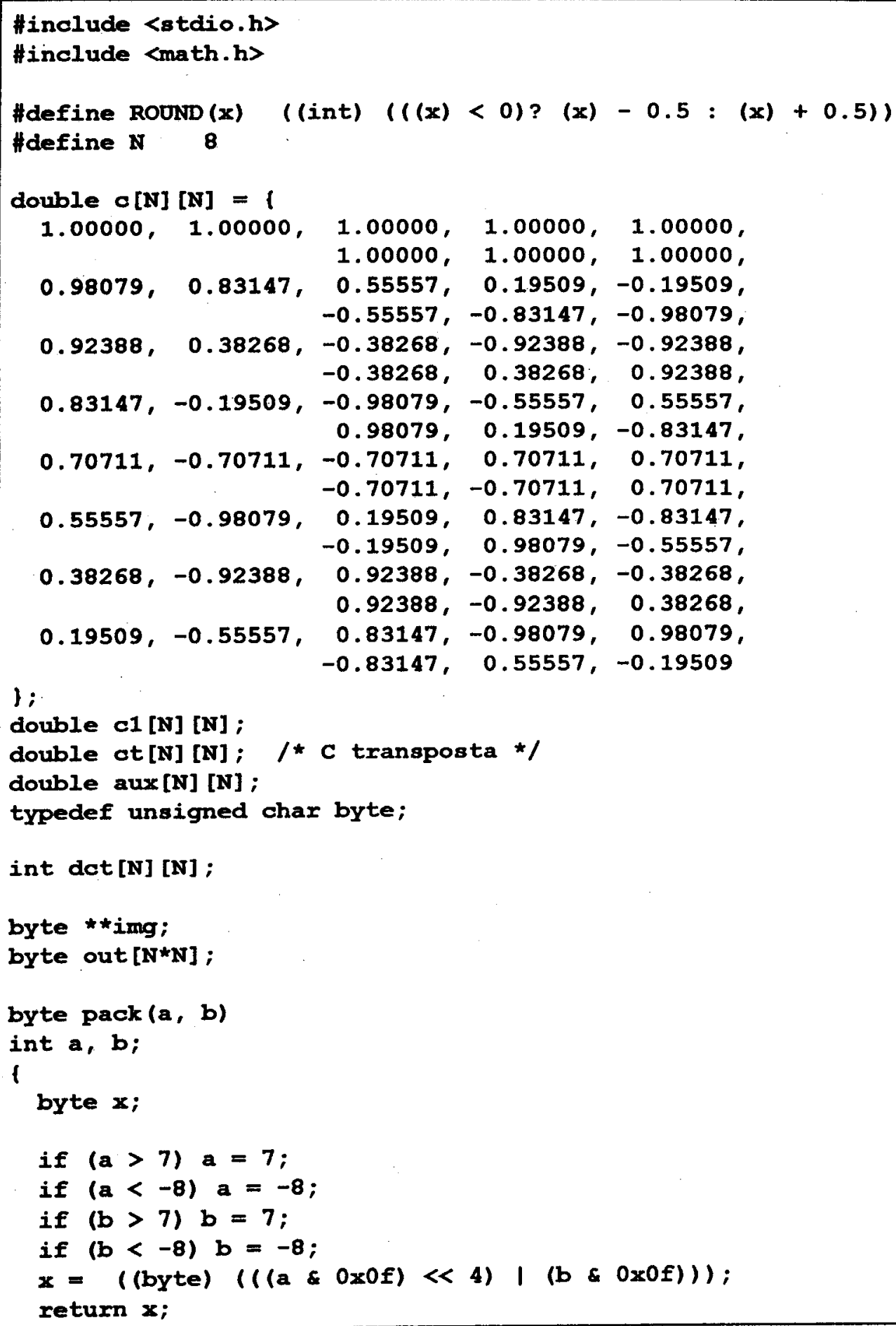




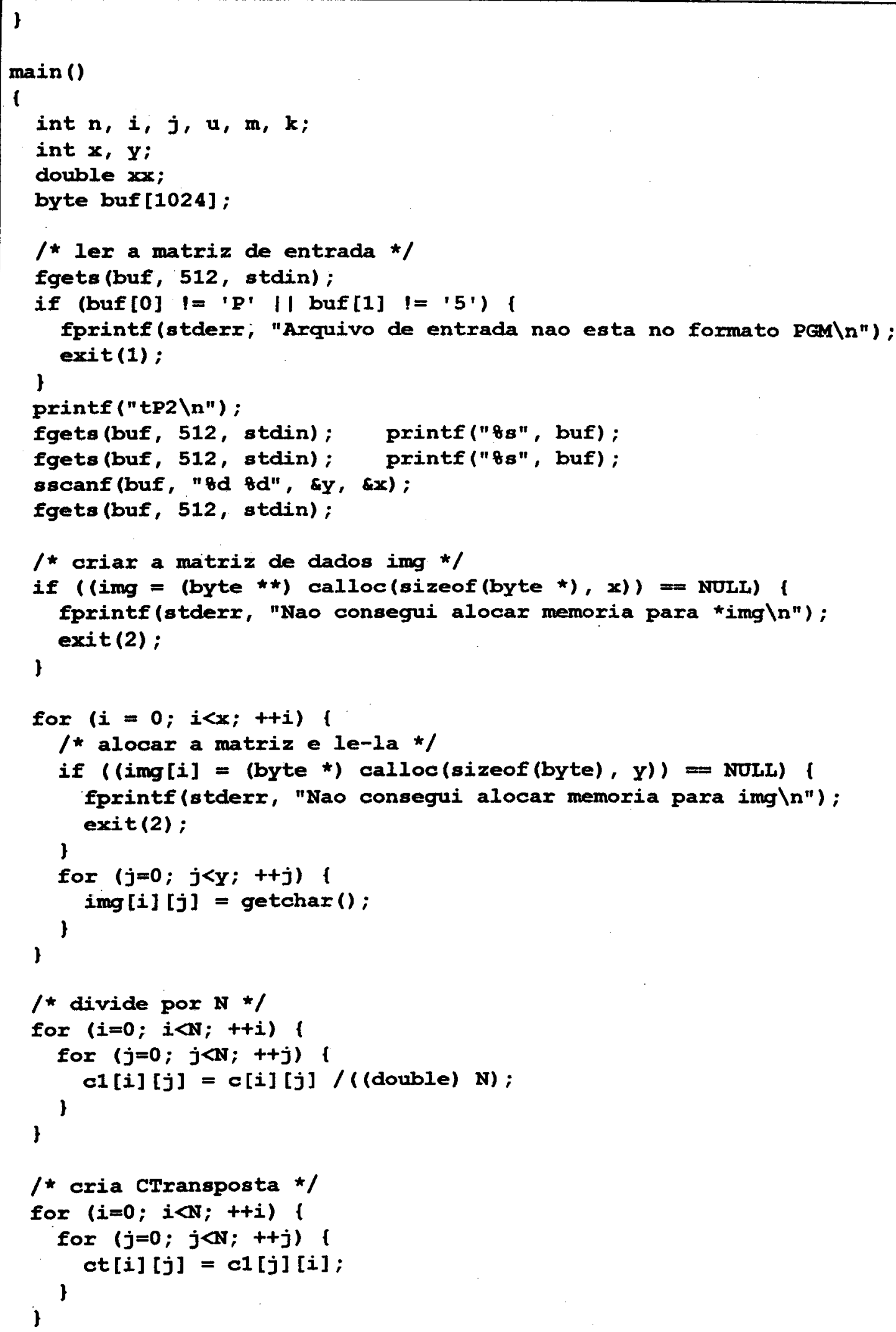




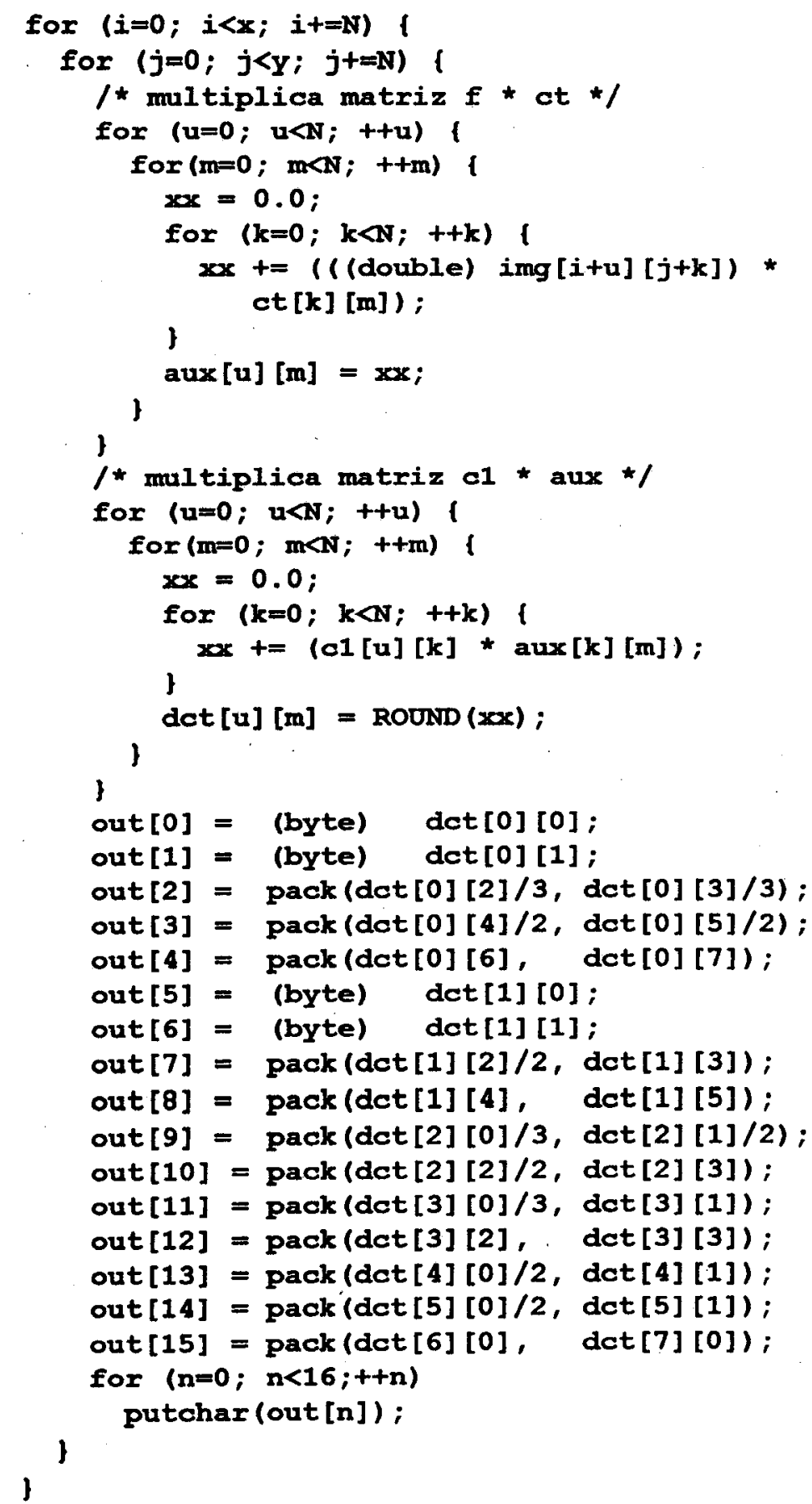


Para usar o programa c8c:

c8c <arquivo.pgm >arquivo. $c 8 c$

Onde arquivo.pgm é o arquivo formato.pgm a ser comprimido e arquivo.c8c é o arquivo comprimido usando DCT $8 * 8$. 
Listagem do programa c8u.c:

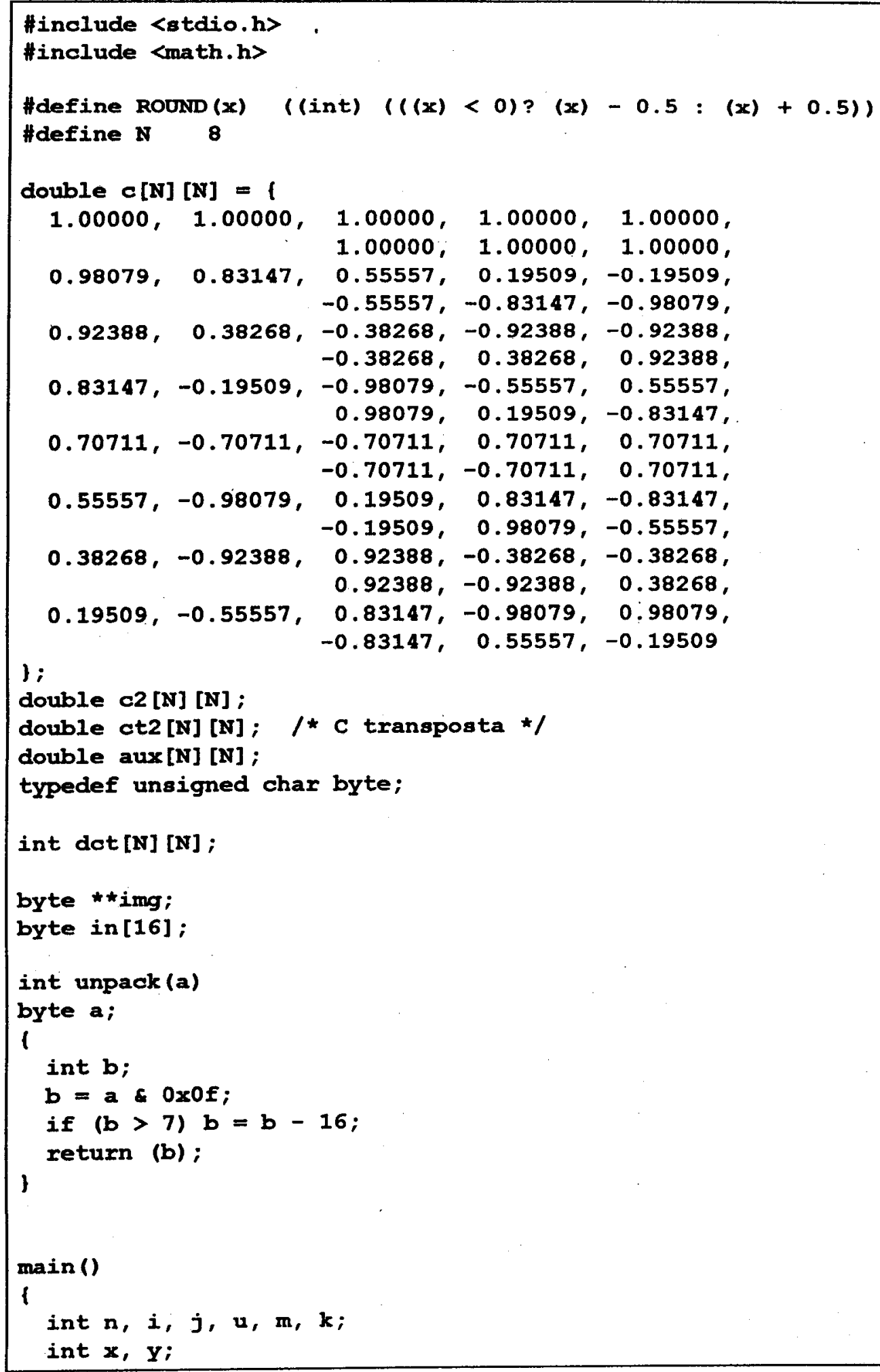




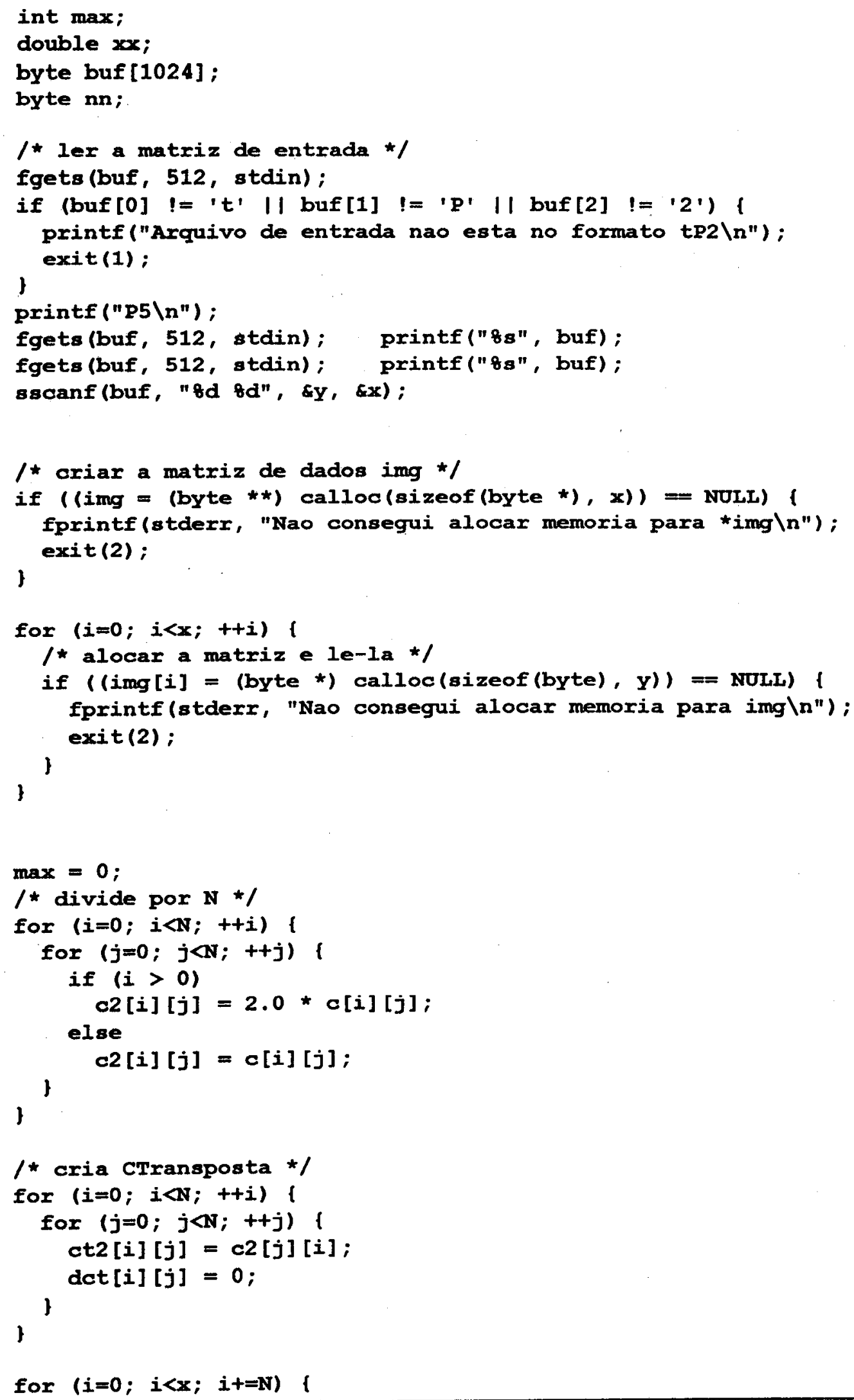




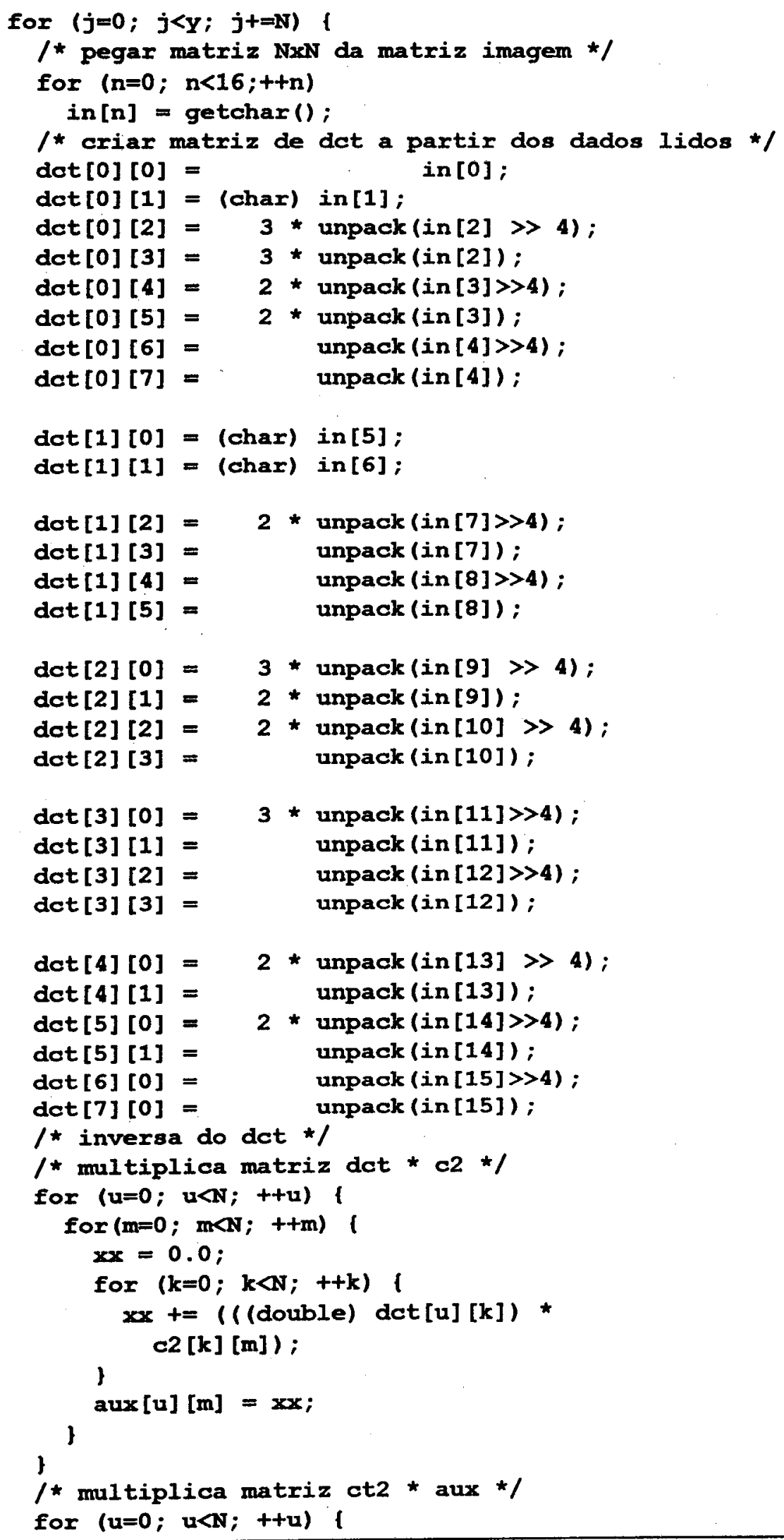




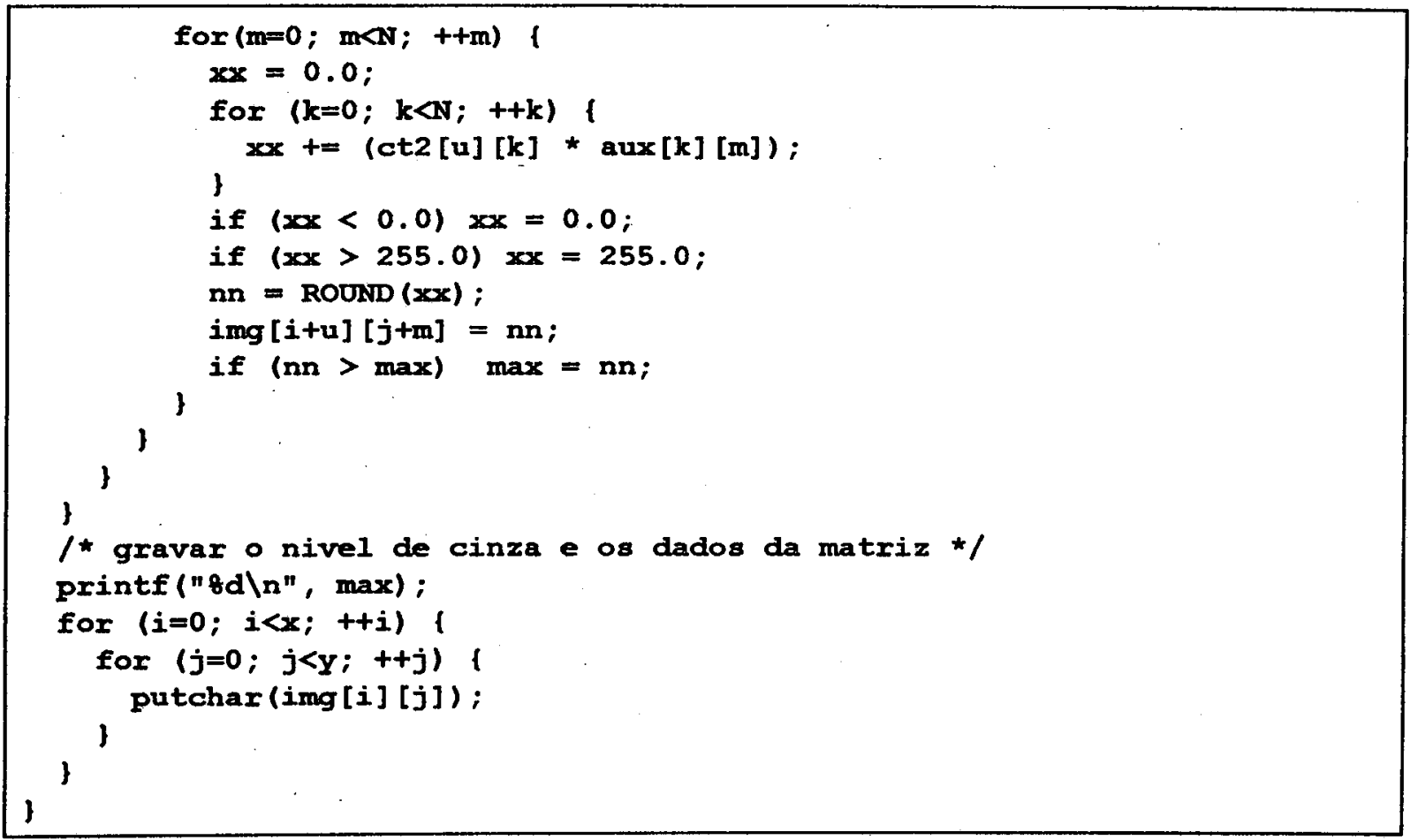

Para usar o descompressor c8u:

c8u <artquivo.c8c >arquivo.pgm

Onde arquivo.c8c é o arquivo já comprimido pelo programa c8c. Arquivo.pgm é o arquivo saída formato .pgm. 


\section{Apêndice G}

Listagem de mse.c:

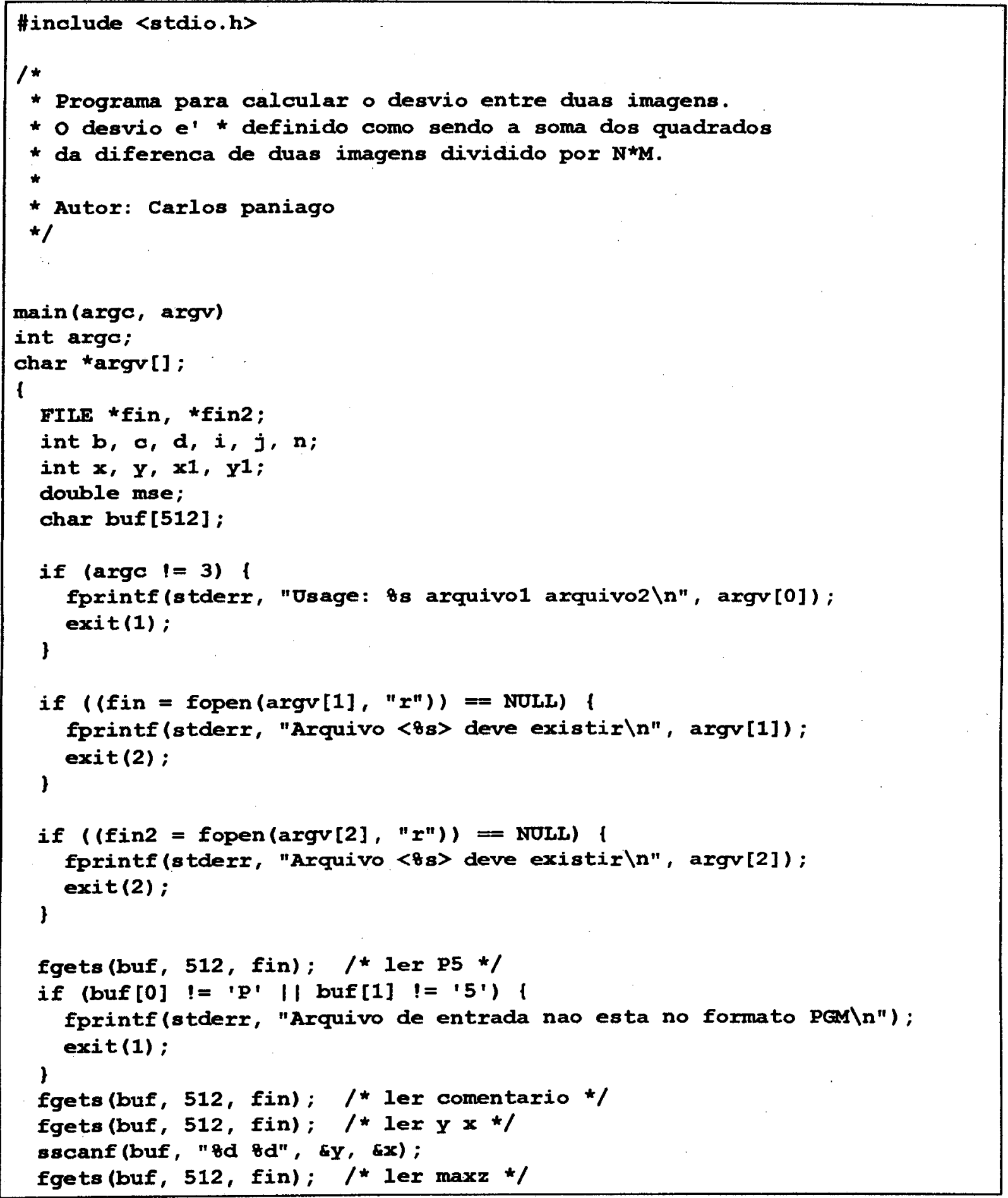




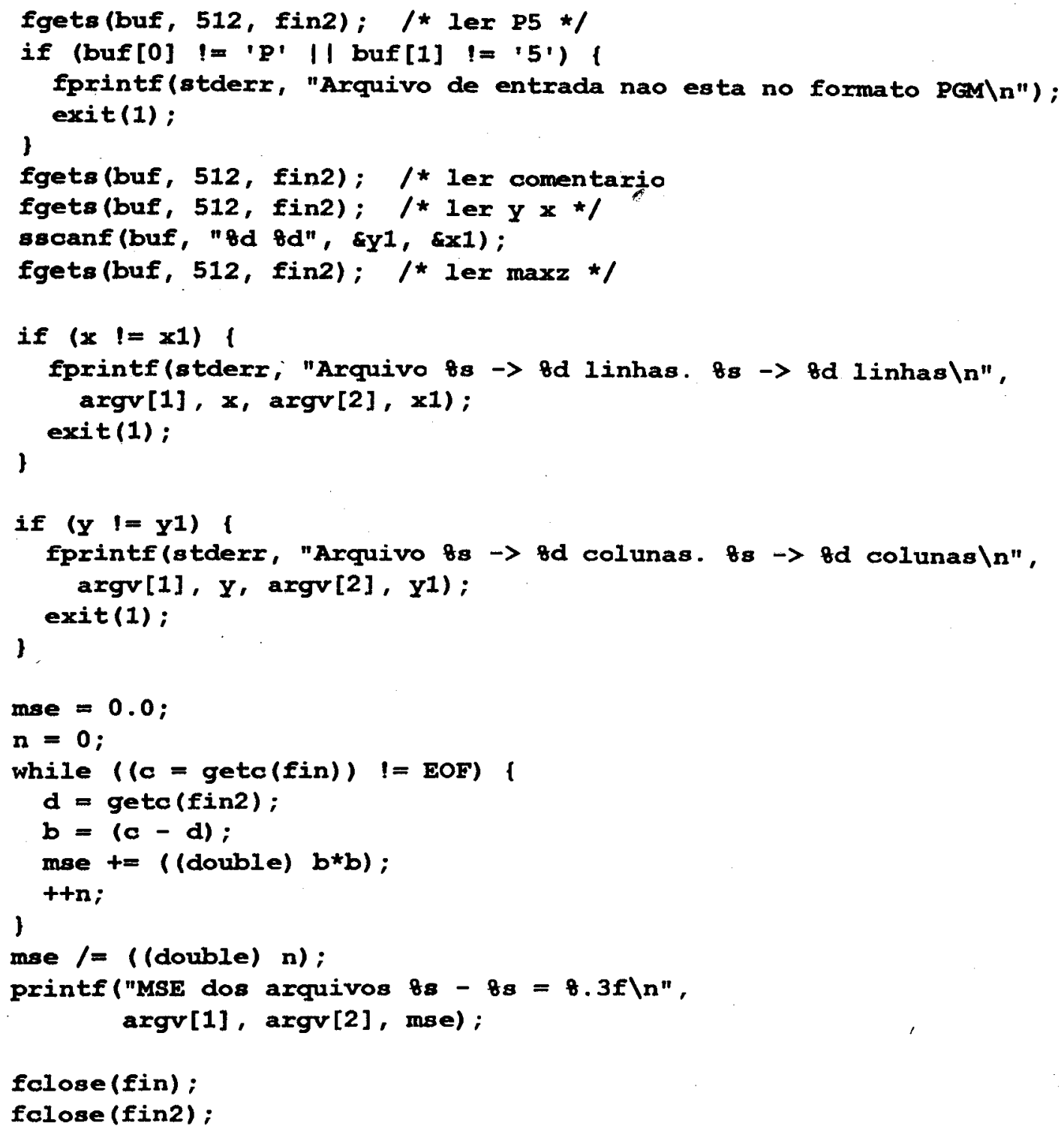


Para usar o programa mse:

mse arquivo1.pgm arquivo2.pgm

Onde arquivol.pgm é o arquivo formato .pgm a ser comparado com a arquivo2.pgm o Resultado é impresso dizendo o nome dos arquivos e o valor do MSE. 